\author{
Universidade de São Paulo \\ Instituto de Física
}

\title{
Simulações computacionais da interação de kinases e ligantes derivados de oxindol
}

\author{
Philippe Alexandre Divina Petersen
}

Orientador: Profa. Dra. Helena Maria Petrilli

Tese de doutorado apresentada ao Instituto de Física para a obtenção do título de Doutor em Ciências

Banca Examinadora:

Profa. Dra. Helena Maria Petrilli (IFUSP)

Prof. Dr. Caetano Rodrigues Miranda (IFUSP)

Profa. Dra. Maria Teresa Moura Lamy (IFUSP)

Prof. Dr. Maurício Domingues Coutinho Neto (UFABC)

Prof. Dr. Antônio Carlos Borin (IQUSP) 


\section{FICHA CATALOGRÁFICA \\ Preparada pelo Serviço de Biblioteca e Informação do Instituto de Física da Universidade de São Paulo}

Petersen, Philippe Alexandre Divina

Simulações computacionais de interação de Kinases e ligantes derivados de oxindol. São Paulo, 2015.

Tese (Doutorado) - Universidade de São Paulo. Instituto de Física. Depto. de Física dos Materiais e Mecânica

Orientadora: Prof $^{\mathrm{a}}$ Dr $^{\mathrm{a}}$ Helena Maria Petrilli

Área de Concentração: Física da Matéria Condensada

Unitermos: 1.Física; 2. Física da Matéria Condensada; 3. Física do estado Sólido; 4. Propriedades dos sólidos.

USP/IF/SBI-001/2016 
"A felicidade não se resume na ausência de problemas, mas sim na sua capacidade de lidar com eles".

\section{Albert Einstein}





\section{Agradecimentos}

Os meus sinceros agradecimentos

À Prof. Dra. Helena Maria Petrilli, que foi minha orientadora, pela atenção e paciência que sempre teve e pelos sábios conselhos que levarei comigo em minha jornada.

À Profa. Dra. Lucy Vitória Credido Assali e Prof. Marília Junqueira Caldas, pela ajuda em momentos delicados.

À Profa. Dra. Vera R. Leopoldo Constantino e seu grupo de pesquisa do IQ, pela grande ajuda e colaborações em diversos trabalhos.

À Profa. Dra. Ana Maria da Costa Ferreira e seu grupo de pesquisa do IQ, pela a grande ajuda e colaboração neste trabalho.

À Profa. Dra. Kaline Coutinho e ao Prof. Dr. Silvio Canuto pelas discussões pertinentes para a realização deste trabalho.

Ao Prof. Dr. Paul Withford pela amizade e conselhos e discussões pertinentes sobre física.

Aos meus amigos e companheiros de trabalho Marcos Brown Gonçalves, Filipe Camargo Dalmatti Lima, Rafael Rodrigues do Nascimento, Vanessa Roberta Rodrigues Cunha, Michele Rocha e todos do grupo da Prof. Dra. Ana Maria e da Profa. Dra. Vera Constantino, José Maximiano Júnior, Luiz Eleno, Ivan Miranda, Eduardo Suarez, Adamor Luz, Arthur Camargo, Arles V. Gil Rebaza, Ana M. G. Valencia, Leonardo Jorge Marion, Rodrigo Ramos, Francisco Nogueira, Rolando 
Larico Mamani, Marcelo Alves dos Santos, Michel Lacerda, Jarlesson Amazonas, Samuel Silva, Joelson Cott (grande amigo), Ricardo Igarashi, Antônio Claúdio Padilha, Denille Lima, André Santos, Fábio Lombardi, Luciano Pereira. Peço sinceras desculpas se esqueci de citar outros amigos.

À Sandra e família, por serem pessoas muito boas e terem tido muita paciência comigo. À Rosana, pela sua calma e prontidão para resolver os problemas.

Aos meus irmãos Benjamin Nicolas, Christopher Gimenez e à minha irmã Andrea, por seu amor e por sempre acreditarem em mim.

Ao meu cunhado Alex Nosovicki e minha cunhada Suellen Gimenez por serem pessoas que me ajudaram nos momentos difíceis.

À minha mãe, por estar do meu lado e ter tido a compreensão nos momentos difíceis.

Às minhas sobrinhas Marielle, Sophie e Laura por me darem a felicidade de ser seu tio.

Ao Laboratório de Computação Científica Avançada da USP (LCCA), CENAPAD e o convênio USP-RICE pelos recursos computacionais necessários para a realização deste trabalho.

Ao INEO (MCT/FAPESP/CNPQ), rede Nanobiomed (CAPES) e redes nacionais dos quais se realizou o presente trabalho.

À CAPES pelo apoio financeiro.

ii 


\section{Resumo}

Os estudos de modelagem molecular das interações entre ligantes baseado em oxindóis (isaepy, isapn, $[\mathrm{Cu}(\text { isapn })]^{2+}$, isaenim e o SU9516) e as proteínas kinases dependentes de ciclina (CDK1 e CDK2) são apresentados neste trabalho. Uma inibição na atividade da CDK1 e CDK2, que catalisam a fosforilação de grupos específicos em proteínas, tem implicações na indução da apoptose celular. O objetivo é tentar determinar qual destes ligantes potencializa a inibição da síntese de ATP (adenosina trifosfato) em ADP (adenosina difosfato) no sítio ativo da CDK1 e CDK2 para, desta forma, induzir a apoptose de células cancerígenas. Os estudos realizados neste trabalho indicam que dentre os ligantes analisados, o isaepy e o isapn obtiveram melhores resultados de estabilidade e ligações de hidrogênio entre aminoácidos dentro do sítio. Analisamos a influência do íon $\mathrm{Cu}$ no aumento da eficácia do isapn na atividade inibitória (complexo $[\mathrm{Cu}(\text { isapn })]^{2+}$ ) e comparamos os resultados obtidos dos estudos do isapn e $[\mathrm{Cu}(\text { isapn })]^{2+}$, quando inseridos no sítio de ligação do ATP da CDK1, com medidas de eletroforese em gel. Verificamos que os nossos resultados foram corroborados com as medidas de eletroforese. Também discutimos os resultados de cálculos de acoplamento hiperfino para o $\mathrm{Cu}$ no $[C u(\text { isapn })]^{2+}$ em diferentes ambientes químicos e fizemos a comparação destes resutados com medidas de EPR. Desta forma, conseguimos verificar o ambiente químico do íon Cu e um aumento da estabilidade do isapn dentro do sítio estudado 
com a inserção do íon $\mathrm{Cu}$. Este trabalho visa contribuir para a síntese de novos ligantes que aumentem a eficácia da inibição da síntese de ATP em ADP nas CDKs e também para a minimização dos custos através da diminuição da realização de experimentos que se baseiam em métodos de tentativa e erro. 


\section{Abstract}

Molecular modeling studies of the interaction of oxindol based ligands (isaepy, isapn

$[C u(\text { isapn })]^{2+}$, isaenim and SU9516) with Cyclin Dependent Kinases proteins (CDK1 and CDK2) are presented here. CDK1 and CDK2 catalyze the phosphorylation of specific groups in proteins and inhibition of its activities implies in induction of cancer cells apoptosis. The goal is to determine which ligands increase the inhibition of ATP (adenosine triphosphate) into ADP (adenosine diphosphate) synthesis which occurs inside the CDK1 and CDK2 active site. We analyze the influence of the $\mathrm{Cu}$ ion on increasing the inhibitory activity in isapn $\left([\mathrm{Cu}(\text { isapn })]^{2+}\right.$ metalcomplex). Comparisons between the results obtained from studies of the isapn and $[\mathrm{Cu}(\text { isapn })]^{2+}$ inserted into the ATP binding site of CDK1 with measurements of gel electrophoresis were performed. The hyperfine coupling at $\mathrm{Cu}$ ion in $[\mathrm{Cu}(\text { isapn })]^{2+}$ in different chemical environments are here obtained and the results are compared with EPR measurements. This work aims to contribute to the development of new ligands which increase the inhibition of the synthesis of ATP into ADP in the CDKs moreover we aim to assist in the reduction of the costs of measurements that are based on trial and error aproaches. 


\section{Conteúdo}

Agradecimentos $\quad$ i

Resumo iii

Abstract $\quad$ v

1 Introdução 1

2 Metodologia $\quad 9$

2.1 Introdução . . . . . . . . . . . . . . . . . . . 9

2.2 A Teoria do Funcional da Densidade . . . . . . . . . . . . 12

2.2.1 O Funcional Híbrido Becke three parameter Lee-Yang-Parr $(\mathrm{B} 3 \mathrm{LYP}) \ldots \ldots \ldots \ldots \ldots \ldots$

2.2.2 Funções de Bases Locais do tipo gaussianas - bases de Pople 18

2.3 O método de Docking para sistemas Receptor-Ligante . . . . . . . . 19

2.3.1 A função scoring: avaliando a afinidade de ligação entre receptor-ligante .................. 20

2.4 A Dinâmica Molecular Clássica para Biomoléculas . . . . . . . . . 22

2.4.1 Os Campos de Forças . . . . . . . . . . . . . . 23

2.4.2 Condições iniciais e etapas utilizadas na Dinâmica Molecular Clássica ........................ 27 
3 Resultados e Discussões $\quad 32$

3.1 Estrutura eletrônica dos compostos isaepy, isaenim, e isapn. . . . . 33

3.1.1 Estrutura eletrônica, geometria e distribuição de carga do isapn e $[C u(i s a p n)]^{2+} \ldots \ldots \ldots \ldots . \ldots . \ldots . \ldots 34$

3.2 Docking dos inibidores isaenim, SU9516 e isaepy na CDK2 . . . . 39

3.2.1 Docking do isapn e $[C u(\text { isapn })]^{2+}$ no sítio da CDK1/ciclinaB 46

3.3 Dinâmica molecular: isaepy, isapn, isaenim, SU9516 e $[C u(\text { isapn })]^{2+}$ no sítio da CDK1 e CDK2 . . . . . . . . . . . . 50

3.3.1 Procedimento para obter a dinâmica molecular: parâmetros utilizados e equilibração dos sistemas . . . . . . . . . 50

3.3.2 Análise dos resultados das dinâmicas moleculares . . . . . 54

3.3.3 Dinâmica do sistema CDK2/SU9516 . . . . . . . . 56

3.3.4 Dinâmicas dos sistemas CDK2/isaepy e CDK2/isaenim . . . 59

3.3.5 Dinâmicas da CDK1-ciclinaB/isapn e

$\mathrm{CDK} 1-$ ciclinaB $/[C u(\text { isapn })]^{2+} \ldots \ldots \ldots . \ldots . \ldots 72$

3.4 Estudos dos parâmetros hiperfinos para o complexo $[C u(\text { isapn })]^{2+} \cdot 78$

3.4.1 Os parâmetros de acoplamento hiperfino para o íon $\mathrm{Cu}$. . . 83

4 Conclusões $\quad 90$

$\begin{array}{lr}\text { Bibliografia } & 102\end{array}$ 



\section{Capítulo 1}

\section{Introdução}

Um dos maiores desafios da biologia molecular é a compreensão dos mecanismos de reconhecimento molecular receptor-ligante. A idéia central é propor e auxiliar na síntese de novos fármacos baseados em suas estruturas quando ativas no seu receptor (macromolécula). Diversos fármacos têm sido sintetizados com o objetivo de ter como alvos preferenciais receptores específicos que afetam um número limitado de processos biológicos relacionados a doenças como câncer, diabetes ou degenerações neurológicas [1]. Um dos alvos a serem investigados são as kinases dependentes de ciclinas (CDKs). As CDKs promovem a fosforilação, através da transferência do grupo $\gamma$-fosfato da adenosina trifosfato (ATP), de resíduos de serina, treonina e tirosina [2]. Desta forma, estas proteínas desempenham papéis fundamentais na regulação de vários processos celulares e do ciclo de divisão celular [3]. O ciclo de divisão celular apresenta quatro fases distintas em seu desenvolvimento mitótico conforme mostrado na Figura 1.1. Cada transição que ocorre entre estas fases se inicia com a atuação de um membro da família das CDKs, que são responsáveis por controlar e guiar as células de uma fase à outra [2]. A CDK2 associada à ciclina $\mathrm{A}$, por exemplo, conduz as células da fase $\mathrm{S}$ à fase $G_{2}$ do processo mitótico (ver Figura 1.1). Na fase S é onde ocorre a duplicação dos 
cromossomos no processo de mitose celular [4-6]. Mais de quinhentas kinases estão codificadas no genoma humano, desempenhando papéis cruciais na transdução de sinal e regulação celular $[7,8]$. A transdução de sinal é o mecanismo no qual as células utilizam mensageiros secundários para se comunicarem, coordenando as diferentes atividades nos diversos tipos de tecidos e órgãos [9]. Em diversas doenças, incluindo o câncer, são verificados alterações acentuadas das atividades biológicas das kinases [4]. A inibição da atividade destas proteínas é tolerada por células saudáveis e isto abre a possibilidade de uma seletividade em inibir células tumorais. Devido a este fato, as variações (modulações) das funções biológicas das kinases são alvos de estudos no desenvolvimento de novas drogas para aplicações clínicas e na pesquisa do mecanismo do processo biológico [10]. Muitas CDKs são controladas e somente ativadas com a presença de fosfatases, tornando o processo de fosforilação reversível, e quaisquer modificações no balanceamento do processo de fosforilação e desfosforilação são críticos para manter a célula tumoral funcional. Estas modificações podem ocorrer através das interferências nas interações das CDKs-substrato ou fosfatase-substrato. 


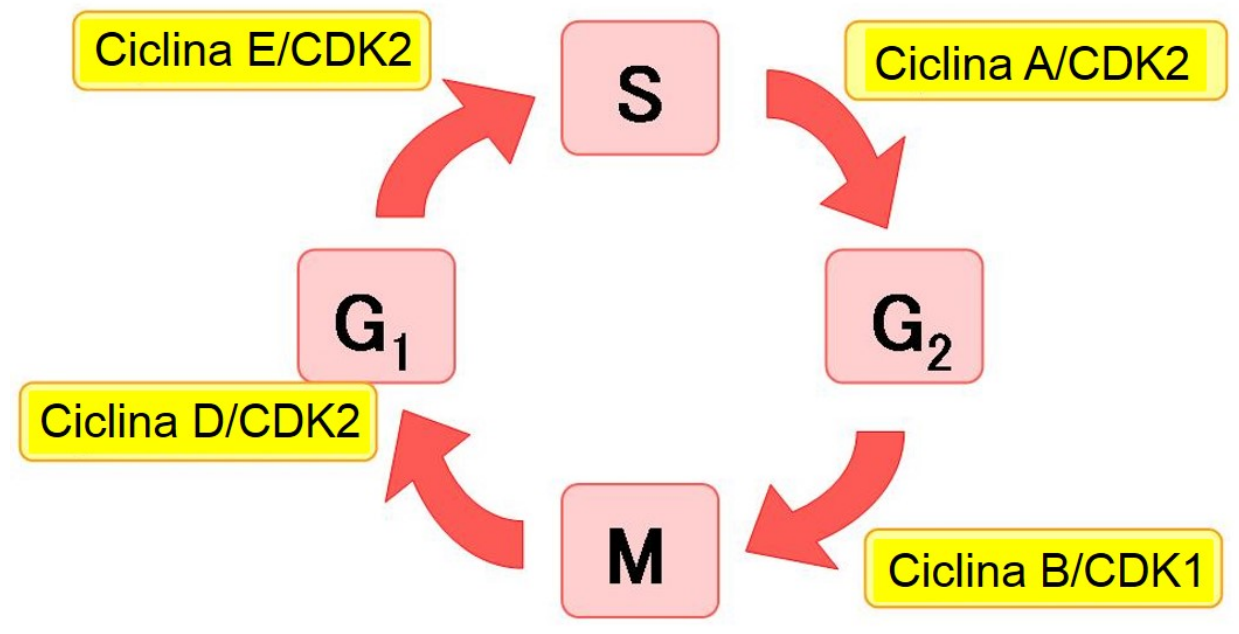

Figura 1.1: As fases do ciclo de divisão celular mitótico e as CDKs que participam e auxiliam as fases do ciclo [2].

Diversos compostos estão em estudo com a função de inibir as CDKs. A inibição das CDKs pode ser crucial para a atividade antitumoral, pois induz a apoptose de células cancerígenas. Alguns inibidores foram sintetizados para competir no sítio de ATP das CDKs e são chamados de inibidores de tipo I [2, 7, 8]. Inibidores do tipo II atuam no reconhecimento e inatividade da conformação da proteína [11]. Outros inibidores foram desenvolvidos para agirem no sítio alostérico das CDKs [12]. Na Figura 1.2 mostramos um esquema dos tipos de inibidores que atuam nas CDKs [13]. Em torno de 80 destes inibidores estão em estágio avançado de testes clínicos, incluindo compostos derivados de indol [14]. 


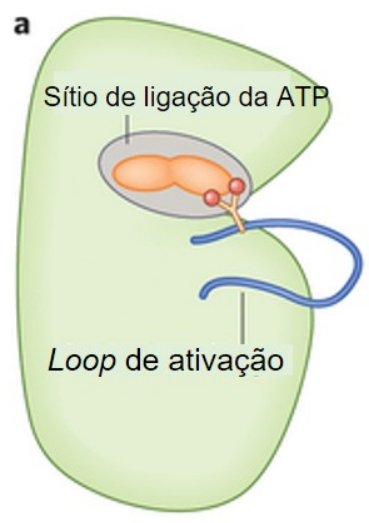

Tipo I

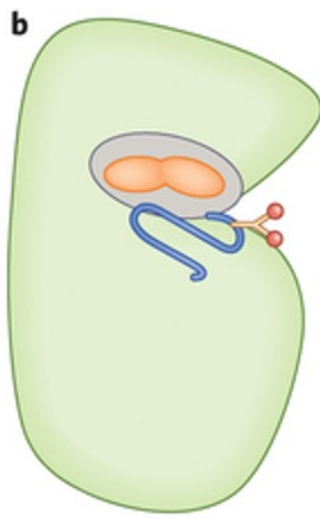

Tipo II

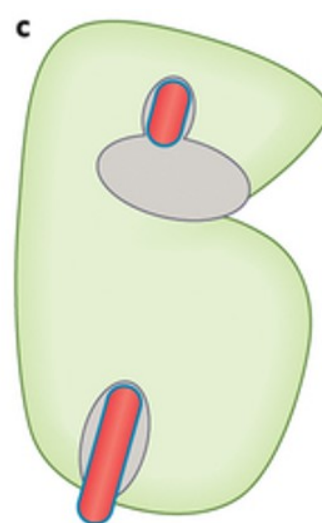

Tipo III

Figura 1.2: Tipos de inibidores que atuam nas CDKs: a) tipo I que competem no sítio de ligação da ATP; b) tipo II que reconhecem e desativam a conformação das CDKs e c) tipo III que interagem com o sítio alostérico das CDKs [13].

Os inibidores do tipo I derivados de indol foram sintetizados, em sua maioria, para atuar no sítio de ATP das kinases. Alguns indóis alcaloides apresentaram relevante atividade inibitória das kinases CDK1 e CDK5 e também apresentaram uma boa atividade antitumoral [7]. Na Figura 1.3 mostramos um esquema em 2D da estrutura base do indol (oxindol). Uma série de inibidores de 3,5-diaminoindazol, agindo como competidores do sítio de ATP das CDKs, foram estudados através de docking molecular e simulação de dinâmica molecular, visando apresentar uma idéia da conformação das moléculas no sítio de ATP, bioatividade e as interações que ocorrem entre os compostos e as kinases [8]. Aliado a esta idéia, e ao crescente conhecimento da atividade antitumoral de alguns complexos metálicos, muitas pesquisas para desenvolver um agente antitumoral com uma grande capacidade de causar apoptose celular estão sendo realizadas. Especificamente, complexos de cobre estão sendo exaustivamente investigados devido ao cobre apresentar baixa citoxicidade [15], e diversos exemplos na literatura indicam a indução da apoptose celular causada por estes compostos [16-18]. 


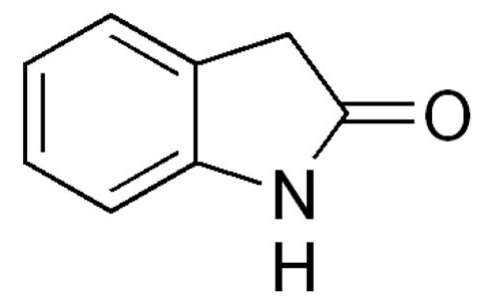

Figura 1.3: Esquema da estrutura em 2D do oxindol.

Recentemente, complexos de cobre derivados de isatina (2,3 dioxindolamina) mostraram ser um potencial agente antitumoral em células leucêmicas humanas [19, 20]. Inspirado neste tipo de estrutura dos oxindóis, novos ligantes de oxindolaminas foram sintetizados [20]. Na Figura 1.4 é mostrado um esquema das estruturas de algumas isatinas-iminas e complexos metálicos [21].

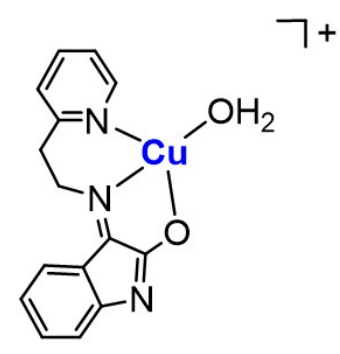

[Cu(isaepy) $\mathrm{H}_{2} \mathrm{O}^{+}$<smiles>OC12NC=CC3N=C(O1)[I+]1NCCN1C32</smiles>

$\left[\mathrm{Cu}\left(\text { isaen) } \mathrm{H}_{2} \mathrm{O}\right]^{+}\right.$

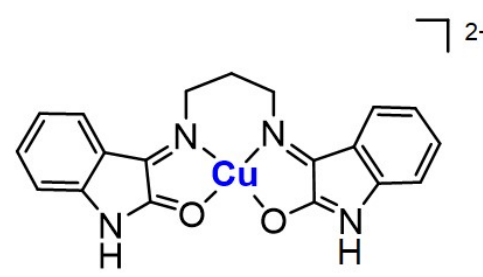

$[\text { Cu(isapn) }]^{2+}$<smiles>O=C1Nc2ccccc2C1=NC[Z8](Cl)(Cl)CCl</smiles>

[Zn(isaepy) $\left.\mathrm{Cl}_{2}\right]$

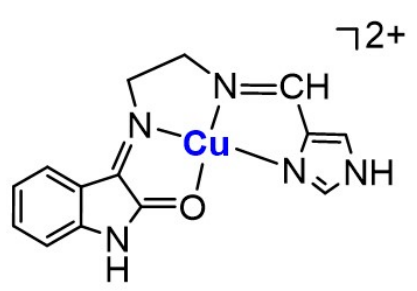

$\left[\mathrm{Cu}(\text { isaenim) }]^{2+}\right.$<smiles></smiles>

[Zn(isambz) $\left.\mathrm{Cl}_{2}\right]$

Figura 1.4: Esquema de alguns complexos metálicos derivados de oxindolaminas que estão em estudo [20, 22, 23].

Estes compostos possuem semelhança estrutural com inibidores derivados de 
oxindóis já testados clinicamente como o SU9516, SU6656 e SU6668 [24-26]. A ideia é, com a inserção do cobre, induzir um aumento significativo da eficiência da apoptose em diferentes células tumorais [22].

Os estudos destes compostos de oxindols com íons metálicos (Figura 1.4), principalmente o cobre (II), são investigados pelo grupo da Profa. Dra. Ana Maria da Costa Ferreira do Instituto de Química (IQ-USP) [20, 22, 23]. Os ligantes estudados são capazes de coordenar o cobre nos estados I e II de oxidação usual no meio biológico e os complexos correspondentes, com ligantes bi-, tri- e tetra-dentados, apresentam alta reatividade em processos oxidativos, causando danos a biomoléculas como carboidratos, lipídeos e o próprio DNA. A preparação e o estudo teórico destas espécies complexas, que apresentam atividade antitumoral acentuada, é de grande importância na verificação da atividade inibitória das kinases CDK2 e CDK1. A partir destes estudos de inibição, espera-se elucidar melhor os mecanismos pelos quais esses complexos de cobre (II) agem como agentes antitumorais, verificando as habilidades destes compostos ao interagir com as kinases.

O objetivo do presente trabalho é realizar, através da modelagem molecular e cálculos de estrutura eletrônica para sistemas receptor/ligante, o estudo da interação de complexos metálicos de cobre (metal + ligante), sintetizados pelo grupo da Profa. Dra. Ana Maria da Costa, com o sítio ativo de adenosina trifosfato (ATP) das kinases CDK2 e CDK1 (receptores). Verificamos a afinidade de ligação e conformação dos compostos no sítio ativo utilizando métodos de dinâmica molecular clássica, docking molecular e Teoria do Funcional da Densidade (DFT). Na Figura 1.5 mostramos os inibidores que estudamos neste trabalho: isaepy, isaenim, isapn e seu complexo $[C u(\text { isapn })]^{2+}$ assim como inibidor SU9516. Uma vez que se tem informações do SU9516 na literatura [24], o estudo deste serviu de referência para comparação com os estudos dos outros inibidores apresentados aqui. Realizamos cálculos de estrutura eletrônica utilizando a DFT [27, 28] para obter a completa

6 
descrição dos inibidores, como a geometria das moléculas e a distribuição das cargas eletrônicas. Analisamos dados obtidos por Electronic Paramagnetic Resonance -EPR para entender o ambiente químico do íon Cu. Mostramos e discutimos os resultados dos estudos de docking molecular dos inibidores no sítio de ATP das kinases CDK1 e CDK2 e também discutimos as simulações de dinâmica molecular clássica das interações dos inibidores sintetizados isaenim, SU9516 e isaepy no sítio ativo da CDK2. Analisamos também o isapn e o $[C u(\text { isapn })]^{2+}$ no sítio de ATP da CDK1 com uma ciclina B ligada (CDK1/ciclinaB) com o objetivo de obter o comportamento (trajetória) destes inibidores quando inseridos no sítio ativo. Por fim, fizemos as análises de clusters das configurações obtidas da dinâmica molecular para os sistemas estudados. As configurações do $[\mathrm{Cu}(\text { isapn })]^{2+}$ obtidas a partir dos cálculos no âmbio da DFT, análise de clusters e simulação de dinâmica em solvente explícito, são utilizadas para os cálculos de espectros EPR. Estudamos a coordenação do cobre no complexo $[C u(\text { isapn })]^{2+}$ isolado no vácuo, em meio contínuo polarizado (Polarizable Continuum Model - PCM)[29] e sob solvatação explícita, de modo a reproduzir as propriedades estruturais e o acoplamento hiperfino magnético observados experimentalmente [20, 23]. 

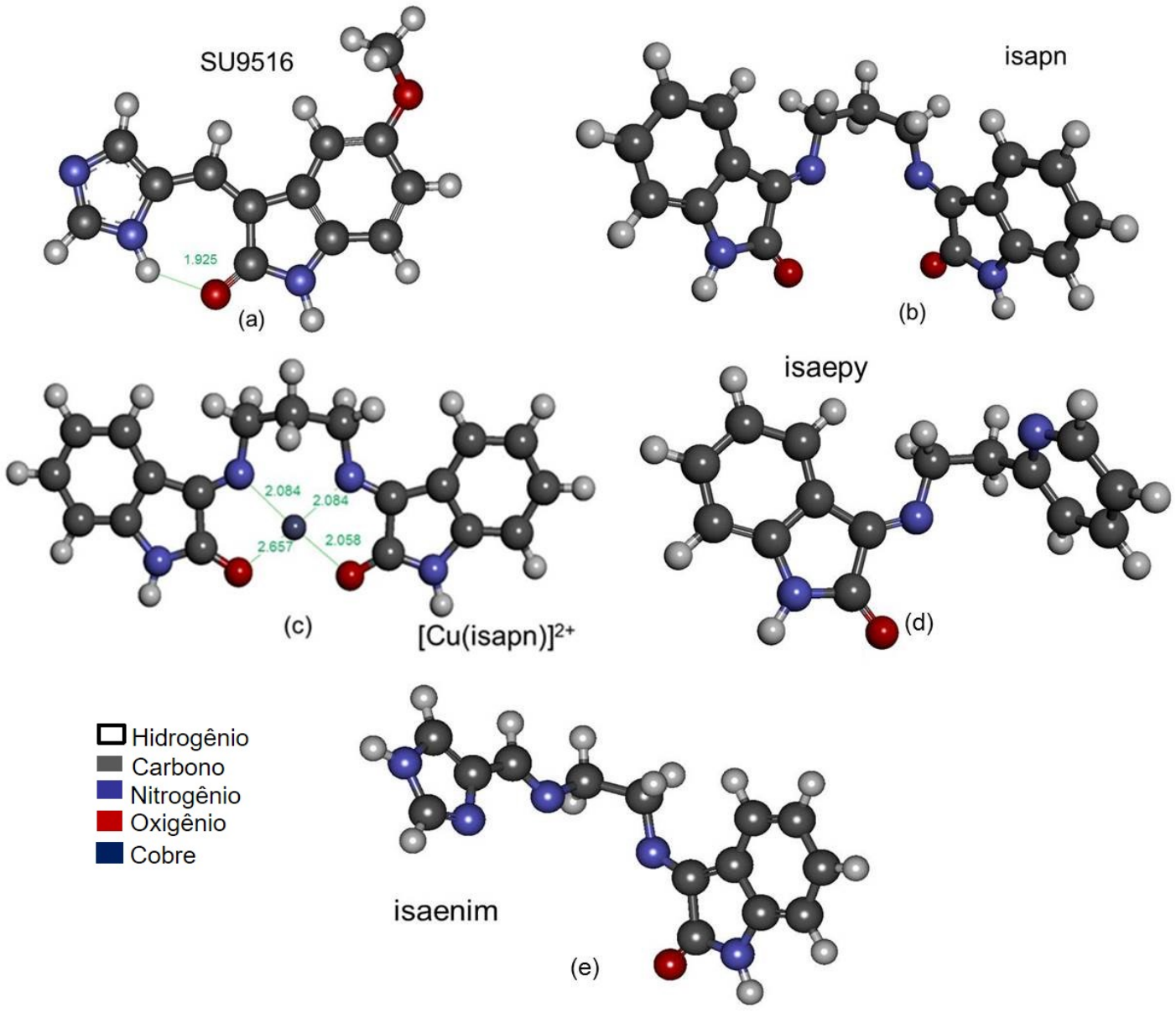

Figura 1.5: Estruturas, obtidas de cálculos no âmbito da DFT, dos inibidores que são estudados neste trabalho: (a) SU9516, (b) isapn, (c) $[C u(\text { isapn })]^{2+}$, (d) isaepy e (e) isaenim. 


\section{Capítulo 2}

\section{Metodologia}

\subsection{Introdução}

A descrição das propriedades químicas e físicas da matéria é um problema complexo de ser resolvido. Normalmente lidamos com sistemas de muitos átomos que estão interagindo entre si e que também podem ser afetados por campos externos. Estes conglomerados (ensembles) de partículas se apresentam na forma gasosa (moléculas e clusters) ou em forma de matéria condensada, que pode ser sólido, líquido ou amorfo, homogêneo e heterogêneo (moléculas em solução e interfaces) [30]. Formalmente, podemos escrever o Hamiltoniano não relativístico de um sistema da seguinte maneira:

$$
\hat{H}=\hat{T}_{n}(\mathbf{R})+\hat{T}_{e}(\mathbf{r})+\hat{V}_{n e}(\mathbf{R})+\hat{V}_{e e}(\mathbf{r})+\hat{V}_{n n}(\mathbf{R}, \mathbf{r})
$$

$\mathrm{Ou}$ 


$$
\begin{aligned}
\hat{H} & =-\sum_{I=1}^{P} \frac{\hbar^{2}}{2 M_{I}} \nabla_{I}^{2}-\sum_{i=1}^{N} \frac{\hbar^{2}}{2 m} \nabla_{i}^{2}+\frac{e^{2}}{2} \sum_{I=1}^{P} \sum_{J \neq I}^{P} \frac{Z_{I} Z_{J}}{\left|\mathbf{R}_{I}-\mathbf{R}_{J}\right|} \\
& +\frac{e^{2}}{2} \sum_{i=1}^{N} \sum_{j \neq i}^{N} \frac{1}{\left|r_{i}-r_{j}\right|}-e^{2} \sum_{I=1}^{P} \sum_{i=1}^{N} \frac{Z_{i}}{\left|\mathbf{R}_{I}-r_{i}\right|},
\end{aligned}
$$

onde $\mathbf{R}=\mathbf{R}_{I}$ e $I=1,2 \ldots P$, são as coordenadas nucleares, $\mathbf{r}=\mathbf{r}_{i}$ e $i=1 \ldots N$ são as coordenadas dos N elétrons do sistema; $Z_{I}$ e $M_{I}$ são, respectivamente, as cargas e massas para o $\mathrm{P}$ núcleos atômicos. A partir do operador $\hat{H}$ geramos os seguintes valores esperados:

- $\left\langle\Psi\left|\hat{T}_{N}\right| \Psi\right\rangle$ : energia cinética dos núcleos;

- $\left\langle\Psi\left|\hat{T}_{e}\right| \Psi\right\rangle$ : energia cinética dos elétrons;

- $\left\langle\Psi\left|\hat{V}_{N e}\right| \Psi\right\rangle$ : energia potencial da interação núcleo-elétron;

- $\left\langle\Psi\left|\hat{V}_{e e}\right| \Psi\right\rangle$ : energia potencial da interação elétron-elétron;

- $\left\langle\Psi\left|\hat{V}_{N N}\right| \Psi\right\rangle$ : energia potencial devido às interações entre os núcleos.

Devido aos elétrons serem férmions, a função de onda eletrônica total deve ser necessariamente antissimétrica.

Em princípio, todas as propriedades de um sistema podem ser obtidas resolvendo a equação de Schrödinger independente do tempo para muitos corpos

$$
\hat{H} \Psi_{i}(\mathbf{r}, \mathbf{R})=E_{i} \Psi_{i}(\mathbf{r}, \mathbf{R})
$$

Na prática, resolver a equação (2.3) é um problema quase insolúvel quando o tratamos somente com as ferramentas da mecânica quântica e ,portanto, é usual utilizar algumas aproximações descritas brevemente a seguir. 
O movimento do núcleo é, em geral, muito menor que o movimento do elétron. Partindo desta ideia, M. Born e J.R. Oppenheimer [31] propuseram que o movimento dos elétrons pode ser descrito para cada configuração instantânea dos núcleos, permanecendo sempre no mesmo estado estacionário do Hamiltoniano eletrônico. Isto significa que com o movimento do núcleo, os elétrons instantaneamente ajustam as suas funções de onda de acordo com a função de onda do núcleo. Desta forma, podemos analisar separadamente o movimento do núcleo e o movimento dos elétrons e podemos escrever a função de onda total, na forma reduzida [30], da seguinte forma

$$
\Psi(\mathbf{R}, \mathbf{r}, t)=\Theta_{m}(\mathbf{R}, t) \Phi_{m}(\mathbf{R}, \mathbf{r})
$$

onde $\Theta_{m}(\mathbf{R}, t)$ são as funções de onda que descrevem a evolução temporal dos núcleos em cada autoestado adiabático eletrônico $\Phi_{m}(\mathbf{R}, \mathbf{r})$.

A equação 2.4 é válida para dinâmica dos núcleos que não causam transições eletrônicas e os elétrons permanecem sempre no mesmo estado $m$ (fundamental ou excitado). Desta forma, podemos reescrever a equação de Schrödinger independente do tempo

$$
\hat{H}_{e} \Phi_{m}(\mathbf{R}, \mathbf{r})=E_{m}(\mathbf{R}) \Phi_{m}(\mathbf{R}, \mathbf{r})
$$

onde o operador Hamiltoniano eletrônico $\left(\hat{H}_{e}\right)$ é dado por

$$
\hat{H}_{e}=\hat{T}_{e}+\hat{V}_{e e}+\hat{V}_{n e}=\hat{H}-\hat{T}_{n}-\hat{V}_{n n} .
$$

Para resolver a equação 2.5 duas metodologias são bastante utilizadas para cálculo das propriedades dos materiais. Os métodos baseados na metodologia de função de onda e os métodos baseados na Teoria do Funcional da Densidade 
(DFT).

O método HF busca uma solução aproximada para o sistema com muitos elétrons no estado fundamental e serve como ponto de partida para outros métodos pós HF como, por exemplo, métodos perturbativos e métodos variacionais. O método HF descreve a função de onda com um único determinante de Slater [32] onde os elétrons satisfazem o princípio de exclusão de Pauli. Na equação 2.7 é mostrado o determinante de Slater para a aproximação HF

$$
\Phi_{H F}=\frac{1}{\sqrt{N !}}\left|\begin{array}{cccc}
\varphi_{1}(1) & \varphi_{2}(1) & \cdots & \varphi_{N}(1) \\
\varphi_{1}(2) & \varphi_{2}(2) & \cdots & \varphi_{N}(2) \\
\vdots & \vdots & \ddots & \vdots \\
\varphi_{1}(N) & \varphi_{2}(N) & \cdots & \varphi_{N}(N)
\end{array}\right|
$$

onde $\varphi_{i}(j)$ são funções das coordenadas espaciais e spin de um único elétron e comumente chamadas de spin-orbitais moleculares [33]. O método variacional é utilizado como técnica na escolha dos orbitais moleculares que vão compor o determinante de Slater. O fator $1 / \sqrt{N !}$ é uma constante de normalização de $\Phi_{H F}$ admitindo que $\varphi_{i}(j)$ são funções ortonormais.

A simplificação da função de onda total do sistema para um determinante único introduz a ideia de que a função de onda total de muitos elétrons pode ser escrita como um produto de funções de onda de um elétron. Apesar de não ser completamente geral, esta função de onda introduz a interação de troca entre partículas de forma exata [32].

\subsection{A Teoria do Funcional da Densidade}

A Teoria do Funcional da Densidade (DFT) tornou-se nas últimas décadas o método mais utilizado para o cálculo de estrutura eletrônica para sólidos e molécu- 
las. O formalismo da DFT tem como variável fundamental a densidade eletrônica. Os dois elementos principais da DFT são o teorema de Hohenberg-Kohn (HK) [27] e as equações de Kohn-Sham [28]. Em 1964, P. Hohenberg e W. Kohn [27] propuseram dois teoremas que se tornaram as bases fundamentais da DFT [27, 30]:

- O potencial externo é determinado, de forma unívoca, pela densidade eletrônica a menos de uma constante aditiva trivial.

O primeiro teorema de HK nos mostra que a energia total do estado ligado de um sistema de elétrons interagentes é um funcional único, porém desconhecido, da densidade eletrônica. O segundo teorema é baseado no princípio variacional da energia

- Desde que a densidade eletrônica $\rho(\mathbf{r})$ determina univocamente o potencial externo $V_{\text {ext }}(\mathbf{r})$, então também determina o estado fundamental da função de onda $\Phi_{m}$. A energia do estado fundamental $E\left(\rho_{0}(\mathbf{r})\right)$ é minima para a densidade $\rho(\mathbf{r})$ exata, então $E\left(\rho_{0}(\mathbf{r})\right)<E_{v}(\rho(\mathbf{r}))$ para qualquer $\rho(\mathbf{r}) \neq \rho_{0}(\mathbf{r})$.

Uma vez que um sistema no estado fundamental com $n$ elétrons descrito por uma função de onda de $3 n$ variáveis (eq. 2.5) pode ser determinado pela densidade eletrônica, podemos substituir a função de onda de $3 n$ variáveis por uma função de onda com apenas 3 variáveis. Desta forma, a energia do estado fundamental de um sistema de muitos corpos fica

$$
\begin{gathered}
E[\rho(\mathbf{r})]=\left\langle\Phi\left|\hat{T}_{e}+\hat{V}_{e e}+\hat{V}_{e x t}\right| \Phi\right\rangle= \\
\left\langle\Phi\left|\hat{T}_{e}+\hat{V}_{e e}\right| \Phi\right\rangle+\left\langle\Phi\left|\hat{V}_{e x t}\right| \Phi\right\rangle=F[\rho(\mathbf{r})]+\int \rho(\mathbf{r}) V_{e x t}(\mathbf{r}) d \mathbf{r}
\end{gathered}
$$

onde $F[\rho(\mathbf{r})]$ é chamado de funcional universal e é válido para qualquer sistema de $n$ elétrons. Sua forma funcional em termos da densidade não é conhecida. Para encontrar o estado fundamental de um sistema não homogêneo de $n$ elétrons 
interagentes, necessita-se encontrar uma descrição precisa do termo do potencial de interação elétron-elétron $\left(\hat{V}_{e e}\right)$. Reescrevendo na forma funcional a energia total de um sistema no estado fundamental (eq. 2.8)

$$
E[\rho(\mathbf{r})]=T_{e}[\rho]+V_{e e}[\rho]+V_{n e}[\rho]
$$

Separamos o termo do potencial de interação elétron-elétron $\left(V_{e e}[\rho]\right)$ em dois ter$\operatorname{mos} V_{C}[\rho]$ e $V_{x c}[\rho]$.

$$
E[\rho(\mathbf{r})]=T_{e}[\rho]+V_{C}[\rho]+V_{x c}[\rho]+V_{n e}[\rho]
$$

$V_{C}[\rho]$ é a energia de interação elétron-elétron de origem Coulombiana e $V_{x c}[\rho]$ é o termo de troca e correlação eletrônicas. Apesar da separação entre as interações eletrostáticas das relações de troca e correlação eletrônicas, o maior desafio ainda é saber como lidar com o termo de correlação inserido no potencial de troca e correlação $\left(V_{x c}[\rho]\right)$.

W. Kohn e L. Sham [28] propuseram substituir a energia cinética dos elétrons interagentes por uma energia cinética de um sistema de elétrons não interagentes. Esta abordagem torna o cálculo mais fácil devido à energia cinética total do sistema ser simplesmente a soma das energias cinéticas de cada elétron individualmente. Desta forma, mapeamos o sistema de elétrons interagentes em um sistema de elétrons não-interagentes. A densidade eletrônica do estado fundamental do sistema de elétrons não interagentes $\rho(\mathbf{r})$ é a mesma obtida por um sistema de muitos corpos interagentes e é dada por

$$
\rho(\mathbf{r})=\sum_{i}^{N} f_{i}\left|\phi_{i}(\mathbf{r})\right|^{2},
$$


onde $f_{i}$ são os estados ocupados do elétron e $\phi_{i}(\mathbf{r})$ são orbitais de uma partícula chamados de orbitais de Kohn-Sham (KS) e são as soluções da equação de Schrödinger de um elétron

$$
\hat{H}_{K S} \phi_{i}(\mathbf{r})=\varepsilon_{i} \phi_{i}(\mathbf{r})
$$

onde $\hat{H}_{K S}$ é o Hamiltoniano de um elétron no esquema de KS

$$
\hat{H}_{K S}=-\frac{\hbar^{2}}{2 m} \nabla^{2}+v_{R}(\mathbf{r})
$$

onde $v_{R}(\mathbf{r})$ é o potencial de referência (potencial de KS) e $m$ a massa do elétron.

Considerando $T_{R}[\rho]$ como energia cinética dos elétrons não interagentes do sistema de referência, podemos reescrever o funcional universal dentro do formalismo de KS da seguinte forma

$$
F[\rho(\mathbf{r})]=T_{R}[\rho]+\frac{1}{2} \iint \frac{\rho(\mathbf{r}) \rho\left(\mathbf{r}^{\prime}\right)}{\left|\mathbf{r}-\mathbf{r}^{\prime}\right|} d \mathbf{r} d \mathbf{r}^{\prime}+\tilde{E}_{X C}[\rho]
$$

onde o termo $\tilde{E}_{X C}[\rho]$ se refere a energia de troca e correlação no formalismo de KS.

Substituindo a expressão dada em (2.14) para $F$ no funcional da energia total (2.10) obtemos o funcional da energia de KS

$$
E_{K S}[\rho]=T_{R}[\rho]+\int \rho(\mathbf{r}) V_{e x t}(\mathbf{r}) d \mathbf{r}+\frac{1}{2} \iint \frac{\rho(\mathbf{r}) \rho\left(\mathbf{r}^{\prime}\right)}{\left|\mathbf{r}-\mathbf{r}^{\prime}\right|} d \mathbf{r} d \mathbf{r}^{\prime}+\tilde{E}_{X C}[\rho]
$$

Obtemos o potencial de KS através da minimização do funcional de $\mathrm{KS}$ em relação à densidade. Usando o cálculo variacional [30,34] temos

$$
V_{K S}(\mathbf{r})=V_{C}(\mathbf{r})+V_{X C}[\rho(\mathbf{r})]+V_{e x t}(\mathbf{r})
$$


onde

$$
V_{x c}[\rho(\mathbf{r})]=\frac{\delta \tilde{E}_{X C}}{\delta \rho(\mathbf{r})}
$$

Toda a ignorância sobre o problema de muitos corpos está inserida no termo $\tilde{E}_{X C}[\rho]$. Necessitamos de aproximações para o termo de troca e correlação para resolver as equações de KS.

Diversas abordagens são encontradas na literatura para a construção da melhor

aproximação para o funcional $\tilde{E}_{X C}[\rho]$. As mais conhecidas são as aproximações de densidade local (LDA - Local Density Approximation ou Local Spin Density Approximation (LSDA) e a aproximação da expansão dos gradientes generalizados (GGA - Generalized Gradient Approximation). A GGA inclui termos de gradiente e derivadas de ordem superiores da densidade [35]. Neste trabalho, utilizamos a aproximação híbrida Hartree-Fock/DFT (HF/DFT) para os funcionais. A ideia dos métodos híbridos é incluir uma fração do termo de troca do método HF no funcional GGA.

\subsubsection{O Funcional Híbrido Becke three parameter Lee-Yang- Parr (B3LYP)}

Os funcionais híbridos de HF/DFT foram desenvolvidos levando em consideração o método de conexão adiabática [36]. O método de conexão adiabática conecta adiabaticamente, o sistema de $\mathrm{N}$ elétrons interagentes $(\lambda=1)$ ao sistema de $\mathrm{N}$ elétrons não interagentes $(\lambda=0)$.

$$
E_{X C}=\int_{0}^{1} U_{X C}^{\lambda} d \lambda
$$


onde o parâmetro $\lambda$ descreve o acoplamento entre elétrons que considera o termo de repulsão Coulombiana e $U_{X C}^{\lambda}$ é a energia potencial de troca e correlação. No limite de $\lambda=0$ temos que energia potencial de troca e correlação é a energia de troca obtida do determinante de Slater para orbitais KS.

Em 1993, A. Becke propôs uma aproximação para a energia de troca e correlação baseado na linearização do funcional em relação a $\lambda$ [37]:

$$
E_{X C}^{B 3 L Y P}=(1-a) E_{X}^{L S D A}+a E_{X}^{H F(\lambda=0)}+b E_{X}^{B 88}+c E_{C}^{L Y P}+(1-c) E_{C}^{V W N}
$$

onde os parâmetros empíricos $a=0.20, b=0.72$ e $c=0.81$ foram otimizados para reproduzir energias de atomização e ionização de moléculas [36]. $E_{X}^{L S D A} \mathrm{e}$ $E_{X}^{B 88}$ são as energias de troca da aproximação LSDA e da proposta por Becke em 1988 [38, 39]. $E_{C}^{L Y P}$ e $E_{C}^{V W N}$ são, respectivamente, as energias de correlação propostas por Lee, Yang e Parr (LYP) [40] e Volsko, Wilk e Nusair (VWN) [41]. A contribuição da troca de HF para $\lambda=0$ (gás de elétrons não interagentes) é calculada pela relação

$$
E_{X}^{H F}=\frac{1}{2} \sum_{1, j} \iint \psi_{i}^{*}\left(\mathbf{r}_{1}\right) \psi_{j}\left(\mathbf{r}_{1}\right) \frac{1}{r_{12}} \psi_{i}^{*}\left(\mathbf{r}_{2}\right) \psi_{j}\left(\mathbf{r}_{2}\right) d r_{1} d r_{2}
$$

Este funcional é comumente chamado de B3LYP (Becke Three Parameter LeeYang-Parr) [37] e é largamente utilizado em cálculos dentro da DFT devido a conseguir reproduzir muito bem geometrias e energias de ligação de sistemas moleculares.

No entanto, não podemos dizer que cálculos utilizando o funcional B3LYP são estritamente de primeiros princípios devido aos ajustes realizados (parametrização) para obter os coeficientes a, b e c (eq. 2.19). No caso do B3LYP, estes parâmetros são obtidos através do fitting de um conjunto de dados de energias de atomização, potenciais iônicos, afinidades de prótons e energia total atômica de moléculas como 
$\mathrm{H}_{2}, \mathrm{CH}_{4}$ e $\mathrm{H}_{2} \mathrm{O}[37,42]$.

\subsubsection{Funções de Bases Locais do tipo gaussianas - bases de Pople}

O uso de funções de base gaussianas para a representação das funções de onda eletrônicas é muito comum no estudo de biomoléculas. A combinação linear de diversas funções de base gaussianas primitivas do tipo atômico gera o conjunto de base gaussiana. O termo base local refere-se ao fato de que as bases gaussianas são centradas sobre os sítios atômicos [43]. Encontram-se diversos trabalhos na literatura sobre a construção e uso das funções de onda gaussianas [43-45]. O simples aumento da função de base não indica necessariamente a melhora do modelo, principalmente quando o sistema apresenta uma grande distribuição de carga anisotrópica. Dividir as funções de base que descrevem os efeitos de anisotropia das cargas auxilia na resolução do problema da distribuição anisotrópica. No entanto ainda temos o problema da distorção dos orbitais moleculares. Se tivermos, por exemplo, um hidrogênio isolado, teremos uma nuvem eletrônica totalmente simétrica (1s). Isto não ocorre se tivermos o hidrogênio em ambiente molecular e teremos um orbital do tipo $\mathrm{p}$ (forma hibrida sp). A solução mais comum para este tipo de distorção do orbital é introduzir na função de base as funções polarizadoras. As funções de polarização possuem um alto valor do número quântico de momento angular e correspondem aos orbitais p para o hidrogênio e orbitais d para os elementos da primeira e segunda linha da tabela periódica. A utilização de funções polarizadoras, na nomenclatura de Pople, são indicadas pelo asterisco *. Dois asteriscos indicam o uso da função de polarização para o hidrogênio e átomos pesados (não hidrogênio) [46].

Um cuidado que o usuário deve ter na escolha das funções de base está relacionado ao tratamento das espécies químicas como ânions e moléculas que contêm pa- 
res isolados pois estas espécies possuem uma quantidade significativa de densidade eletrônica distante do centro nuclear. Para isto, funções difusas são acrescentadas na função de base. As funções difusas são indicadas, na nomenclatura de Pople, pelo símbolo $+\mathrm{e}++$ indica o uso de funções difusas para o hidrogênio e para átomos pesados.

No presente trabalho utilizamos a base de Pople 6-311 $++\mathrm{G}^{* *}$ [47] que é composta de seis funções gaussianas para a região mais interna da estrutura eletrônica (core atômico). Os orbitais de valência são descritos por três funções de base (triple-zeta basis): a primeira pela combinação linear de três gaussianas, a segunda e a terceira por uma gaussiana.

\subsection{O método de Docking para sistemas Receptor- Ligante}

Uma descrição detalhada do processo de reconhecimento molecular receptorligante através de simulação computacional é motivada pela necessidade de redução do tempo e dos altos custos no desenvolvimento de novos medicamentos [48]. Este processo altamente complexo envolve um grande número de interações intermoleculares entre o ligante e a molécula receptora. O método computacional de docking receptor-ligante é uma tentativa de descrevê-lo. Os maiores desafios do método são a predição de um modo de ligação (sítio ativo) de um receptor (proteínas, enzimas, DNA) e a tentativa de obter a afinidade de ligação entre o receptor e o ligante. O desenvolvimento de um algoritmo que investiga a hipersuperfície de energia potencial (potential energy surface, PES) e a predição da afinidade de ligação de um complexo receptor-ligante são os principais objetivos do estudo de docking receptor-ligante. Com isso, pode-se determinar a melhor conformação do ligante em relação ao sítio ativo do receptor. A afinidade de ligação é obtida por 
um modelo que avalia a energia livre de ligação (função scoring) e o modelo deve ser viável computacionalmente e determinar dentre dois ligantes distintos, aquele com maior afinidade de ligação para um mesmo receptor. Outro fator muito importante a ser estudado é a afinidade de ligação entre o receptor e o ligante [36]. Os primeiros algoritmos de docking surgiram na década de 80 e desde então vários métodos têm sido implementados. Os métodos de docking se diferenciam em relação ao grau de flexibilidade das moléculas biológicas interagentes e pelo método de otimização empregado na investigação da hipersuperfície de energia potencial [48].

\subsubsection{A função scoring: avaliando a afinidade de ligação entre receptor-ligante}

A dependência conformacional da função scoring utilizada pelo software $\mathrm{Au}$ toDock Vina [49] é dado por:

$$
c=\sum_{i<j} f_{t_{i} t_{j}}\left(r_{i j}\right)
$$

Aqui a soma é sobre todos os pares de átomos que se movem em relação uns aos outros, normalmente, excluindo interações de átomos separados por três ligações covalentes consecutivas. Cada átomo i é atribuído ao tipo $t_{i}$ e $f_{i j}$ é a função de interação simétrica da distância interatômica $r_{i j}$. O valor de c pode ser escrito como a soma das contribuições intermoleculares e intramoleculares:

$$
c=c_{\text {inter }}+c_{\text {intra }}
$$

O algoritmo de otimização tenta encontrar o mínimo global de c e outras conformações de baixo scoring, do qual ele faz um ranking das conformações de mais 
baixa energia.

A energia de ligação esperada é calculada da contribuição intermolecular da conformação com o menor scoring, designada como conformação 1:

$$
s_{1}=g\left(c_{1}-c_{\text {intra }}\right)=g\left(c_{\text {inter } 1}\right)
$$

onde a função $g$ pode ser uma função arbitrária estritamente crescente, suave e possivelmente não linear.

O arquivo de saída também mostra outras conformações com seus valores de $\mathrm{s}$, no entanto para preservar o ranking, estes valores usam o $c_{\text {intra }}$ do melhor modo de ligação:

$$
s_{1}=g\left(c_{i}-c_{\text {intra1 }}\right)
$$

A implementação particular da função scoring para o Autodock Vina 4 foi o ajuste da função além da regressão linear. A função scoring combina as vantagens dos potenciais bem conhecidos com funções scoring empíricas extraindo a informação empírica das preferências conformacionais do complexo receptor-ligante e medidas de afinidade.

A função de interação $f_{t_{i} t_{j}}$ é definida em relação à distância $d_{i j}=r_{i j}-R_{t_{i}}-R_{t_{j}}$ tal que:

$$
f_{t_{i} t_{j}}\left(r_{i j}\right) \equiv h_{t_{i} t_{j}}\left(d_{i j}\right)
$$

onde $R_{t}$ é o raio de van der Waals para o átomo t. A função $h_{t_{i} t_{j}}$ é dada pela soma ponderada das interações estéricas idênticas para todos os pares de átomos, interações hidrofóbicas entre átomos hidrofóbicos e, quando aplicável, ligações de hidrogênio. Os valores ponderados para estes parâmetros utilizados no presente 
trabalho são apresentados na tabela 2.1.

Tabela 2.1: Valores ponderados, termos e significados utilizados na função scoring do Autodock Vina 4 [49].

\begin{tabular}{ccc}
\hline \hline $\begin{array}{c}\text { Valores } \\
\text { ponderados }\end{array}$ & Termos & Significado \\
\hline$-0,0356$ & gauss $_{1}(d)=e^{(d / 0,5)^{2}}$ & interações \\
& estéricas \\
$-0,00516$ & gauss $_{2}(d)=e^{-((d-3) / 2)^{2}}$ & interações \\
0,840 & repulsão & estéricas \\
$-0,0351$ & Interação hidrofóbica & 1 se $d<0,5 \AA ; 0$ se $d \geq 1,5 \AA$ \\
$-0,587$ & Ligação de hidrogênio $d \geq 0$ \\
0,0585 & 1 se $d<-0,7 \AA ; 0$ se $d>0 \AA$ \\
\hline \hline
\end{tabular}

\subsection{A Dinâmica Molecular Clássica para Biomolé- culas}

A Dinâmica Molecular (DM) é umas das principais ferramentas para o estudo de sistemas atômico-moleculares (físicos, químicos e biológicos) constituídos por um grande conjunto de átomos ou moléculas [36]. A simulação de DM determina os movimentos das partículas de um dado sistema para o qual se conhece o potencial de interação (campo de forças) e as equações que regem este movimento. A evolução temporal das componentes destes sistemas pode então ser estudada 
para determinar as propriedades macroscópicas, de acordo com os princípios fundamentais da mecânica estatística. A DM é frequentemente usada no estudo de proteínas e biomoléculas, onde trajetórias dos átomos e moléculas são determinadas pela resolução das equações de movimento de Newton. A partir das posições e velocidades das partículas num dado instante $t_{0}$ e o cálculo das forças resultantes em cada partícula as posições e as velocidades num instante posterior $t_{0}+\delta t$ são determinadas. As novas posições são utilizadas, então, para o cálculo das novas forças, obtendo-se a configuração do sistema no instante $t_{0}+2 \delta t$. Este procedimento é realizado de forma repetitiva gerando as trajetórias das moléculas para todo o sistema[36].

\subsubsection{Os Campos de Forças}

Campos de Forças descrevem as energias de um dado sistema como somente uma função das posições nucleares. Apesar dessa aproximação, parametrizar um Campo de Força ainda pode ser um desafio muito grande, uma vez que os parâmetros do potencial efetivo clássico são ajustados, de modo a reproduzir propriedades estruturais e termodinâmicas do sistema; no caso de moléculas como proteínas, a parametrização é ainda mais complicada, pois dados experimentais termodinâmicos disponíveis para proteínas são limitados. Muitas vezes este processo de parametrização envolve um trabalho sistemático que reproduz os dados energéticos através de cálculos de mecânica quântica ab initio envolvendo os elétrons [50].

A escolha dos potenciais de interação intra e intermoleculares é fundamental para a descrição correta do sistema em estudo. Podemos escrever a relação do potencial total do sistema da seguinte forma:

$$
V_{\text {total }}=\sum V_{\text {inter }}+\sum V_{\text {intra }}
$$


Uma forma de descrever a energia potencial $V_{\text {total }}$ da equação 2.26 do sistema é

$$
V=\sum_{i, j} V_{R}\left(r_{i j}\right)+\sum_{i, j, k} V_{\theta}\left(\theta_{i j k}\right)+\sum_{i, j, k, l} V_{\phi}\left(\phi_{i j k l}\right)+\sum_{i, j} V_{e l}\left(r_{i j}\right)+\sum_{i, j} V_{v d W}\left(r_{i j}\right),
$$

em que $V_{R}\left(r_{i j}\right)$ corresponde à energia de estiramento (ligação) entre os átomos $i$ e $j, V_{\theta}\left(\theta_{i j k}\right)$ à energia das deformações angulares e $V_{\phi}\left(\phi_{i j k l}\right)$ às torções do diedro (deformações dos ângulos diedros). Os termos que representam o potencial intermolecular são o $V_{e l}$ e $V_{v d W}$ que correspondem, respectivamente, ao potencial eletrostático e à energia de van der Waals.

Podemos escrever o termo $V_{R}$, na aproximação harmônica, como

$$
V_{R}=\frac{1}{2} K_{R}\left(r_{i j}-r_{0 i j}\right)^{2}
$$

onde $K_{R}$ e $r_{0 i j}$ são a constante de força e o comprimento de equilíbrio da ligação. No caso do potencial $V_{\theta}$, podemos escrever a relação, na aproximação harmônica da seguinte forma:

$$
V_{\theta}=\frac{1}{2} K_{\theta}\left(\theta_{i j k}-\theta_{0 i j k}\right)^{2}
$$

onde $\theta_{0 i j k}$ corresponde ao ângulo de equilíbrio. O termo que representa o potencial de torção relacionada ao ângulo diedro $\phi_{i j k l}$ pode ser escrito como

$$
V_{\phi}=\frac{1}{2} V_{i j k l}\left[1+\cos \left(n \phi_{i j k l}-\phi_{0 i j k l}\right]\right.
$$

onde $V_{i j k l}, n$ e $\phi_{0 i j k l}$ são, respectivamente, a amplitude da barreira de energia, a periodicidade da função e o deslocamento angular de equilíbrio. 
A interação Coulombiana é utilizada para descrever o potencial eletrostático $V_{e l}$ e é dado por

$$
V_{e l}=\frac{1}{4 \pi \epsilon} \frac{Q_{i} Q_{j}}{r_{i j}}
$$

onde $\epsilon$ é a constante dielétrica, $Q_{i}$ e $Q_{j}$ são as cargas efetivas dos pares de átomos $i$ e $j$ separados por uma distância $r_{i j}$.

Neste trabalho, a distribuição de cargas parciais Q dos átomos dos inibidores estudados foram obtidas através do método CHELPG (Charges from Electrostatic Potentials using a Grid based method) [51]. O processo utilizado pelo CHELPG para obter as cargas atômicas considera o cálculo do Potencial Eletrostático Molecular (PEM) através de um número de pontos espaçados na faixa entre 0,3 e 0,8 , dentro de uma malha de energia na forma de um cubo que envolve a molécula. As dimensões do cubo são escolhidas de forma a alocar a molécula no centro, adicionando 2,8 $\AA$ de espaço livre entre a molécula e a extremidade da caixa em todas as três dimensões. Todos os pontos que estão dentro do raio de van der Waals da molécula são desconsiderados na montagem da PEM e, em todos os pontos válidos da grade, as cargas atômicas são obtidas de forma a reproduzir a PEM. A única restrição do procedimento é que a soma de todas as cargas atômicas obtidas necessariamente deva ser igual à carga total do sistema, que é mantida constante durante o processo. Uma vez escolhidos os pontos da grade o potencial eletrostático é calculado para cada ponto através do cálculo da função de onda dos elétrons, utilizando a mecânica quântica, e da geometria da molécula. Neste trabalho, determinamos o potencial eletrostático utilizando a DFT com o funcional B3LYP e o conjunto de base $6-311++\mathrm{G}^{* *}$.

O termo $V_{v d W}\left(r_{i j}\right)$ corresponde a energia de van der Waals e é representado 
pelo potencial de Lennard-Jones do tipo 6-12,

$$
V_{v d W}=4 \epsilon_{i j}\left[\left(\frac{\sigma_{i j}}{r_{i j}}\right)^{12}-\left(\frac{\sigma_{i j}}{r_{i j}}\right)^{6}\right]
$$

onde $\epsilon_{i j}$ e $\sigma_{i j}$ são os parâmetros de energia e diâmetro de Lennard-Jones. O primeiro termo do potencial de Lennard - Jones $\left(r_{i j}{ }^{-12}\right)$ descreve o potencial de repulsão para distâncias curtas e o termo $\left(r_{i j}{ }^{-6}\right)$ descreve o potencial atrativo de longo alcance (dispersão de London).

Existem diversos Campos de Forças desenvolvidos para descrever a expressão 2.27, cada um com uma característica específica para simular um dado sistema. Dentre os mais conhecidos podemos destacar o OPLS (Optimized Potentials for Liquid Simulations), AMBER (Assisted Model Building with Energy Refinement [52, 53], CHARMM (Chemistry at Harvard Macromolecular Mechanics) [54] e o GROMOS (Groningen Molecular Simulation) [55]. Todos estes campos de força estão bem estabelecidos e são usados para estudar biomoléculas em geral, devido a possuírem parâmetros apropriados para proteínas, peptídeos, sacarídeos e ácido nucleicos. Infelizmente os parâmetros não são transferíveis, entre campos de forças, por usarem moléculas e protocolos diferentes em suas parametrizações. No entanto, dois campos de força parametrizados de formas distintas podem vir a fornecer a mesma precisão na descrição de uma determinada propriedade de um mesmo sistema.

O campo de força GROMOS na parametrização 53A6 [56, 57], dentro do pacote GROMACS, foi utilizado para as DM apresentadas nesta tese. No entanto, ainda não existe consenso na literatura sobre quais parâmetros devam ser utilizados na presença de metais de transição na simulação de complexos metálicos. Nesta tese, os parâmetros utilizados para simular o íon cobre no complexo foram obtidas a partir da ref. [58], onde o procedimento utilizado para obter os parâmetros 
foi o Force Matching de uma simulação de dinâmica molecular quântica para o $\left[\mathrm{Cu}(\text { enim }) \mathrm{H}_{2} \mathrm{O}\right]^{2+}$, um complexo semelhante aos estudados neste trabalho. A idéia do Force Matching é obter os potenciais de energia clássicos a partir de informações obtidas dos cálulos de primeiros princípios. Este procedimento está baseado na tentativa de obter as forças, a partir de cálculos de primeiros princípios, que mais se aproximam às forças obtidas do potencial de energia, o que é diferente dos métodos usuais que utilizam informações de dados experimentais para obter os potenciais de energia.

\subsubsection{Condições iniciais e etapas utilizadas na Dinâmica Mo- lecular Clássica}

Utilizamos a abordagem de condições periódicas de contorno para simular a DM. Centralizamos a posição da proteína-ligante em uma célula unitária de dimensões que não permitissem interações com as células unitárias vizinhas. Para simular o efeito do solvente no sistema estudado, foram adicionadas moléculas de água na célula unitária. O modelo utilizado para simular os clusters de água foi o Simple Point Charge (SPC) [59] que é um solvente explicito. A molécula de água no modelo SPC possui três sítios de carga com predominância de carga positiva nos átomos de hidrogênio e carga negativa no átomo de oxigênio. O ângulo de ligação H-O-H é 109, $42^{\circ}$ e as distâncias das ligações OH são de $1 \AA$, com a molécula de água na forma rígida das suas ligações. Para neutralizar a carga total na célula unitária, adicionamos contra íons de $\mathrm{Cl}^{-}$ou $\mathrm{Na}^{+}$ao solvente. No GROMACS, os contra íons podem ser inseridos como substituindo moléculas de água do solvente. Os programas genbox e genions foram utilizados para gerar as moléculas de água e os íons na célula unitária, respectivamente. As forças de curto alcance (van der Waals e Coulombiana) são limitadas por um raio de corte esférico pré-estabelecido que, no nosso caso foi de $10 \AA$. Para forças de longo alcance utilizamos o potencial 
de Particle-mesh Ewald [60] que substitui a força de interação simples entre duas moléculas por uma força efetiva obtida do método da soma infinita e, desta forma, somam-se todas as interações entre todas as imagens periódicas dessas partículas.

Apesar das condições iniciais estarem estabelecidas, o sistema ainda não se encontra em equilíbrio térmico e de pressão. Este processo de equilíbrio, conhecido comumente por equilibração do sistema, foi realizado neste trabalho, através das seguintes etapas: a) minimização da energia; b) equilíbrio térmico; c) equilíbrio da pressão.

A minimização de energia ou otimização de geometria do sistema, tenta identificar as posições atômicas que caracterizam o mínimo local da Energia Potencial V. Este processo relaxa as distâncias, ângulos e contatos intermoleculares de modo a encontrar o mínimo local mais próximo. O método de gradiente conjugado (GC) foi utilizado para obter a minimização de energia neste trabalho [61]. O GC utiliza informações obtidas das derivadas de primeira ordem do potencial com relação às posições atômicas. Para achar um mínimo local de energia utiliza-se a parte negativa do gradiente da função em um determinado ponto. Caso o vetor gradiente se desloque numa direção definida por ser positiva, a função crescerá a uma taxa mais elevada. Se o vetor gradiente se deslocar numa direção definida como negativa a função decrescerá à taxa mais elevada [61]. Após a minimização de energia e obtenção das posições iniciais devemos especificar as velocidades iniciais de todos os átomos do sistema e, desta forma, resolver as equações de movimento. As velocidades iniciais foram obtidas através da distribuição de Maxwell-Boltzmann em que a energia cinética é determinada pela temperatura $\mathrm{T}$ especificada

$$
\frac{3}{2} N k_{B} T=\frac{1}{2} \sum_{i=1}^{N} m_{i} v_{i}^{2},
$$

onde $\mathrm{N}$ é o numero de partículas $m_{i}$ e $v_{i}$ são a massa e a velocidade da partícula 
$i$. Aquecemos, gradualmente, de $0 \mathrm{~K}$ até a temperatura ambiente de $\mathrm{T}=300 \mathrm{~K}$ os sistemas aqui em estudo.

Estabelecidas as condições iniciais de posições e velocidades dos átomos utilizamos o algoritmo leap-frog para integrar as equações de movimento e determinar as posições e velocidades nas etapas seguintes, construindo a trajetória do sistema. O leap-frog é uma modificação do algoritmo de Verlet no qual a velocidade é calculada de forma explícita, aumentando a precisão numérica obtida. As velocidades são dadas por

$$
v\left(t+\frac{1}{2} \delta t\right)=v\left(t-\frac{1}{2} \delta t\right)+\delta t \cdot a(t)
$$

onde

$$
r(t+\delta t)=r(t)+\delta t v\left(t+\frac{1}{2} \delta t\right)
$$

No tempo t, a velocidade é calculada por:

$$
v(t)=\frac{1}{2}\left[v\left(t-\frac{1}{2} \delta t\right)+v\left(t+\frac{1}{2} \delta t\right)\right]
$$

\section{Ensembles NVT e NPT}

Emsembles são um grande conjunto de réplicas do sistema de interesse, que diferem entre si pelas atribuições das coordenadas e momentos das partículas. Uma técnica muito comum utilizada na MD é manter um ou mais parâmetros macroscópicos fixos dentro destes ensembles, para atingir o equilíbrio do sistema. Para alcançar o equilíbrio térmico, realizamos uma DM no ensemble NVT (ensemble canônico), onde a temperatura, o volume da caixa e o número de moléculas são mantidos fixos. A ideia é controlar a DM de tal forma que as temperaturas instantâneas $T_{\text {inst. }}$ do sistema convirjam para a temperatura $T$ desejada, e que o sistema 
se mantenha nesta $T$ durante todas as etapas subsequentes da DM. O termostato utilizado neste trabalho foi o de Berendsen [62] que permite um controle da taxa com a qual a temperatura instantânea se aproxima da temperatura desejada. Para controlar a temperatura, um banho térmico é acoplado ao sistema, permitindo trocas de calor, possibilitando o fornecimento ou retirada de energia térmica do sistema de interesse. O ensemble NVT pode ser utilizado em etapas posteriores para reequilibrar o sistema ao estado termodinâmico desejado.

No ensemble NPT, o volume do sistema varia e a pressão e temperatura são mantidas constantes. A variação do volume ocorre de forma controlada através do escalonamento das dimensões da caixa de simulação por um fator $\gamma$. Neste trabalho foi utilizada a aproximação de Parrinello-Rahman [63, 64] para simular a DM em ensemble NPT. Com o barostato de Parrinello-Rahman os vetores da caixa são representadas pela matriz $\mathbf{b}$ e obedecem à equação da matriz de movimento

$$
\frac{d \mathbf{b}^{2}}{d t^{2}}=V \mathbf{W}^{-1} \mathbf{b}^{\prime-1}\left(\mathbf{P}-\mathbf{P}_{r e f}\right)
$$

onde $\mathrm{V}$ é o volume da caixa e $\mathbf{W}$ é a matriz dos parâmetros de massa. As matrizes $\mathbf{P}$ e $\mathbf{P}_{r e f}$ são as pressões instantâneas e de referência, respectivamente. As equações de movimento das partículas foram modificadas

$$
\begin{gathered}
\frac{d^{2} \mathbf{r}_{i}}{d t^{2}}=\frac{\mathbf{F}_{i}}{m_{i}}-\mathbf{M} \frac{d \mathbf{r}_{i}}{d t}, \\
\mathbf{M}=\mathbf{b}^{-1}\left[\mathbf{b} \frac{d \mathbf{b}^{\prime}}{d t}+\mathbf{b} \frac{d \mathbf{b}^{\prime}}{d t} \mathbf{b}^{\prime-1}\right] .
\end{gathered}
$$

A matriz inversa dos parâmetros de massa $\mathbf{W}^{-1}$ determina a força do acoplamento e como a caixa pode ser deformada. O termo que expressa a relação da matriz 
inversa $\mathbf{W}^{-1}$ é dado por:

$$
\left(\mathbf{W}^{-1}\right)_{i j}=\frac{4 \pi^{2} \beta_{i j}}{3 \tau_{p}^{2} L}
$$

onde $\beta$ é a compressibilidade isotérmica, $\tau_{p}$ é a constante de tempo para a pressão e L é a maior dimensão da caixa. 


\section{Capítulo 3}

\section{Resultados e Discussões}

Neste capítulo mostraremos os resultados obtidos nos estudos dos inibidores isapn, $C u[\text { isapn }]^{2+}$ frente à kinase CDK1/ciclina $\mathrm{B}$ e os estudos dos inibidores SU9516, isaenim e isaepy ligados à CDK2. Estes serviram de base para obtenção dos resultados obtidos para o isapn e $C u[i s a p n]^{2+}$. Os resultados de otimização de estrutura e, no caso do isapn e $C u[i s a p n]^{2+}$, a comparação entre as estruturas das moléculas em vácuo e inseridas em meio polarizado contínuo (Polarizable Continuum Model - PCM)[29] obtidos dos cálculos dentro da DFT são discutidos. Verificamos e analisamos as distribuições de carga nos átomos do isapn e $C u[i s a p n]^{2+}$, quando inseridos em vácuo e em meio polarizado.

Resultados de docking dos inibidores no sítio ativo da CDK2 e CDK1/ciclina B onde ocorre a ligação da molécula de ATP são analisados assim como as posições de cada ligante no sítio. A influência do íon Cu nas configurações obtidas para o complexo $C u[i s a p n]^{2+}$ é discutida. Após a análise de docking dos sistemas estudados, discutimos os resultados obtidos nas dinâmicas moleculares (DM) realizadas para cada sistema estudado neste trabalho. O tempo de DM para todos os sistemas foi 10 ns. Fizemos as análises de clusters das estruturas obtidas dos inibidores quando inseridos no sítio de ligação da ATP na CDK2 e na CDK1/ciclina B. Verificamos 
as ligações de hidrogênio entre os inibidores com o sítio ativo e também fizemos as análises dos comportamentos dos inibidores durante todas as DM.

\subsection{Estrutura eletrônica dos compostos isaepy, isa- enim, e isapn.}

As distribuições de carga parciais nos átomos dos inibidores foram obtidas através de cálculos de estrutura eletrônica dentro da DFT e utilizando o código computacional Gaussian09 na edição revisada A.2 [65]. Para obtenção das cargas parciais foi necessário, primeiro, fazer cálculos de otimização de estrutura das moléculas. As estruturas tridimensionais inicialmente propostas para o isaepy, isaenim, isapn e $[\mathrm{Cu}(\text { isapn })]^{2+}$ foram desenvolvidas baseadas na estrutura do inibidor SU9516 [66]. Os cálculos de otimização, no vácuo e em meio polazarizado contínuo (PCM) que simula a água foram realizados considerando o funcional B3LYP e a base gaussiana $6-311++\mathrm{G}^{* *}$. Discutimos aqui a influência do meio químico para a obtenção da distribuição de carga, utilizando o caso do isapn e $[C u(\text { isapn })]^{2+}$ como exemplos. Para o íon $\mathrm{Cu}$, utilizamos o raio de van der Waals de valor $1,4 \AA$.

Na Figura 3.1 mostramos as estruturas dos inibidores isaepy, $\left[\mathrm{Cu}(\text { isaepy }) \mathrm{H}_{2} \mathrm{O}\right]^{1+}$, isaenim e $[\mathrm{Cu}(\text { isaenim })]^{2+}$ obtidas através dos cálculos, no âmbito da DFT, aqui realizados. Verificamos que, com o íon $\mathrm{Cu}$ inserido no isaenim e isaepy, as estruturas ficam mais rígidas e com menor grau de liberdade. Nos dois casos, percebemos que o íon $\mathrm{Cu}$ fica preso nas moléculas e as distâncias das ligações formadas da interação do íon $\mathrm{Cu}$ com os átomos nos ligantes são semelhantes e com valor de aproximadamente $2 \AA$. As estruturas obtidas aqui para o $[\mathrm{Cu}(\text { isapn })]^{2+}$ e $[C u(\text { isaenim })]^{2+}$ estão em acordo com as estruturas obtidas na literatura [23] e são mostradas nas Figuras 3.1 e 3.2. Uma molécula de água foi inserida para manter a coordenação tetraédrica do íon Cu no caso do isaepy. A forma ceto-ceto 
foi considerada para todos os inibidores e assim todos os hidrogênios do isaepy e isaenim são considerados nos cálculos. A escolha da forma ceto-ceto foi feita de acordo com medidas de Dicroísmo Circular realizadas em pH acima de 7,4 onde foi verificada uma alta estabilidade relativa desta forma, nos casos do isaepy, isaenim e isapn [23].
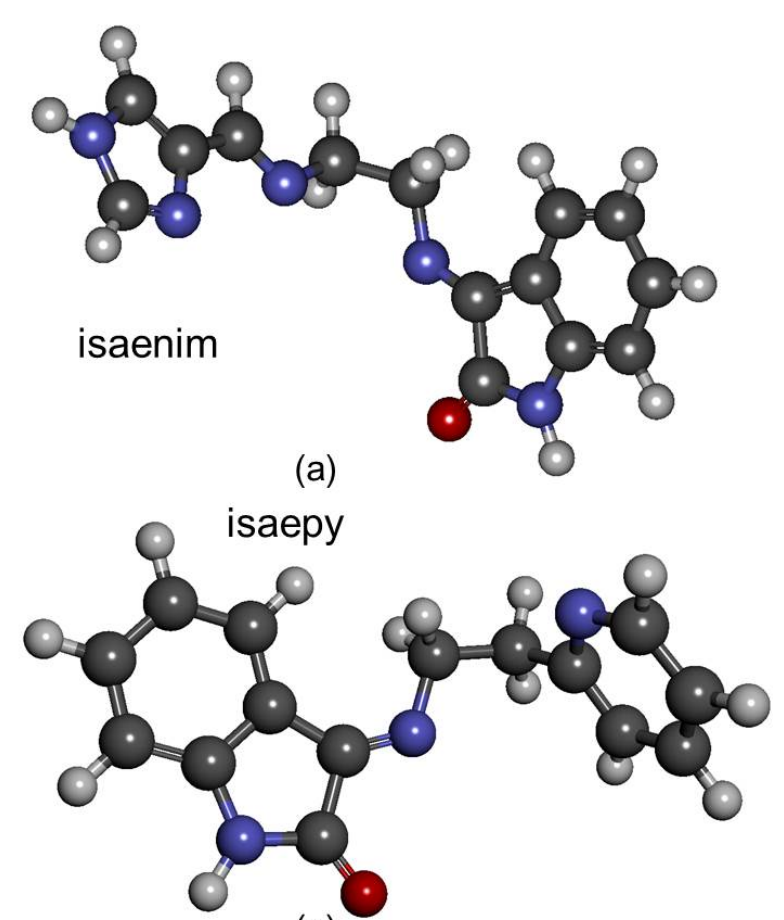

(c)

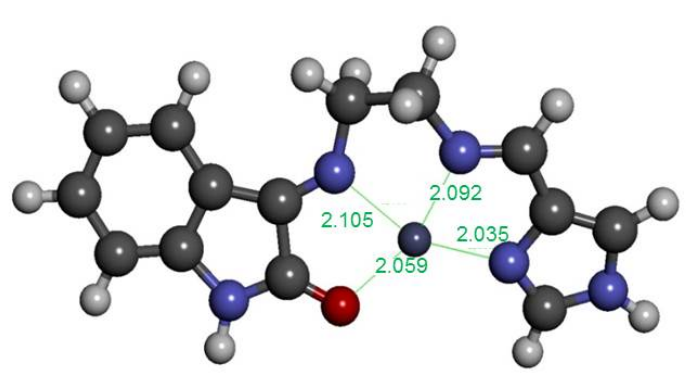

$[\mathrm{Cu}(\text { isaenim })]^{2+}$

(b)

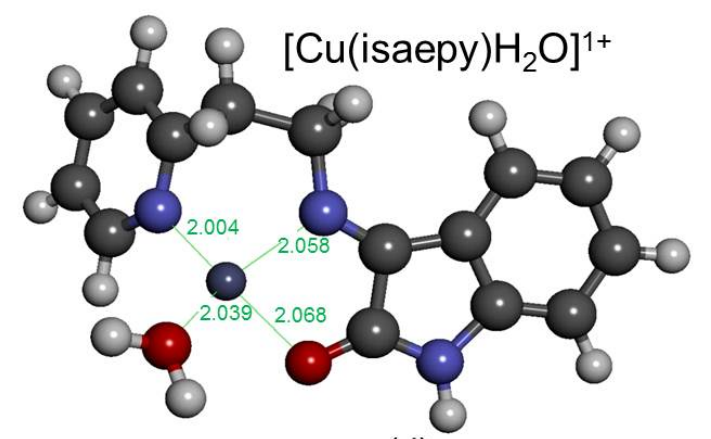

(d)

Figura 3.1: Estruturas obtidas por cálculos de estrutura eletrônica: (a) isaenim, (b) $[\mathrm{Cu}(\text { isaenim })]^{2+}$, (c) isaepy e (d) $\left[\mathrm{Cu}(\text { isaepy }) \mathrm{H}_{2} \mathrm{O}\right]^{1+}$. As distâncias de ligação do íon $\mathrm{Cu}$ no isaenim e isaepy são mostradas na cor verde.

\subsubsection{Estrutura eletrônica, geometria e distribuição de carga do isapn e $[C u(\text { isapn })]^{2+}$}

Na Figura 3.2 mostramos as estruturas do SU9516, isapn e $[C u(\text { isapn })]^{2+}$ obtidas após otimização de geometria. O SU9516 ficou com uma estrutura planar e 
verificamos uma ligação de hidrogênio O-H de 1,925 $\AA$. No caso do $[C u(\text { isapn })]^{2+}$ o íon $\mathrm{Cu}$ manteve-se tetra coordenado e, novamente, as distâncias das ligações do íon $\mathrm{Cu}$ com os átomos no $[\mathrm{Cu}(\text { isapn })]^{2+}$ são semelhantes e com valores próximos de $2 \AA$.
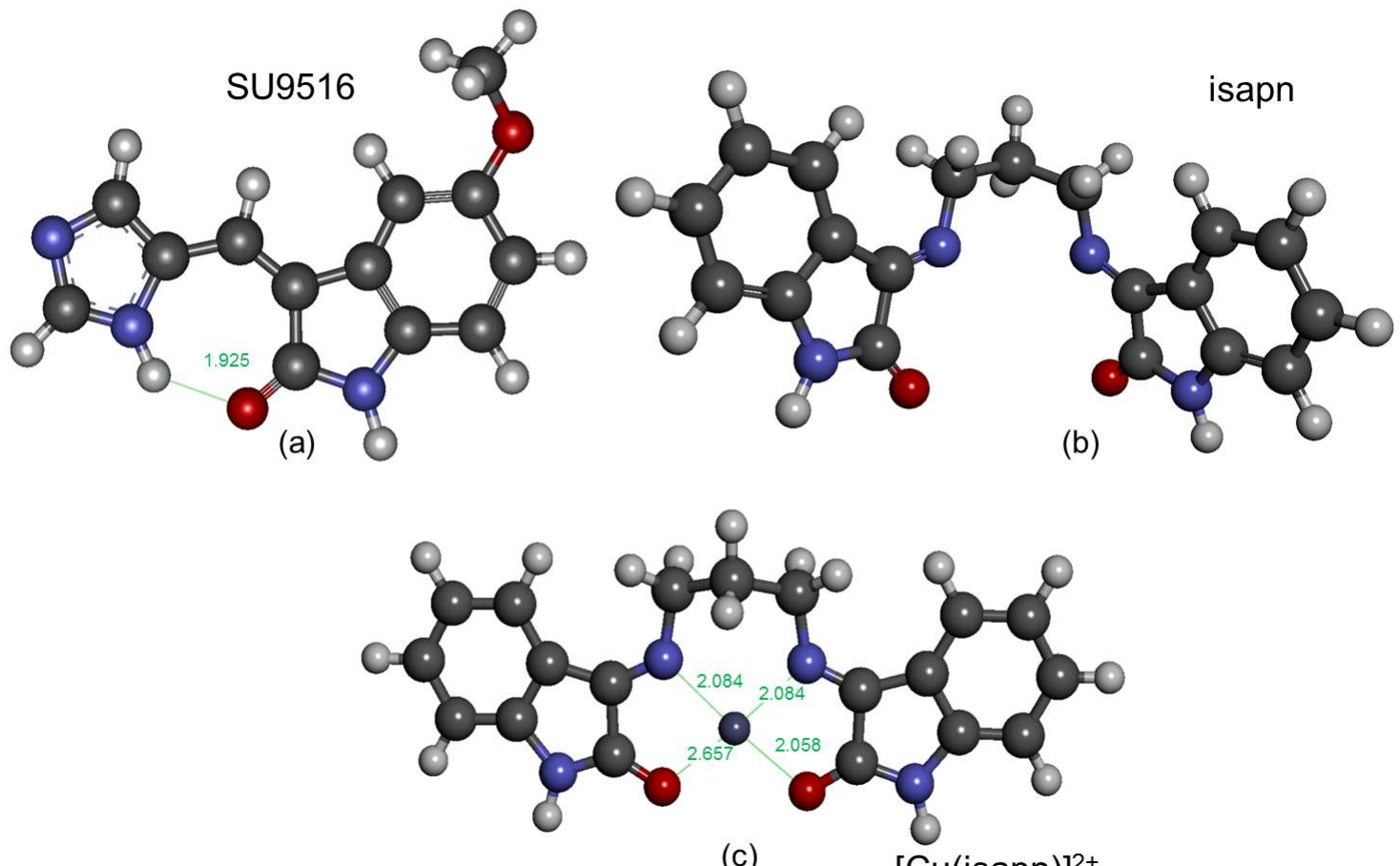

(c)

$[\mathrm{Cu}(\text { isapn })]^{2+}$

Figura 3.2: Estruturas obtidas: (a) SU9516, (b) isapn e (c) $[C u(\text { isapn })]^{2+}$. As distâncias de ligação O-H no SU9516 e do íon Cu no $[C u(\text { isapn })]^{2+}$ são mostradas na cor verde.

Na Figura 3.3 são mostradas as estruturas obtidas para o isapn e $[\mathrm{Cu}(\text { isapn })]^{2+}$ em vácuo e em PCM, que simula o meio aquoso. Verificamos que a geometria otimizada para o $[\mathrm{Cu}(\text { isapn })]^{2+}$ não variou com a mudança de ambiente químico. No entanto, a sobreposição das estruturas obtidas do isapn em vácuo e em PCM mostram que os resultados das otimizações diferem entre si. 
(a)

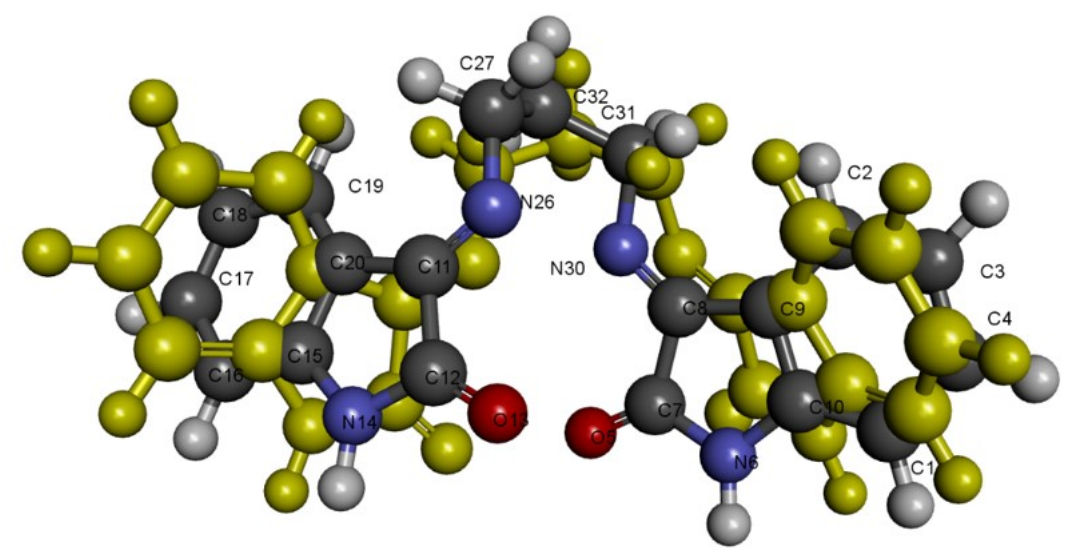

(b)

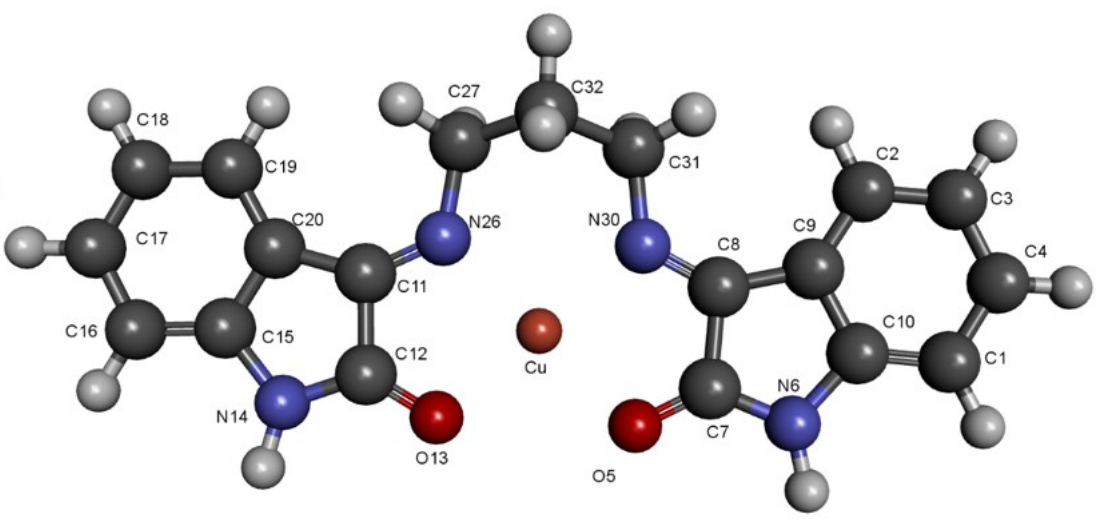

Figura 3.3: Sobreposição das estruturas obtidas em vácuo e em PCM (em amarelo) para (a) isapn e (b) $[C u(\text { isapn })]^{2+}$.

A estrutura do isapn quando submetida ao meio polarizado (em amarelo), sofre um maior empacotamento comparado à estrutura obtida em vácuo, de forma que é observada a torção do diedro N26-C27-C32-C31. No caso do $[\mathrm{Cu}(\text { isapn })]^{2+}$, as estruturas obtidas na simulação em vácuo e em PCM praticamente são idênticas. Isto indica, neste caso, que o meio não influenciou a estrutura do complexo e que a estrutura do isapn se tornou muito estável com a inserção do íon $\mathrm{Cu}$, ficando totalmente planar e a geometria da molécula não se modificou. Na tabela 3.1 apresentamos os valores obtidos das cargas parciais nos átomos do isapn e $[C u(\text { isapn })]^{2+}$ em vácuo e PCM. Verificamos que as cargas parciais obtidas para os átomos do isapn no vácuo diferem ligeiramente das cargas obtidas para os áto- 
Tabela 3.1: Distribuição de cargas (em unidades de carga do elétron $e$ ) obtidas pelo método CHELPG para o isapn e $[\mathrm{Cu}(\text { isapn })]^{2+}$. A nomenclatura dos átomos se refere à Figura 3.3

\begin{tabular}{|c|c|c|c|c|}
\hline Átomos & $\begin{array}{c}\text { DISTRIBUIÇÃO } \\
\text { isapn } \\
\text { (vácuo) }\end{array}$ & $\begin{array}{c}\mathrm{DE} \\
\text { isapn } \\
(\mathrm{PCM})\end{array}$ & $\begin{array}{c}\text { CARGAS (unidades de } e) \\
{[C u(\text { isapn })]^{2+}} \\
(\text { vácuo })\end{array}$ & $\begin{array}{c}{[C u(\text { isapn })]^{2+}} \\
(\mathrm{PCM})\end{array}$ \\
\hline $\mathrm{Cu}$ & - & - & 0.815 & 0.902 \\
\hline $\mathrm{C} 1$ & -0.242 & -0.233 & -0.155 & -0.169 \\
\hline $\mathrm{C} 2$ & 0.010 & 0.073 & 0.001 & -0.007 \\
\hline C3 & -0.182 & -0.215 & -0.115 & -0.134 \\
\hline $\mathrm{C} 4$ & -0.030 & -0.035 & 0.031 & -0.019 \\
\hline $\mathrm{O} 5$ & -0.575 & -0.663 & -0.467 & -0.523 \\
\hline N6 & -0.698 & -0.668 & -0.528 & -0.538 \\
\hline $\mathrm{C} 7$ & 0.701 & 0.706 & 0.600 & 0.639 \\
\hline $\mathrm{C} 8$ & 0.337 & 0.428 & 0.259 & 0.264 \\
\hline C9 & -0.178 & -0.257 & -0.119 & -0.109 \\
\hline $\mathrm{C} 10$ & 0.359 & 0.334 & 0.242 & 0.265 \\
\hline $\mathrm{C} 11$ & 0.319 & 0.374 & 0.279 & 0.285 \\
\hline $\mathrm{C} 12$ & 0.761 & 0.672 & 0.577 & 0.617 \\
\hline $\mathrm{O} 13$ & -0.574 & -0.640 & -0.452 & -0.509 \\
\hline N14 & -0.776 & -0.645 & -0.531 & -0.542 \\
\hline $\mathrm{C} 15$ & 0.411 & 0.323 & 0.274 & 0.297 \\
\hline C16 & -0.276 & -0.226 & -0.195 & -0.209 \\
\hline $\mathrm{C} 17$ & -0.003 & -0.039 & 0.065 & 0.016 \\
\hline C18 & -0.195 & -0.203 & -0.134 & -0.153 \\
\hline C19 & -0.034 & 0.026 & 0.001 & -0.005 \\
\hline $\mathrm{C} 20$ & -0.177 & -0.212 & -0.133 & -0.124 \\
\hline N26 & -0.705 & -0.761 & -0.533 & -0.496 \\
\hline $\mathrm{C} 27$ & 0.823 & 0.888 & 0.430 & 0.440 \\
\hline N30 & -0.651 & -0.859 & -0.520 & -0.482 \\
\hline C31 & 0.562 & 0.983 & 0.418 & 0.427 \\
\hline C 32 & -0.161 & -0.666 & -0.288 & -0.298 \\
\hline
\end{tabular}

mos do isapn em PCM. As diferenças mais importantes podem ser observadas quando comparamos as cargas dos átomos O5,C15, C12, C31 C32 N30 com diferenças comparativas de 0.1 para $\mathrm{O} 5, \mathrm{C} 12$ e $\mathrm{C} 15 ; 0.2$ para N30 e 0.4 e 0.5 para C31 e C32 respectivamente. Com a inserção do $\mathrm{Cu}$ estas diferenças se tornam 
muito pequenas, com 0.06 de maior desvio. A diferença nas distribuições de carga destes átomos, no caso do isapn, deve-se à diferença das estruturas otimizadas obtidas. Devido às estruturas obtidas com o íon $\mathrm{Cu}$ serem praticamente idênticas, não se verificam grandes desvios nas distribuições de carga quando comparamos o $[C u(\text { isapn })]^{2+}$ em vácuo e em PCM. Comparando as cargas do isapn com e sem o íon $\mathrm{Cu}$, verificamos que a distribuição de carga é alterada sensivelmente com a inserção do metal. Os átomos que fazem ligação com o íon Cu são os que possuem maior variação na sua distribuição de carga. Após as análises das geometrias e distribuições de carga, observamos que o meio não influenciou na distribuição de carga obtida pelo método CHELPG. No entanto, observa-se, após a inserção do íon $\mathrm{Cu}$ no isapn, uma notável variação na distribuição de carga da molécula quando simulado em vácuo e em PCM. Com o intuito de melhor adequar a nossa modelagem para os sistemas estudados neste trabalho, adotamos as distribuições de cargas dos átomos dos ligantes obtidas na simulação utilizando o PCM. 


\subsection{Docking dos inibidores isaenim, SU9516 e isa- epy na CDK2}

Iniciamos os estudos de docking molecular com os inibidores na função de "ligantes" e a CDK2 e CDK1/ciclinaB como "receptores". Encontramos com certa facilidade na literatura a estrutura da CDK2, no entanto, não encontramos nenhuma informação a respeito da estrutura cristalográfica da CDK1 e da CDK1/ciclinaB. Devido a este fato, a estrutura utilizada neste trabalho foi obtida de um modelo homólogo da estrutura da CDK2/ciclina A e esta foi obtida por cristalografia de raio-X. A estrutura da CDK2 e CDK2/ciclina A utilizadas podem ser encontradas no banco de dados do Protein Data Bank através dos identificadores 1FIN [67] e 1HCL [68] respectivamente. Na Figura 3.4 mostramos as estruturas da CDK2/ciclinaA e da homóloga CDK1/ciclinaB, utilizada neste trabalho. Este modelo foi desenvolvido por McGrath et al e pode ser obtido consultando o banco de dados do Protein Data Bank (PDB) com o identificador 1T30 [69]. 

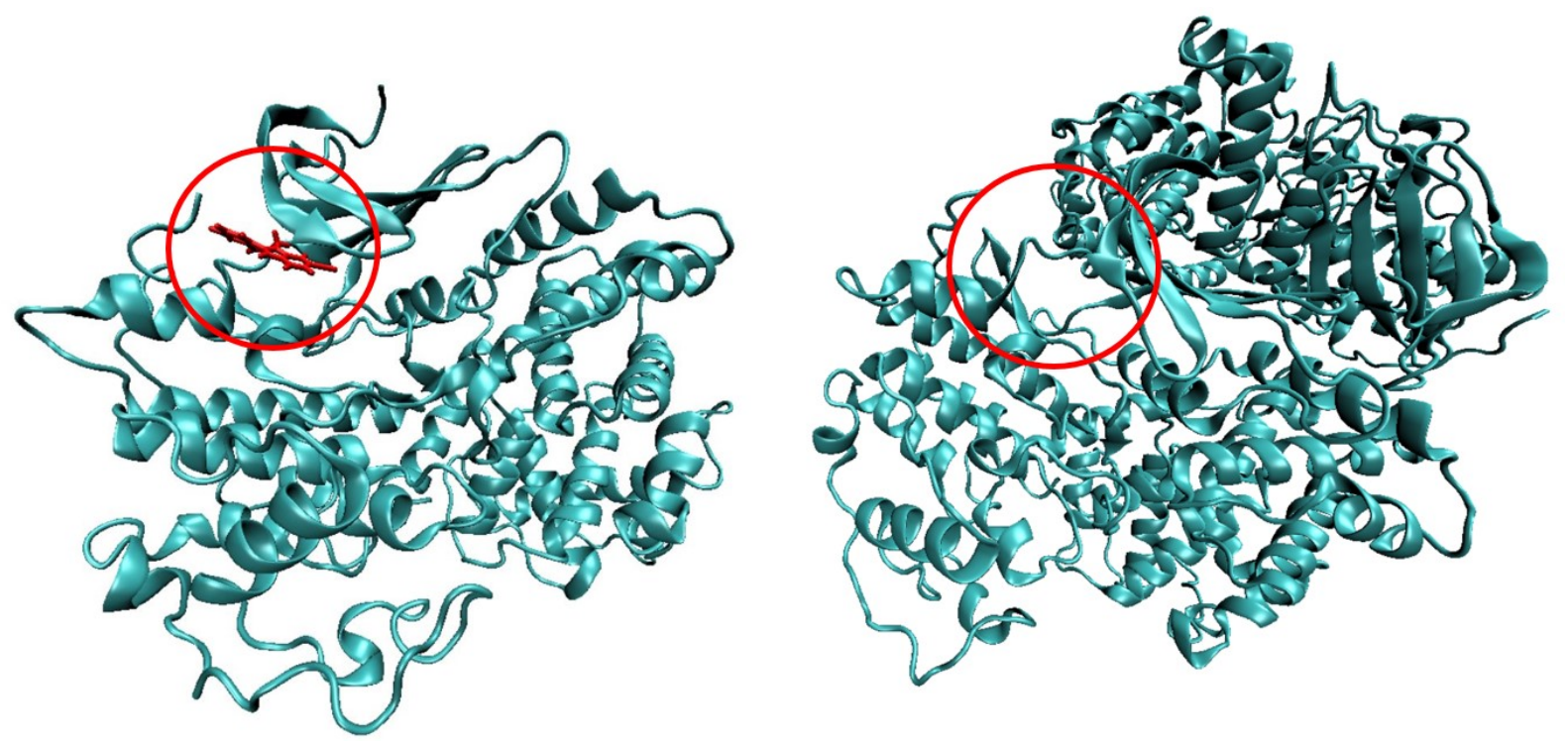

Figura 3.4: Estruturas da CDK1/ciclinaB (esquerda, identificador PDB: 1T30) e CDK2/ciclinaA (direita, identificador PDB: 1FIN). O círculo vermelho indica a posição onde o inibidor interage com o sítio nas CDKs onde ocorre a ligação das moléculas de ATP.

Para os cálculos de docking utilizamos o programa autodock vina 4 [49] implementado no pacote computacional AutoDockTools. Consideramos para o docking os inibidores flexíveis. No entanto, a CDK2 e CDK1/ciclinaB ficaram rígidas. Fizemos o docking do SU9516 no sítio da CDK2 e comparamos com resultados de raio-X [24, 66, 70, 71]. Na Figura 3.5 apresentamos a sobreposição da SU9516 obtida pelo método de docking utilizado neste trabalho e a obtida por raio-X. Verificamos que o método que utilizamos obteve uma estrutura de SU9516 muito semelhante a do raio-X do sistema CDK2/SU9516. Uma pequena torção é observada na estrutura do SU9516 obtida por docking, devido ao fato de que consideramos os átomos de hidrogênio da molécula. Esta diferença nas geometrias do SU9516 se deve ao raio-X não conseguir identificar os átomos de hidrogênio da estrutura e portanto seus resultados não levam em consideração as interações destes átomos no sistema. 


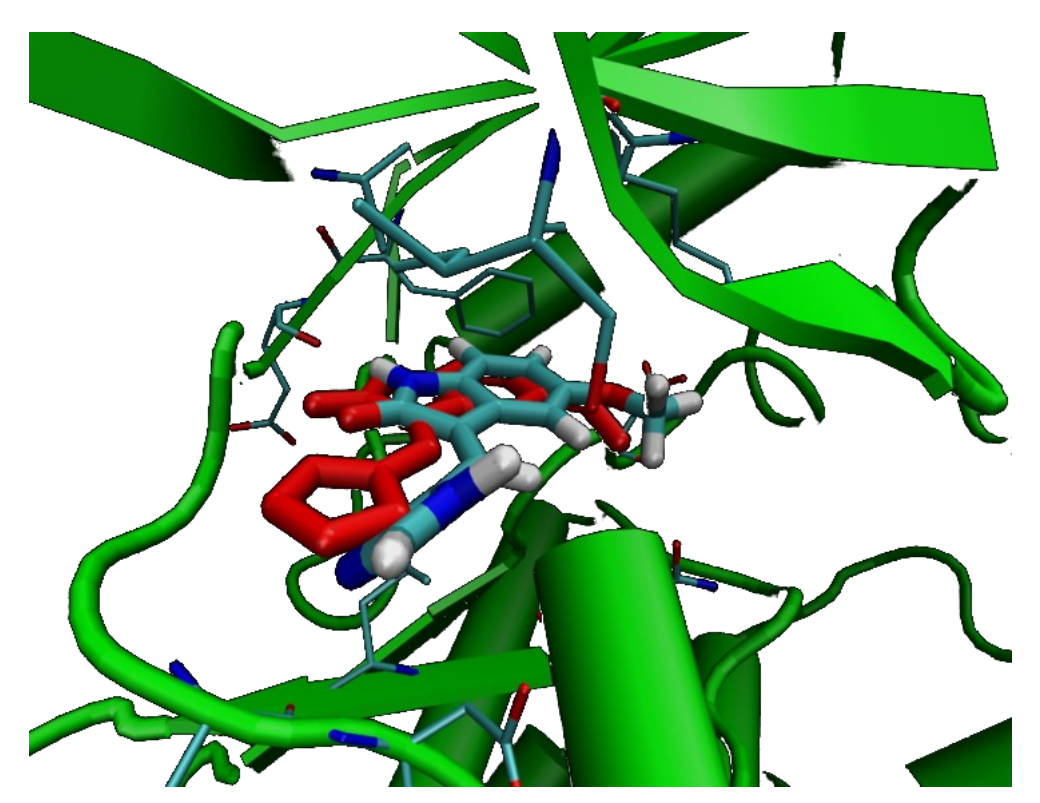

Figura 3.5: Estrutura do SU9516 obtida por raio-X (em vermelho) e através do método de docking utilizado neste trabalho.

Após várias tentativas de docking, conseguimos estabelecer o tamanho da grade de energia em 13x13x13 $\AA$ e foi escolhida a estrutura do inibidor com o menor valor de energia obtida pelo método de scoring. A escolha do centro da grade de energia para os cálculos de docking do isaepy e do isaenim foram feitas com base na comparação direta da estrutura do raio-X da molécula SU9516 ligada no mesmo sítio ativo da CDK2. Após a sobreposição das estruturas obtidas para o isaenim e isaepy com a estrutura do SU9516 obtida da literatura [24, 66, 70, 71], verificamos que os centros de massas do isaenim e do isaepy coincidiram com o centro de massa do SU9516. Desta forma, estimamos a possível localização dos centros de massa destes ligantes no sítio da CDK2. As configurações obtidas para o SU9516, isaepy e isaenim no sítio são mostrados na Figura 3.6. Os aminoácidos observados nas Figuras 3.6, 3.7 e 3.10 foram obtidos considerando o fator de escala igual a um para o raio de van der Walls (vdW) da interação entre átomos do ligante e átomos do sítio e, desta forma, temos uma soma direta dos raios de vdW do átomo do ligante com o átomo do aminoácido mais próximo. 


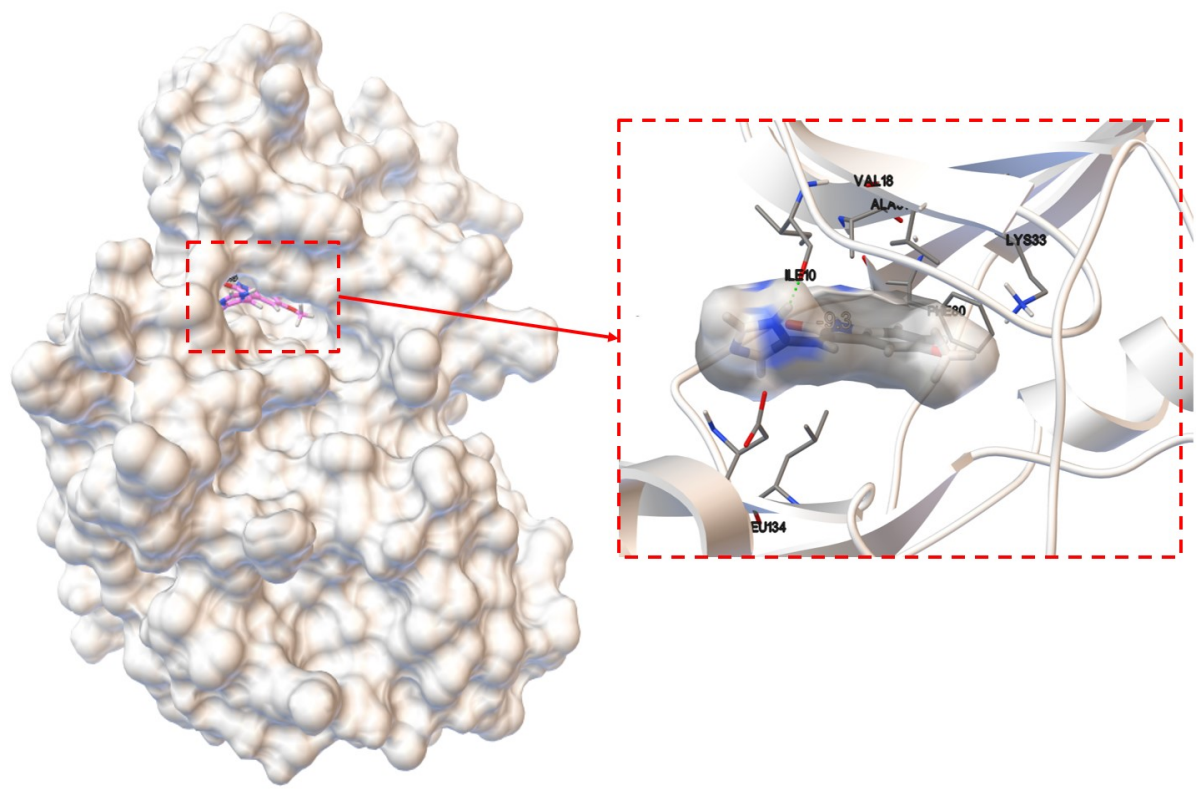

(a)

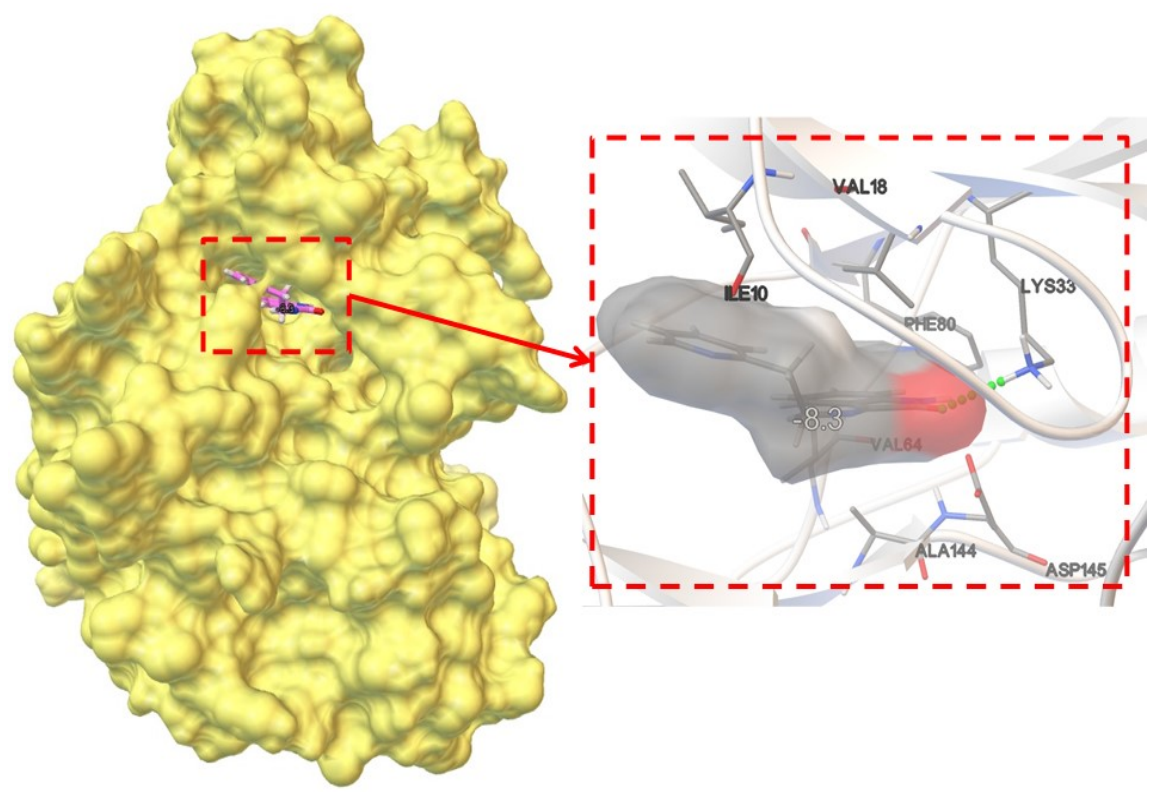

(b)

Figura 3.6: Ilustração do docking do (a) SU9516 e do (b) isaepy no sítio da CDK2. 


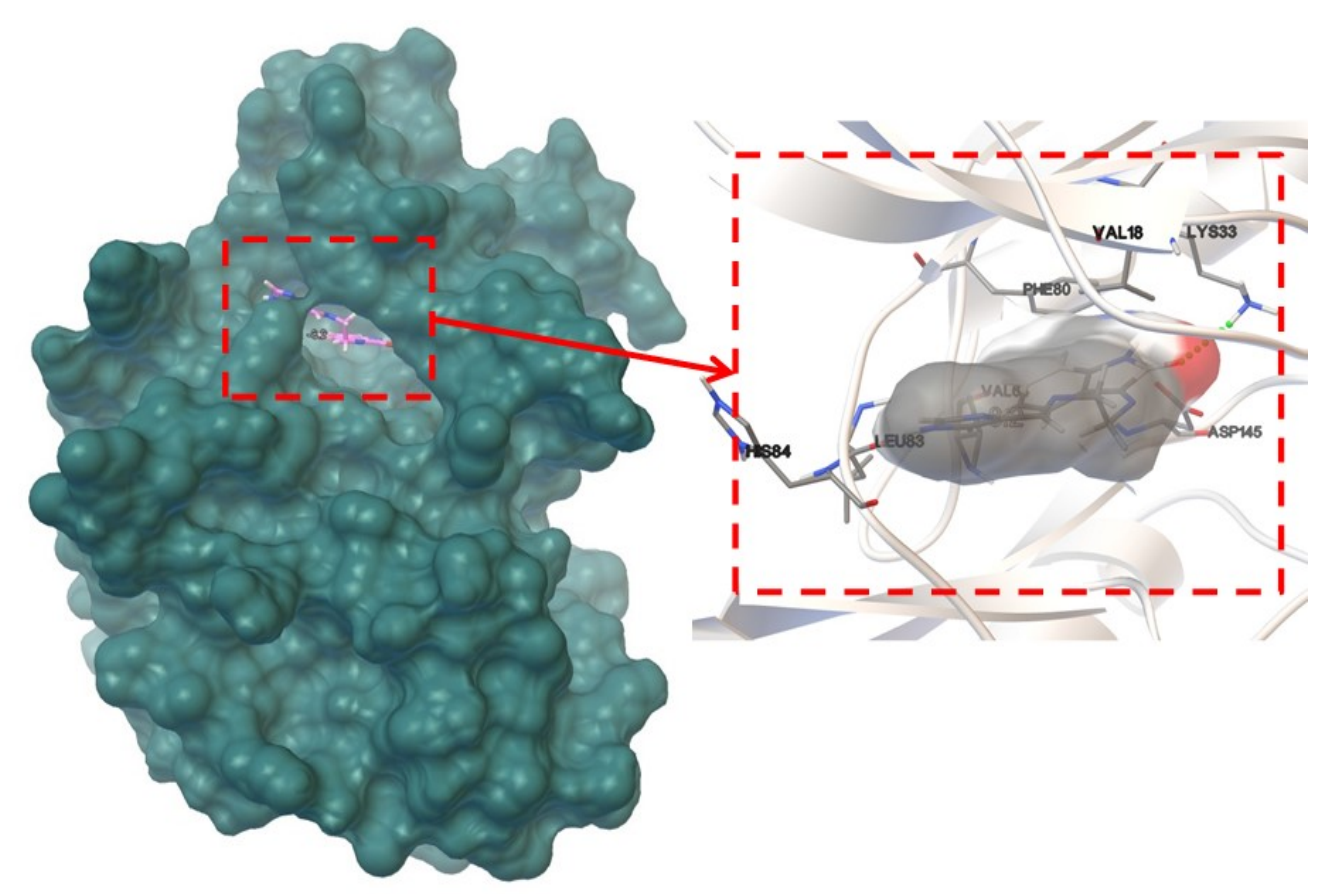

Figura 3.7: Ilustração do docking do isaenim no sítio da CDK2.

Analisando a Figura 3.8.a observamos que o SU9516 interage com oito aminoácidos do sítio ativo e faz uma ligação de hidrogênio com a isoleucina (ILE10). Esta ligação de hidrogênio contribuiu para a torção da molécula no sítio. Notamos uma interação com o anel da fenilalanina (PHE80), valina (VAL18), alanina (ALA31), leucina (LEU134) e lisina (LYS33). Observamos que o ácido aspártico (ASP145) interage com o oxigênio da SU9516 e a asparagina (ASN132) interage numa ligação C-H. A energia de afinidade do SU9516, quando ligada ao sítio ativo do CDK2, é de $-9,3 \mathrm{kcal} / \mathrm{mol}$. O isaepy (Figura 3.8.b) interage com sete aminoácidos do sítio ativo e faz uma ligação de hidrogênio com a lisina (LYS33), duas interações com a valina (VAL18 e VAL64) e uma com a isoleucina (ILE10), notamos também uma interação forte com o anel da fenilalanina (PHE80) e com uma alanina (ALA144). A energia de afinidade da isaepy quando ligada ao sítio ativo da CDK2 é de -8,3 $\mathrm{kcal} / \mathrm{mol}$.

A interação do ligante isaenim com o sítio ativo da CDK2 é mostrada na 
Figura 3.9. O isaenim interage com sete aminoácidos do sítio e faz uma ligação de hidrogênio com a lisina (LYS33) e duas interações com a valina (VAL18 e VAL64), uma interação com uma leucina (LEU83) e uma com o ácido aspártico (ASP145). Novamente observa-se uma interação com a fenilalanina (PHE80) e uma interação com uma histidina (HIS84). A energia de afinidade da isaenim quando ligada ao sítio ativo da CDK2 é de -8,2 kcal/mol, assemelhando-se ao obtido para o isaepy. A semelhança das interações e energia de afinidade do SU9516, isaepy e do isaenim no sítio do CDK2 se deve à semelhança nas geometrias e composição química das moléculas. 


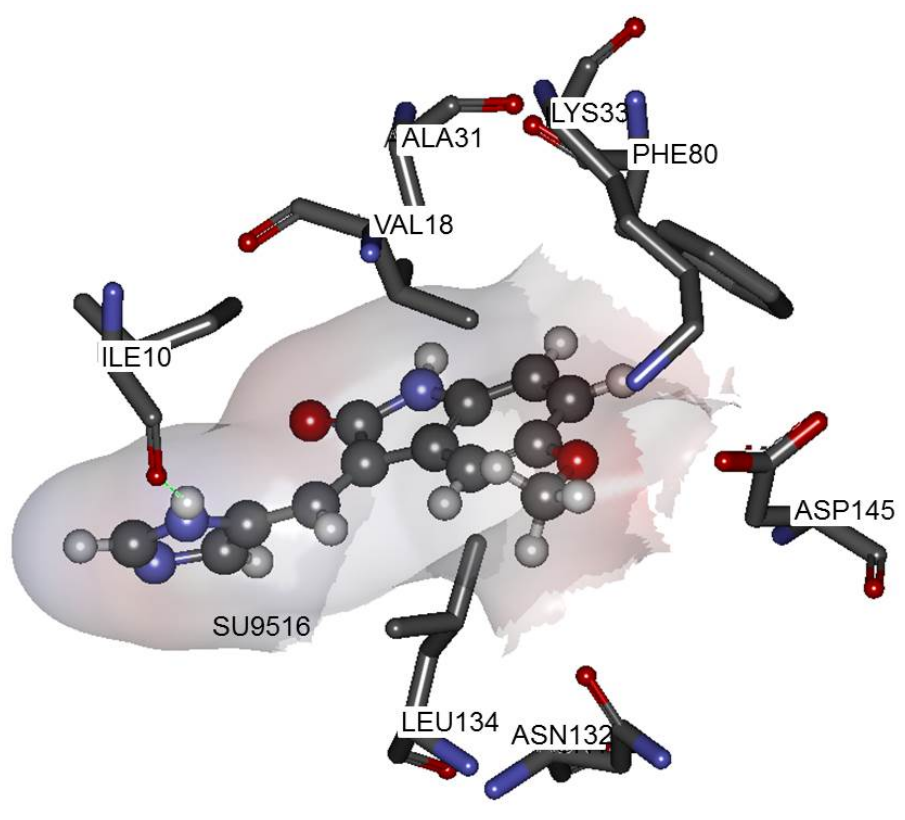

(a)

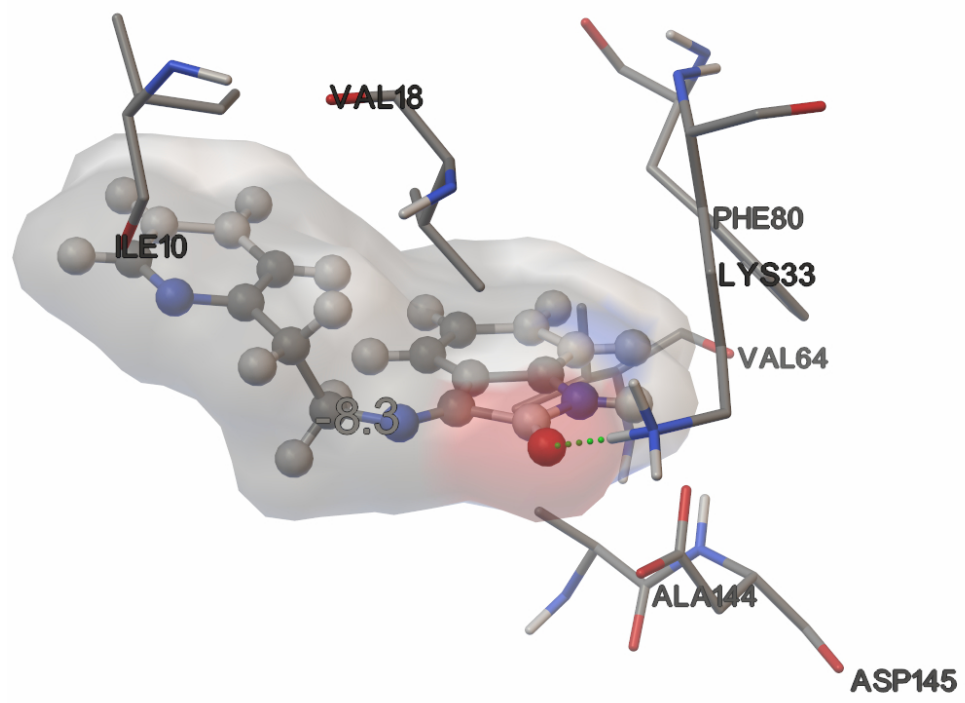

(b)

Figura 3.8: Aminoácidos, com seus nomes de resíduos, a uma distância de até $3 \AA$ do (a) SU9516 e (b) isaepy. As superfícies de potencial eletrostático do SU916 e do isaepy são mostradas em cinza claro e a ligação de hidrogênio é ilustrada pela linha pontilhada em verde. 


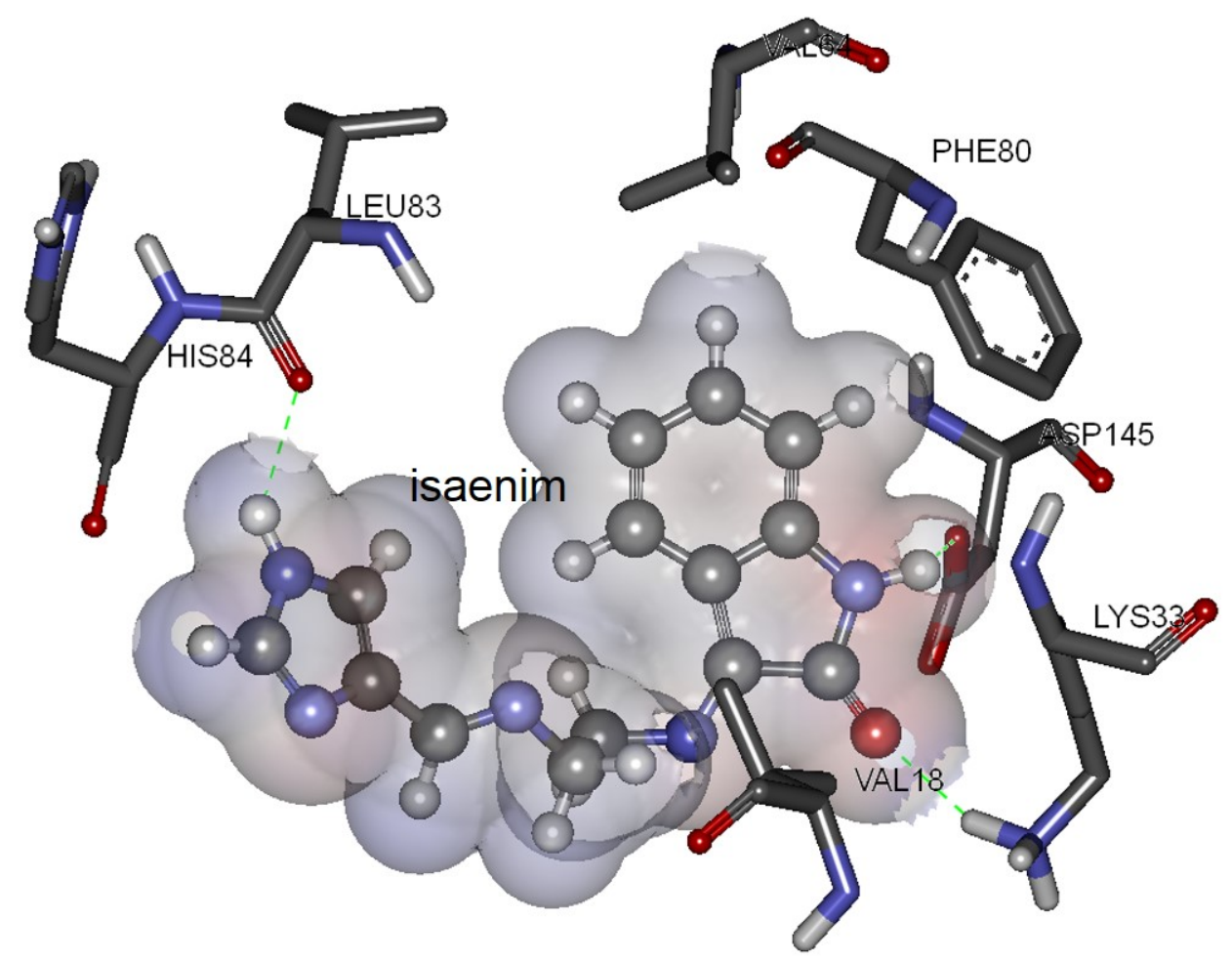

Figura 3.9: Aminoácidos, com seus nomes de resíduos, a uma distância de até $3 \AA$ do isaenim. A superfície de potencial eletrostático do isaenim é mostrada em cinza claro e a ligação de hidrogênio é ilustrada pela linha pontilhada em verde.

\subsubsection{Docking do isapn e $[C u(\text { isapn })]^{2+}$ no sítio da CDK1/ciclinaB}

As configurações obtidas para o isapn e $[C u(\text { isapn })]^{2+}$ no sítio ativo da CDK1/ciclinaB são mostradas na Figura 3.10. 


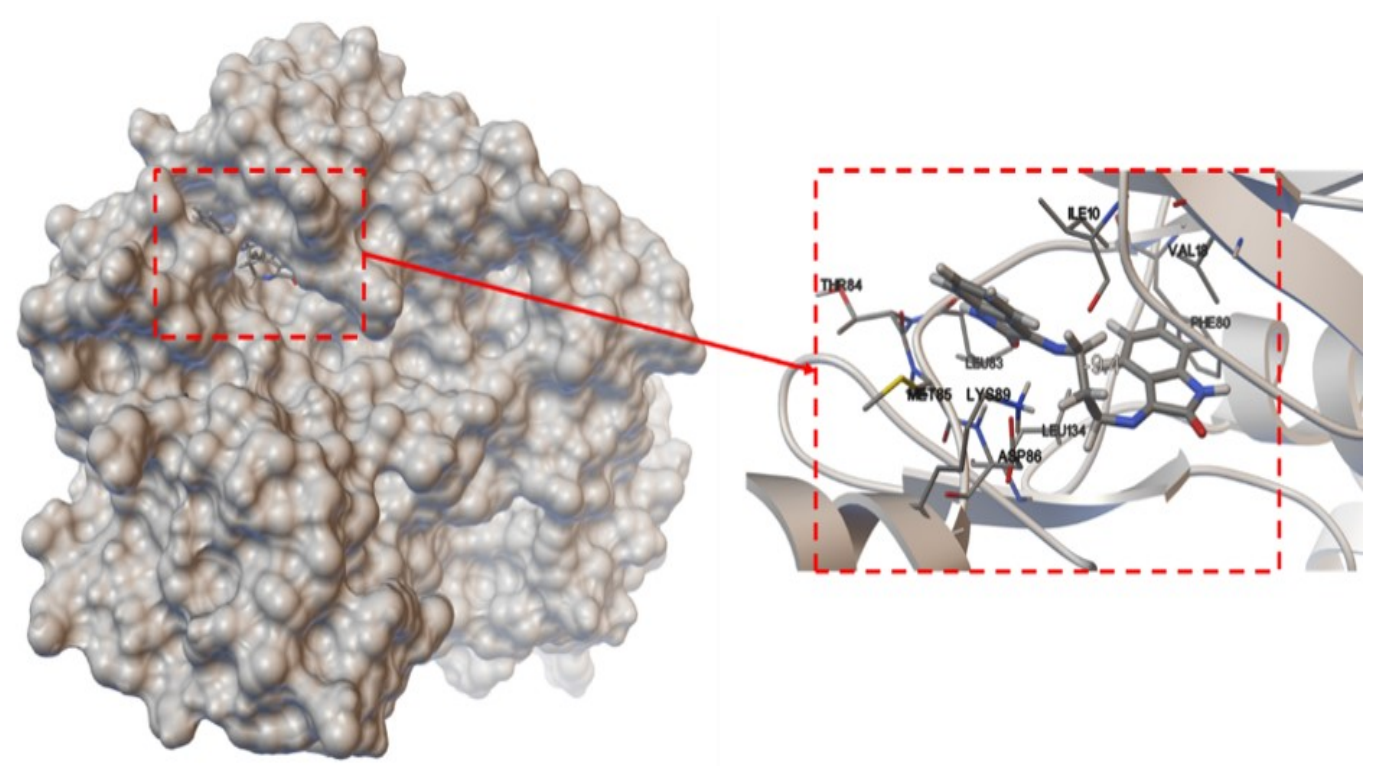

(a)

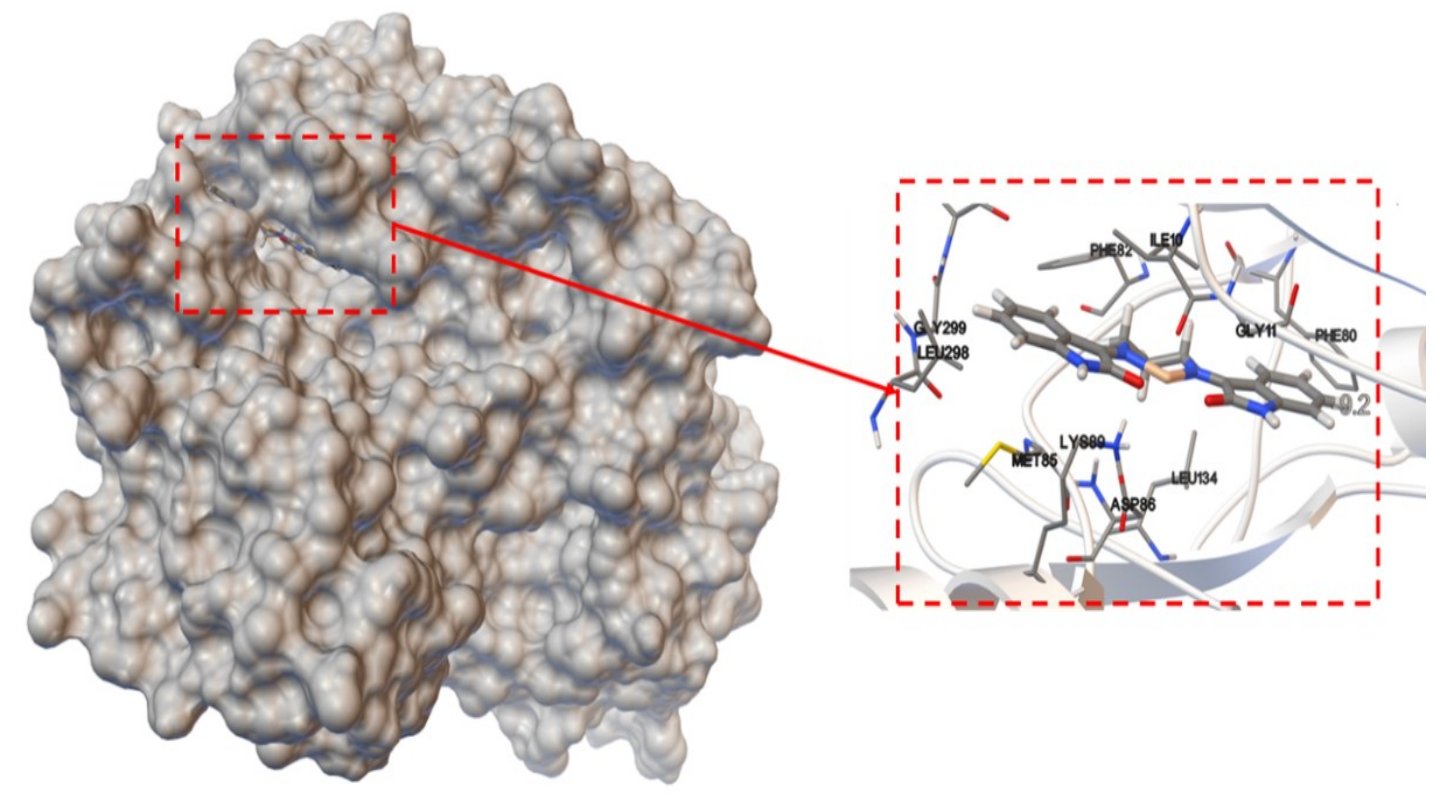

(b)

Figura 3.10: Ilustração da configuração obtida por docking para o (a) isapn e para o (b) $[\mathrm{Cu}(\text { isapn })]^{2+}$ no sítio ativo da CDK1. 
Na Figura 3.11 mostramos os aminoácidos que interagem diretamente com o isapn e $[C u(\text { isapn })]^{2+}$. Observamos nove aminoácidos em contato direto com isapn, uma ligação de hidrogênio com a LEU83 e uma forte interação do tipo $\pi$ com o anel aromático da fenilalanina (PHE82). Quatro interações com duas fenilalaninas (PHE80 e PHE82) e duas leucinas (LEU83 e LEU134) são observadas e o ângulo do diedro N4-C18-C19-C17 tem o valor de aproximadamente 100 graus. O resultado foi uma conformação do isapn que deixa os átomos de oxigênio O1 e O2 em lados opostos. A energia de afinidade estimada para o isapn no sítio do CDK1 foi de $-9,4 \mathrm{kcal} / \mathrm{mol}$. Para o $[\mathrm{Cu}(\text { isapn })]^{2+}$, são verificados onze aminoácidos em contato direto com a molécula e uma ligação de hidrogênio com a LYS89 (Figura 3.11.b), duas interações com as fenilalaninas (PHE80 e PHE82) e duas interações com as leucinas LEU83 e LEU134. A energia de afinidade do $[C u(\text { isapn })]^{2+}$ no sítio da CDK1 foi de $-9,2 \mathrm{kcal} / \mathrm{mol}$, valor semelhante ao obtido para o isapn. A estrutura do $[\mathrm{Cu}(\text { isapn })]^{2+}$ continuou planar devido à coordenação do íon $\mathrm{Cu}$ com o isapn. 


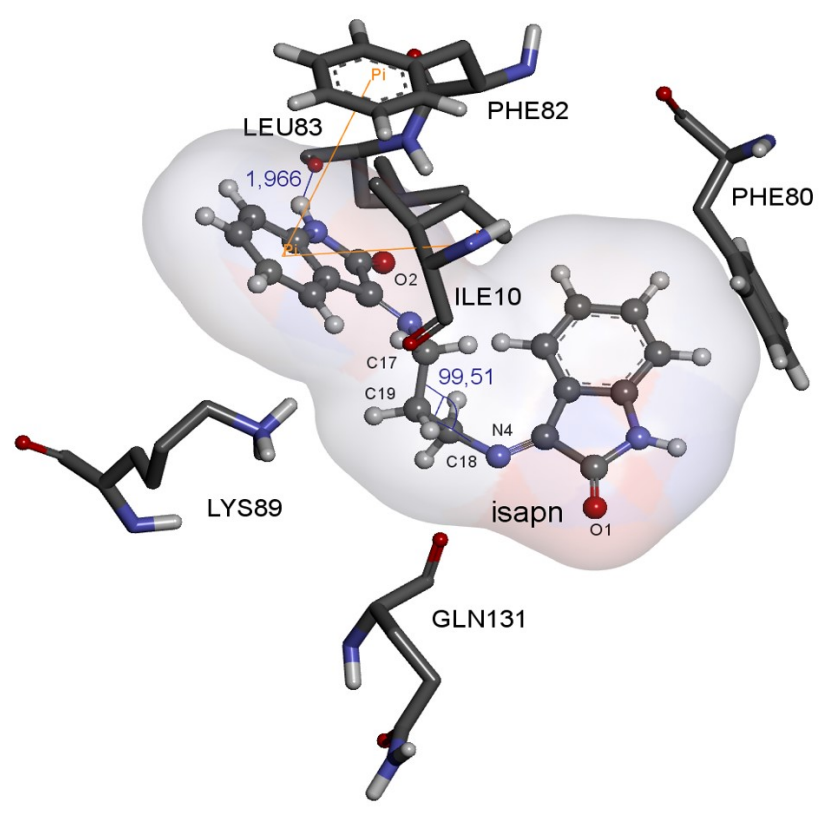

(a)

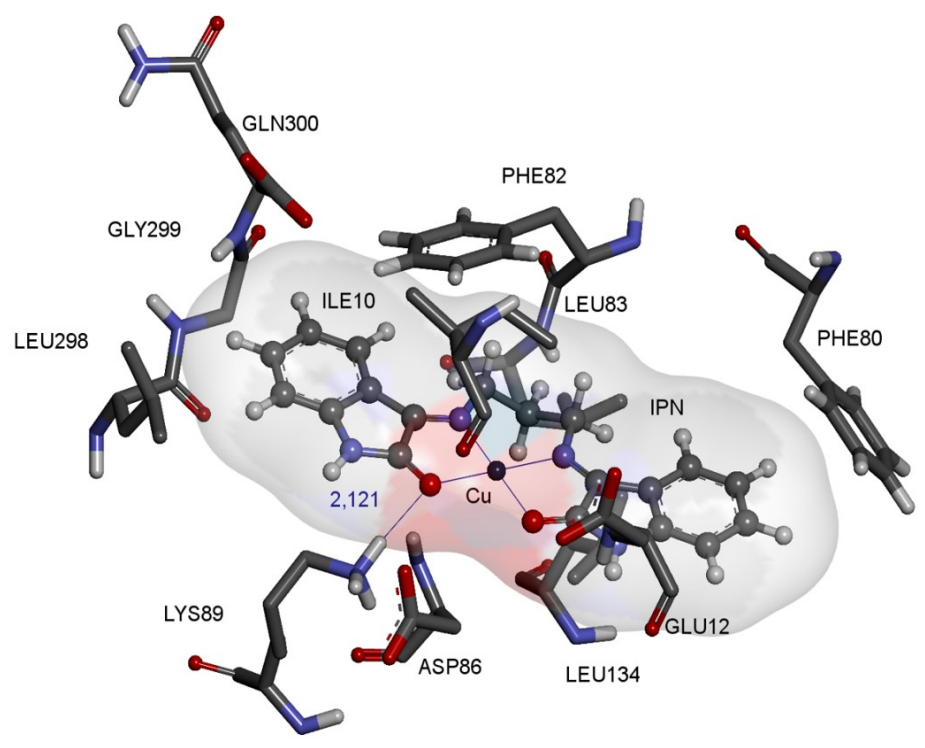

(b)

Figura 3.11: Aminoácidos com seus nomes de resíduos a uma distância de até $3 \AA$ do (a) isapn e (b) $[C u(\text { isapn })]^{2+}$. As linhas em azul ilustram as distâncias de ligação e o ângulo torcional do diedro N4-C18-C19-C17 e as linhas em amarelo ilustram as interações $\pi$. 


\subsection{Dinâmica molecular: isaepy, isapn, isaenim, SU9516 e $[C u(\text { isapn })]^{2+}$ no sítio da CDK1 e CDK2}

Discutimos aqui os resultados de DM obtidos para os sistemas estudados neste trabalho. Tivemos, primeiramente, que adotar um protocolo de equilibração para a obter as condições iniciais das dinâmicas e também parametrizar os ligantes (construir a topologia) para o campo de força GROMOS 53a6. Adotaremos as nomenclaturas CDK2/ligante para os sistemas que possui o ligante inserido no sítio onde se liga o ATP na CDK2 e CDK1-ciclinaB/ligante para os sistemas que possuem o ligante inserido no sítio onde se liga o ATP na CDK1 somada a macromolécula ciclina B que está ligada na CDK1.

\subsubsection{Procedimento para obter a dinâmica molecular: pa- râmetros utilizados e equilibração dos sistemas}

Utilizamos o programa Automated Topology Builder (ATB) and Repository (versão 2.2) para a construção das topologias dos ligantes [72] e fazendo também um refinamento da topologia obtida segundo o manual do GROMOS vol.3 (Force Field and Topology Data Set). Desta forma, nos certificamos de que a descrição fornecida pela utilização do campo de força, para os ligantes, estava correta. Utilizamos moléculas com conformações, tipos atômicos e ligações semelhantes aos das moléculas SU9516, isaenim, isaepy e isapn. Todas as informações como tipos de ligação, distâncias de ligação e os outros parâmetros necessários para descrever as moléculas com o campo de força GROMOS 53a6 foram obtidas do manual GROMOS vol.3. Isto não foi necessário para a CDK2 CDK1-ciclinaB devido ao fato de que todos os aminoácidos já estavam parametrizados para o campo de força 
$[57,73]$.

Para a parametrização do cobre foi utilizado o procedimento de Force Matching (FM). A parametrização do íon $\mathrm{Cu}$ foi baseada nas contantes de força (k) obtidas para o $[\mathrm{Cu}(\text { isaenim })]^{2+}$, que é bem similar ao $[\mathrm{Cu}(\text { isapn })]^{2+}$, como pode ser observado pela Figura 3.12.

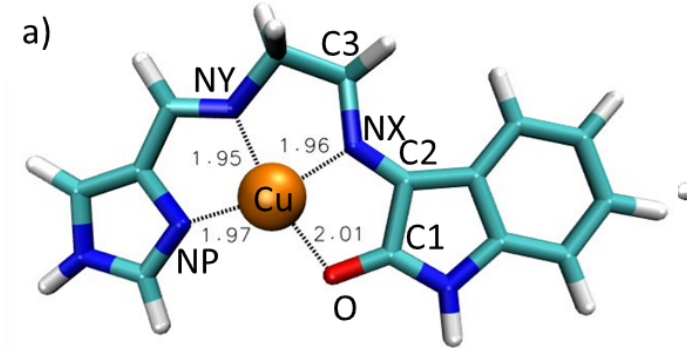

$\left[\mathrm{Cu}(\text { isaenim) }]^{2+}\right.$

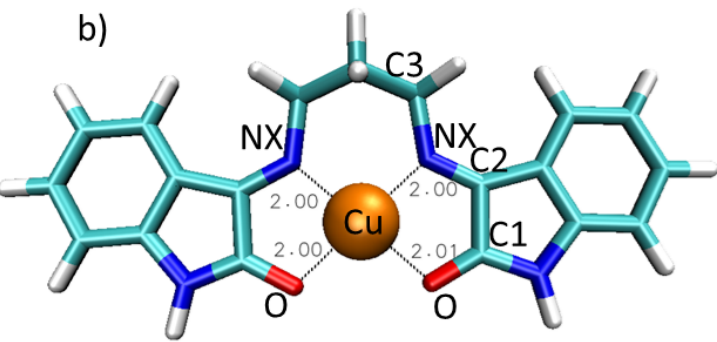

$[\mathrm{Cu}(\text { isapn })]^{2+}$

Figura 3.12: Átomos similares em torno do íon $\mathrm{Cu}$ (em marrom) nos complexos metálicos: a) $[\mathrm{Cu}(\text { isaenim })]^{2+}$ e b) $[\mathrm{Cu}(\text { isapn })]^{2+}$. NX e NP são os nitrogênios (em azul), C1, C2 e C3 são os carbonos (em ciano) e O são os oxigênios (vermelho). Distâncias de ligação em $\AA$.

Cálculos de Mecânica Quântica/Mecânica Molecular (QM/MM) foram realizados durante 5 ps de simulação utilizando o código CPMD [74, 75], considerando a parte QM para o $[\mathrm{Cu}(\text { isaenim })]^{2+}$ e moléculas de água para a parte MM. As constantes de forças para o $\mathrm{Cu}$ e as distâncias de equilíbrio de ligação são apresentadas na tabela 3.2 e são mostrados os ângulos de ligação e os ângulos de equilíbrio na tabela 3.3. Como estes cálculos foram realizados com o campo de força universal (GAFF) [76] do pacote AMBER, tivemos que fazer a conversão das constantes para o campo de força GROMOS 53a6 no GROMACS. 
Tabela 3.2: Distâncias de equilíbrio $r_{e q}$ e constantes de força $k_{r}$ para o íon $\mathrm{Cu}$ no complexo $[\mathrm{Cu}(\text { isapn })]^{2+}$.

\begin{tabular}{|c|c|c|c|}
\hline Ligações & $\begin{array}{c}k_{r(A M B E R)} \\
\left(k c a l / \operatorname{mol}^{2}\right)\end{array}$ & $\begin{array}{l}r_{e q} \\
(\AA)\end{array}$ & $\begin{array}{c}k_{r(\text { GROMOS })} \\
\left(10^{5} \mathrm{~kJ} / \mathrm{mol} \mathrm{nm}^{4}\right)\end{array}$ \\
\hline $\mathrm{Cu}-\mathrm{O}$ & 35,53 & 2,06 & 1,74 \\
\hline $\mathrm{Cu}-\mathrm{NX}$ & 33,24 & 1,97 & 1,78 \\
\hline
\end{tabular}

O modelo de solvente explícito simple point charge (SPC) [59] foi utilizado para simular os clusters de água nas DMs. A célula unitária considerada nas simulações de DM que envolvem a CDK2 foram células cúbicas de dimensões $90 \AA ̊ x 90 \AA ̊ x 90 \AA$ contendo 22500 moléculas de água num total de 70220 átomos (CDK2/ligante + água). Para CDK1-ciclinaB a célula unitária foi de dimensões $120 \AA x 160 \AA x 120 \AA$, contendo 74000 moléculas de água, num total de 228000 moléculas (CDK1-ciclinaB/isapn + água). Em todos os casos, adicionamos seis íons cloreto $\left(\mathrm{Cl}^{-}\right)$no solvente para a neutralização da carga elétrica total dos sistemas.

Tabela 3.3: Ângulos de equilíbrio $\theta_{e q}$ e constantes de força $k_{\theta}$ para o íon $\mathrm{Cu}$ no complexo $[\mathrm{Cu}(\text { isapn })]^{2+}$.

\begin{tabular}{cccc}
\hline \hline Ângulos & $\begin{array}{c}k_{\theta(\text { AMBER })} \\
(k \text { cal/mol.rad }\end{array}$ & $\begin{array}{c}\theta_{\text {eq }} \\
(\text { graus })\end{array}$ & $\begin{array}{c}k_{\theta(\text { GROMOS })} \\
(k J / m o l)\end{array}$ \\
\hline Cu-O-C1 & 40,00 & 108,79 & 187,48 \\
Cu-NX-C2 & 25,82 & 111,66 & 125,87 \\
Cu-NX-C3 & 21,52 & 124,17 & 132,23 \\
O-Cu-NX & 21,00 & 84,24 & 89,57 \\
NX-Cu-NX & 47,01 & 96,43 & 199,92 \\
NX-Cu-O & 21,00 & 84,27 & 86,56 \\
\hline \hline
\end{tabular}

O método de Mesh Ewald (PME) foi utilizado para calcular as interações Cou- 
lombianas de longo alcance e um raio de corte de $10 \AA$ foi fixado para os cálculos de curto alcance de Coulomb e interações de Van der Walls. Para a equilibração dos sistemas utilizamos o seguinte procedimento:(1) relaxação estrutural do solvente, usando o método de gradiente conjugado (CG), considerando o critério de convergência em 150,0kJ/mol.nm; (2) minimização de energia do sistema todo considerando o mesmo critério de convergência; (3) simulação do emsemble NVT com aumento linear e gradativo, durante 2 ns, da temperatura até estabilizar em 300K, utilizando o termostato modificado de Berendsen (v-rescale); (4) simulação do emsemble NPT, de 1 ns, para a estabilização da pressão do sistema, utilizando o barostato de Parrinello-Rahman. Após a equilibração dos sistemas, 10 ns de DM foram realizadas a temperatura ambiente $(300 \mathrm{~K})$ e pressão de 1 bar (aproximadamente $1 \mathrm{~atm})$. Os átomos de hidrogênio foram considerados nas DMs. 


\subsubsection{Análise dos resultados das dinâmicas moleculares}

Um importante parâmetro para caracterizar a estrutura da proteína durante as DMs é a função de raio de giro $(\mathrm{R}(\mathrm{g}))$ onde se analisa a compactação da estrutura da CDK2 e CDK1-ciclinaB ao longo da DM: quanto menor for este índice, maior será a compactação da proteína. Na Figura 3.13, apresentamos os resultados de $\mathrm{R}(\mathrm{g})$ para a CDK2 nos sistemas estudados.
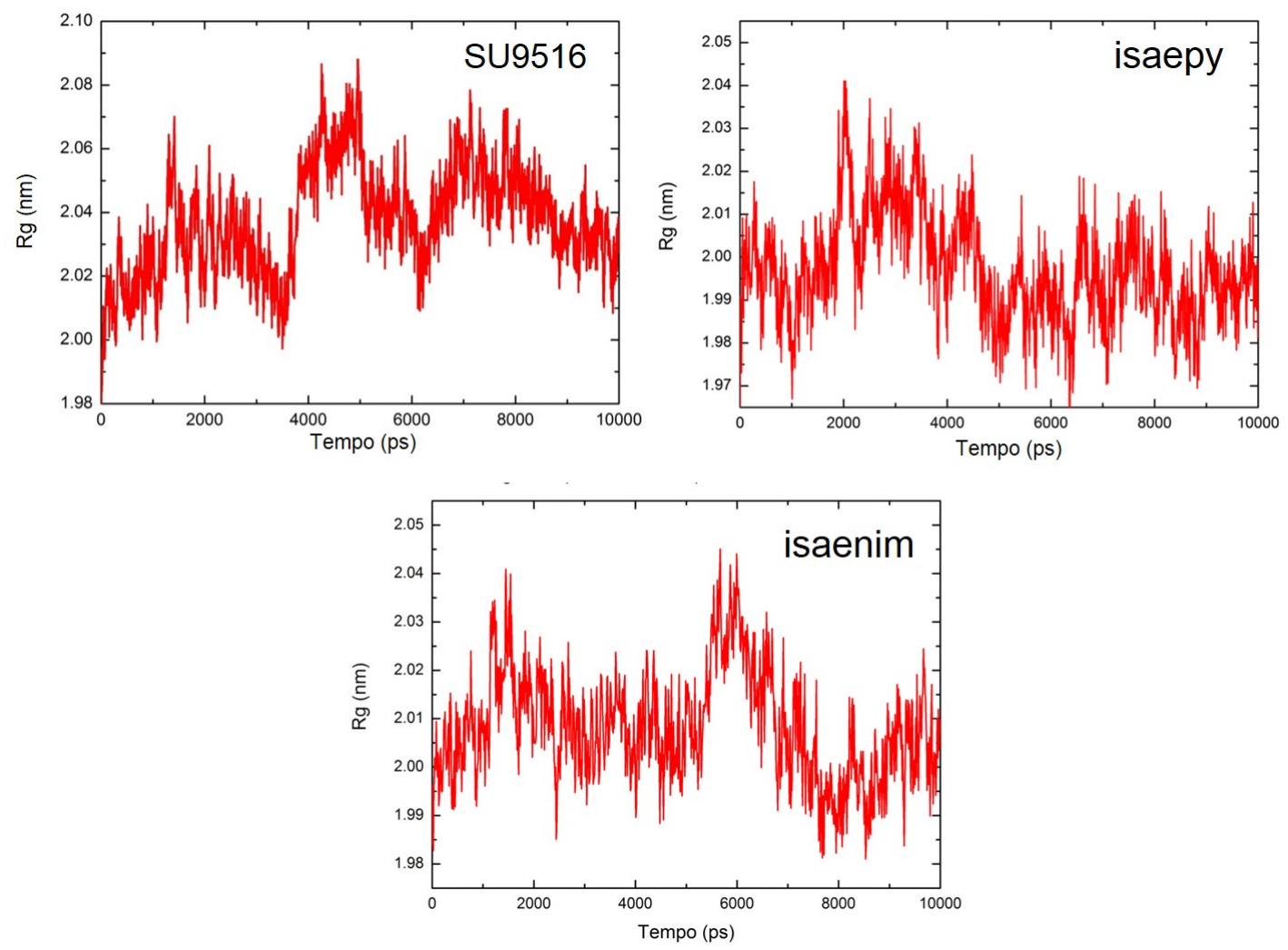

Figura 3.13: Raio de giro R(g) para a CDK2 nos sistemas (a) CDK2/SU9516, (b) CDK2/isaepy e (c) CDK2/isaenim.

Observamos na Figura 3.13 que o R(g) está variando entre 2,05 nm e 1,98 nm em todos os sistemas. Observamos no sistema CDK2/isaenim que nos instantes 1950 ps e 6000 ps temos que a CDK2 está menos enovelada (compactada). No caso da CDK2/isaepy verificamos que o menor empacotamento da proteína ocorre 
no intervalo entre 2000 ps e 3000 ps, enquanto que a CDK2/SU9516 apresentou um menor enovelamento entre 4000 ps e 6000 ps. A maior compactação da proteína CDK2 ocorre no instante de simulação 8000 ps para a CDK2/isaenim e em 9000 ps para o sistema CDK2/isaepy. Estes resultados implicam que a proteína se comportou de forma bem compacta nos três sistemas e não foi observado o desenovelamento (desnaturação) da sua estrutura. O mesmo comportamento foi observado para os sistemas CDK1-ciclinaB/isapn e CDK1-ciclinaB/[Cu(isapn $)]^{2+}$ conforme podemos observar na Figura 3.14. As estruturas estão bem equilibradas nas duas DMs e os valores médios do $\mathrm{R}(\mathrm{g})$ para CDK1-ciclinaB/isapn e CDK1ciclinaB $/[C u(\text { isapn })]^{2+}$ foram bem semelhantes com $2,62 \mathrm{~nm}$ e $2,59 \mathrm{~nm}$ respectivamente.

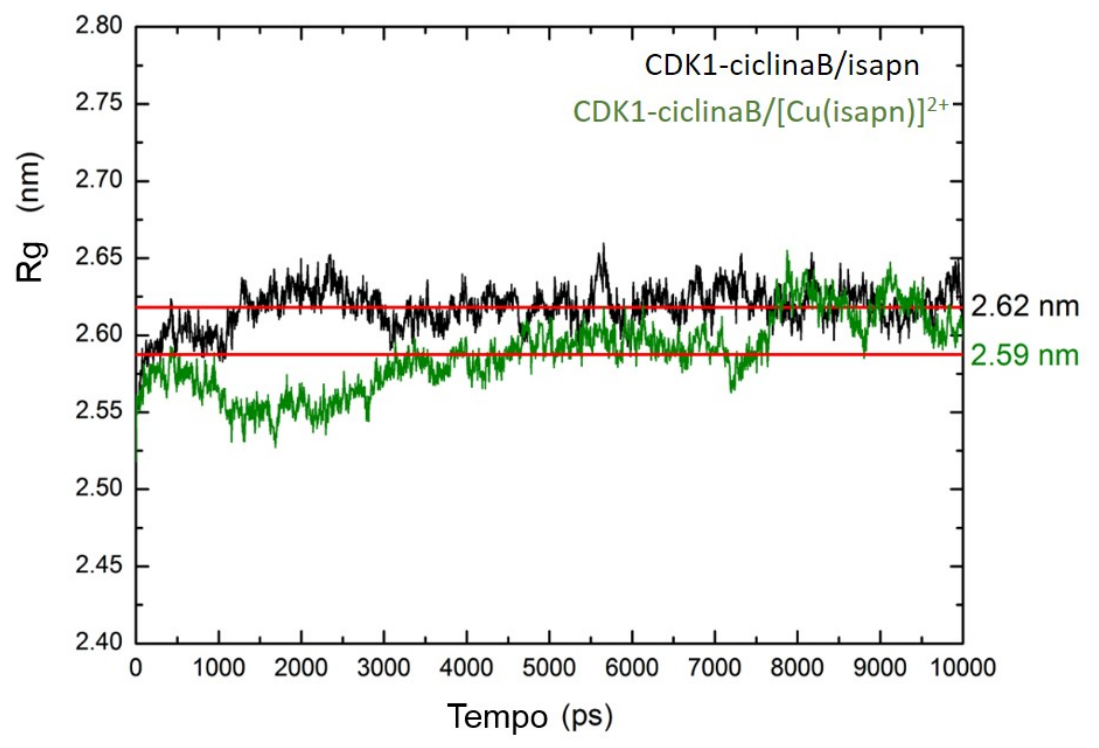

Figura 3.14: $\mathrm{R}(\mathrm{g})$ obtidos durante a $\mathrm{DM}$ para os sistemas CDK1-ciclina $\mathrm{B} /$ isapn e CDK1-ciclina $\mathrm{B} /[\mathrm{Cu}(\text { isapn })]^{2+}$. As linhas vermelhas representam a média do $\mathrm{R}(\mathrm{g})$ para as proteínas durante a simulação. 


\subsubsection{Dinâmica do sistema CDK2/SU9516}

A análise do desvio quadrático médio (Root Mean Square Deviation-RMSD) nos dá uma ideia do deslocamento da molécula e mudanças de conformação durante a DM. Na Figura 3.15 mostramos a evolução temporal do RMSD para o centro de massa do SU9516.

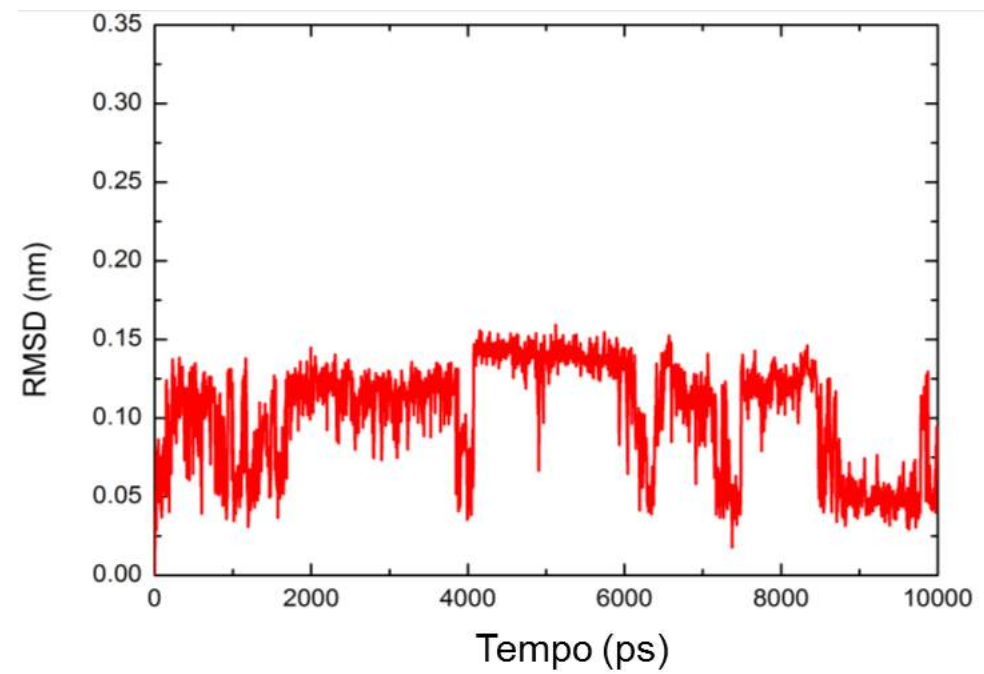

Figura 3.15: RMSD para o centro de massa do SU9516 para o sistema CDK2/SU9516.

Analisando a Figura 3.15 verificamos que o deslocamento do SU9516, quando inserido na CDK2, foi em média 1,2 , o que pode ser considerado bem pequeno, o que indica que a molécula ficou bem estabilizada neste sítio. Verificamos uma pequena mudança da conformação do SU9516 após 8 ns de dinâmica, relacionada à torção do diedro C2-C1-C17-C23. Esta torção ocorreu devido a competição entre os oxigênios da ILE10 e da GLN131 pela ligação de hidrogênio com o SU9516. Outra análise importante da dinâmica foi a frequência de interação dos aminoácidos com o SU9516 durante a DM. Na Figura 3.16 mostramos os histogramas que nos dão as informações sobre as frequências em que os aminoácidos interagem com o SU9516, onde os aminoácidos são representados pelo número do resíduo utilizado na DM. 


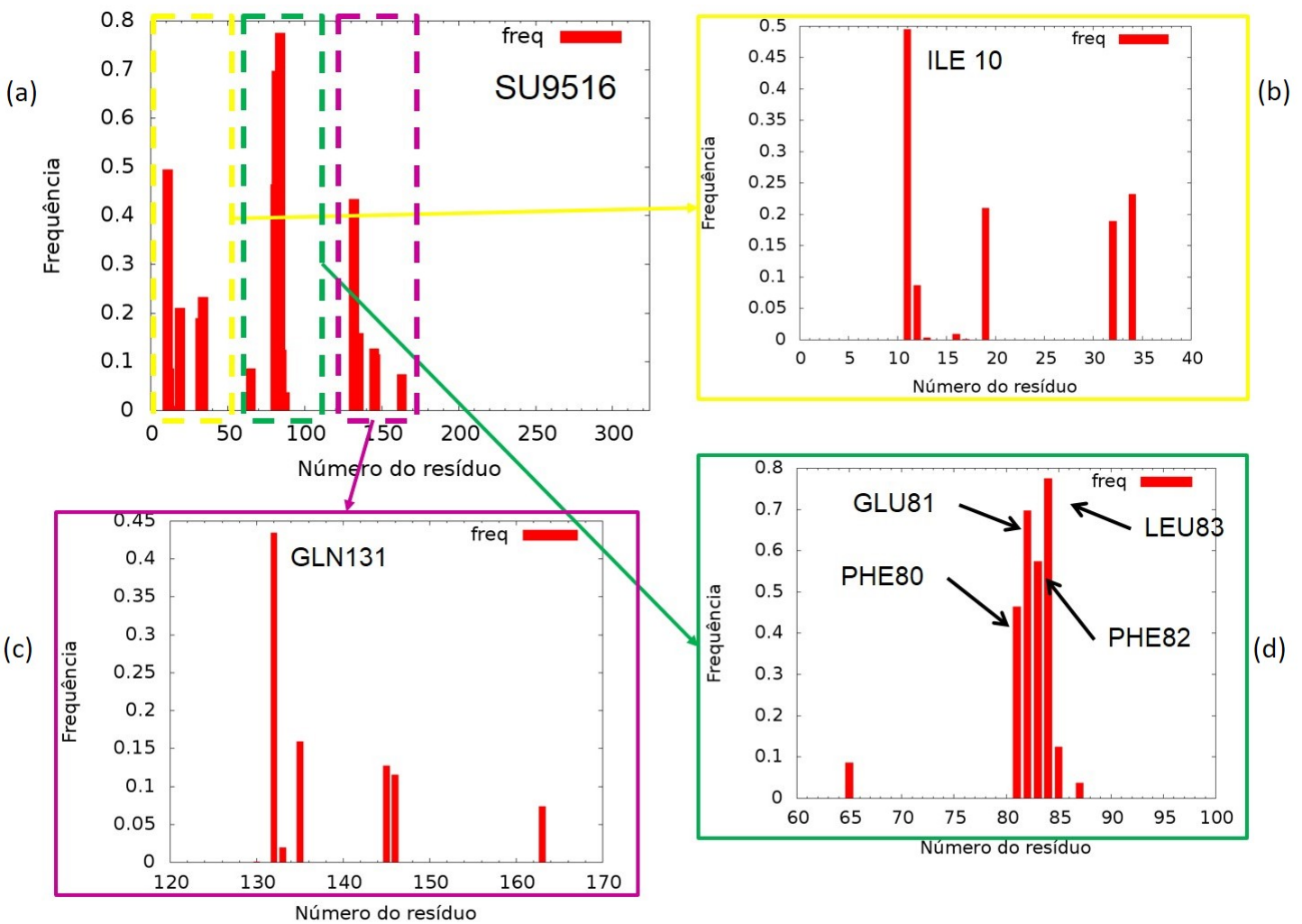

Figura 3.16: a) Histograma da frequência de interação entre os aminoácidos (número de resíduo) e o SU9516. Detalhamento das regiões: b) 0 - 40, indicado pelos retângulos pontilhado e contínuo em amarelo, repectivamente; c) 60 - 100 indicado pelos retângulos pontilhado e contínuo em verde, repectivamente; d) 120 - 170 indicado pelos retângulos pontilhado e contínuo em violeta, repectivamente.

Podemos observar que os aminoácidos que mais interagem com SU9516 durante a DM são: ILE10, PHE80, GLU81, PHE82, LEU83 e GLN131. Verificamos que a ILE10 interage com o SU9516 em torno de 50\% da DM e a GLN131, em torno de $43 \%$. Se levarmos em consideração a competitividade da ligação de hidrogênio entre GLN131 e ILE10, a ILE10 manteve por maior tempo, da DM, a ligação de hidrogênio com o SU9516. Os aminoácidos PHE80, GLU81, PHE82 e LEU83 foram os que mais estiveram em contato com o SU9516 (50\%, 70\%, 58\% e $78 \%$ respectivamente). Estes aminoácidos estiveram em contato com a parte oxindol da SU9516 e foram os responsáveis por mantê-la inserida na CDK2. 
Na Figura 3.17 destacamos a estrutura representativa do SU9516 com maior ocorrência (1400 configurações) na DM e obtida pela análise de clusters. Mostramos também os aminoácidos (em até 3 Å de distância dos átomos do SU9516) que mais interagiram com a molécula durante a DM.

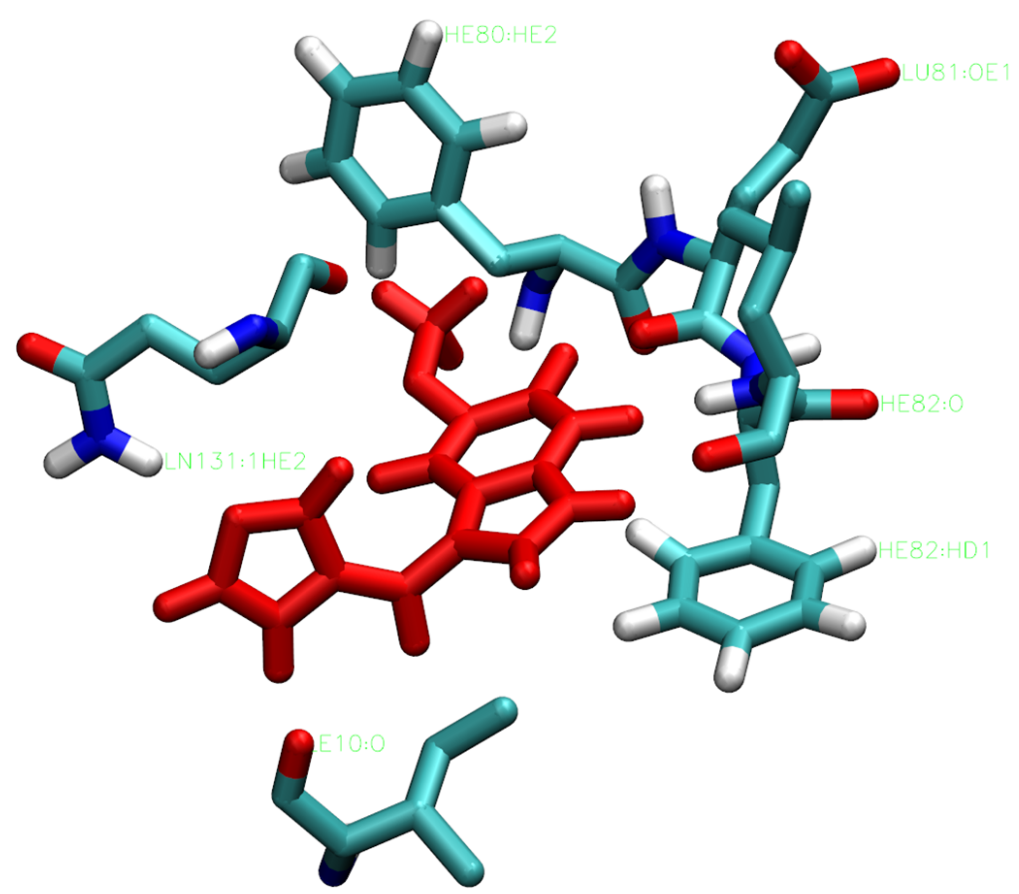

Figura 3.17: Estrutura do SU9516 (em vermelho) obtida após análise de clusters na DM. Aminoácidos (átomos com legenda em verde) que mais interagiram com o SU9516 são mostrados.

No total tivemos 10 clusters de configurações da SU9516, sendo 2,2 A, o valor médio do RMSD, com relação à estrutura apresentada na Figura 3.17. Fizemos a análise das ligações de hidrogênio que ocorreram entre a molécula e os aminoácidos do sítio da CDK2 considerado durante a DM, conforme apresentado na Figura 3.18. 


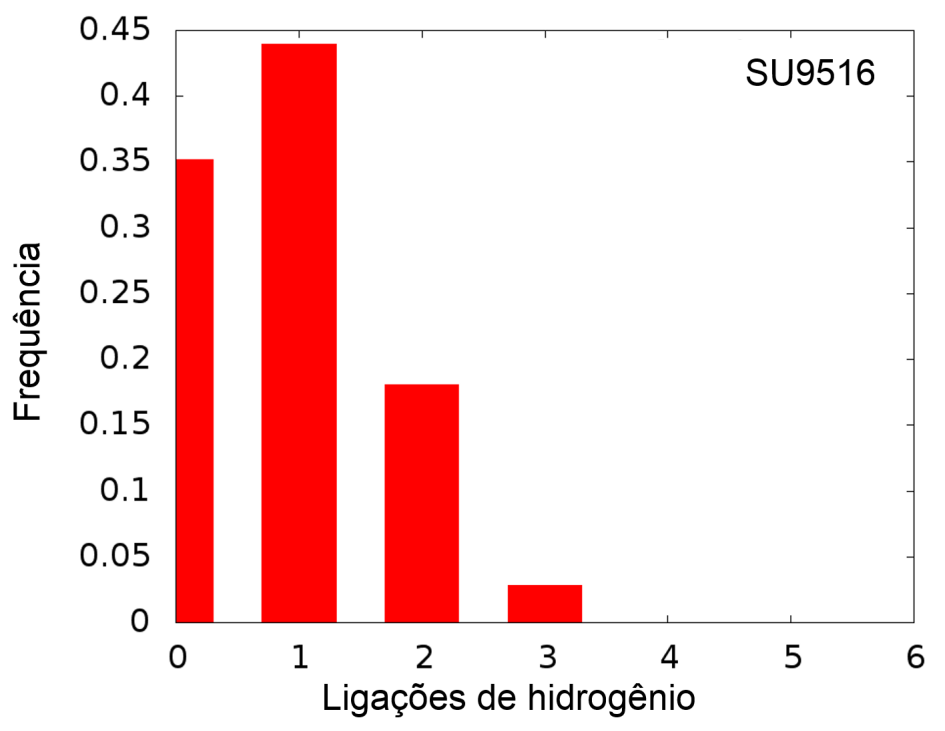

Figura 3.18: Histograma da ocorrência de ligação de hidrogênio entre os aminoácidos e o SU9516 inserido na CDK2.

Analisando o histograma da Figura 3.18 verificamos que durante toda a DM, tivemos uma predominância de uma ligação de hidrogênio entre o SU9516 e 1 aminoácido do sítio, com aproximadamente 45\% da DM tendo esta conformação. $35 \%$ das conformações não tiveram nenhuma ligação de hidrogênio e em 18\% duas ligações; verificamos um índice muito baixo de três ligações de hidrogênio, com valor em torno de $5 \%$ de todas as conformações obtidas da DM.

\subsubsection{Dinâmicas dos sistemas CDK2/isaepy e CDK2/isaenim}

Na Figura 3.19 mostramos o RMSD do centro de massa do isaepy obtidos nos últimos 5000 ps de simulação, e na Figura 3.20 mostramos o correspondente RMSD para o isaenim. O RMSD, obtido durante as DMs, para a CDK2 e para a sua estrutura primária (backbone) também são apresentados. 

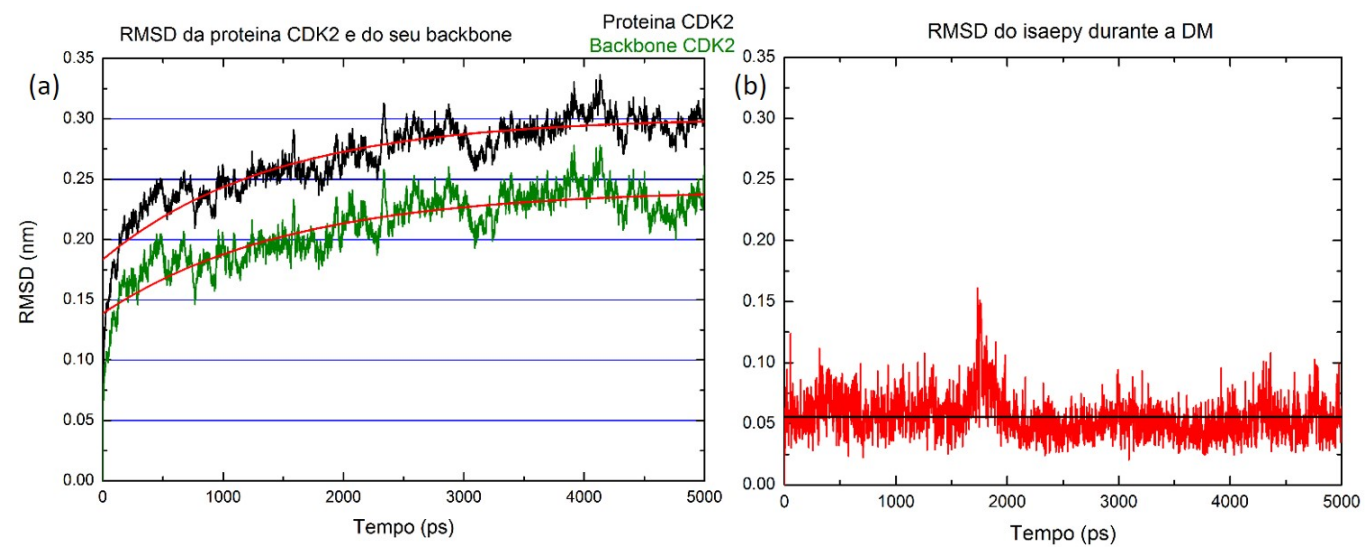

Figura 3.19: a) RMSD para a CDK2 (curva em preto) e do seu backbone (curva em verde); b) RMSD para o centro de massa do isaepy para o sistema CDK2/isaepy.
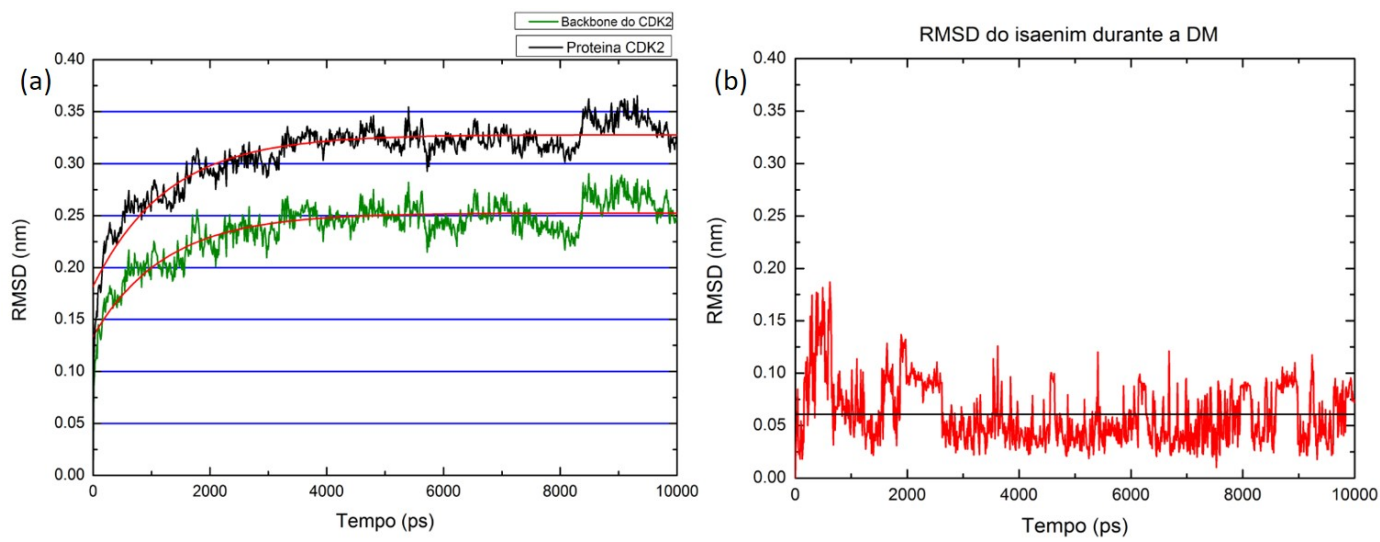

Figura 3.20: a) RMSD da CDK2 (curva em preto) e do seu backbone (curva em verde); b) RMSD para o centro de massa do isaenim para o sistema CDK2/isaenim.

Verificamos que o RMSD obtido para o backbone (Figuras 3.19a e 3.20a) é aproximadamente $0,1 \mathrm{~nm}$ menor que o RMSD da CDK2. Este resultado era esperado, considerando que, no caso da CDK2, o deslocamento médio de toda a sua estrutura e não somente o deslocamento médio da sua estrutura primária contribui para o RMSD. Em todos os casos, a CDK2 tem um RMSD pequeno sendo 0,35 nm para a CDK2/isaenim e 0,30 nm para a CDK2/isaepy, (em relação à estrutura inicial de raio-X) indicando a ausência de grandes deslocamentos, durante toda a dinâmica. Observamos que o comportamento da CDK2 seguiu a tendência geral 
de seu backbone, indicando que a proteína teve baixa mobilidade durante as duas DMs. O valor do RMSD médio obtido para o isaepy (Figura 3.19b) foi de 0,05 nm e observamos um pico no intervalo entre 1800 ps e 2000 ps. No caso do isaenim, o valor do RMSD médio foi de aproximadamente 0,06 nm (Figura 3.20b). Nestes casos, podemos dizer que tanto o isaepy quanto isaenim estão bem estabilizados dentro do sítio considerado. Observamos algumas variações no RMSD do isaenim, principalmente no intervalo de simulação entre 0 ps e 1000 ps, 2000 ps e 3000 ps, 8500 ps e 9000 ps que indicam a presença de uma mudança da conformação do isaenim no sítio. Comparando os RMSD verificamos que o isaepy se desloca menos que o isaenim dentro do sitio da CDK2. Na Figura 3.21 mostramos os histogramas que nos dão as informações sobre as frequências em que os aminoácidos interagem com o isaepy, onde os aminoácidos são representados pelo número do resíduo utilizado na DM. 


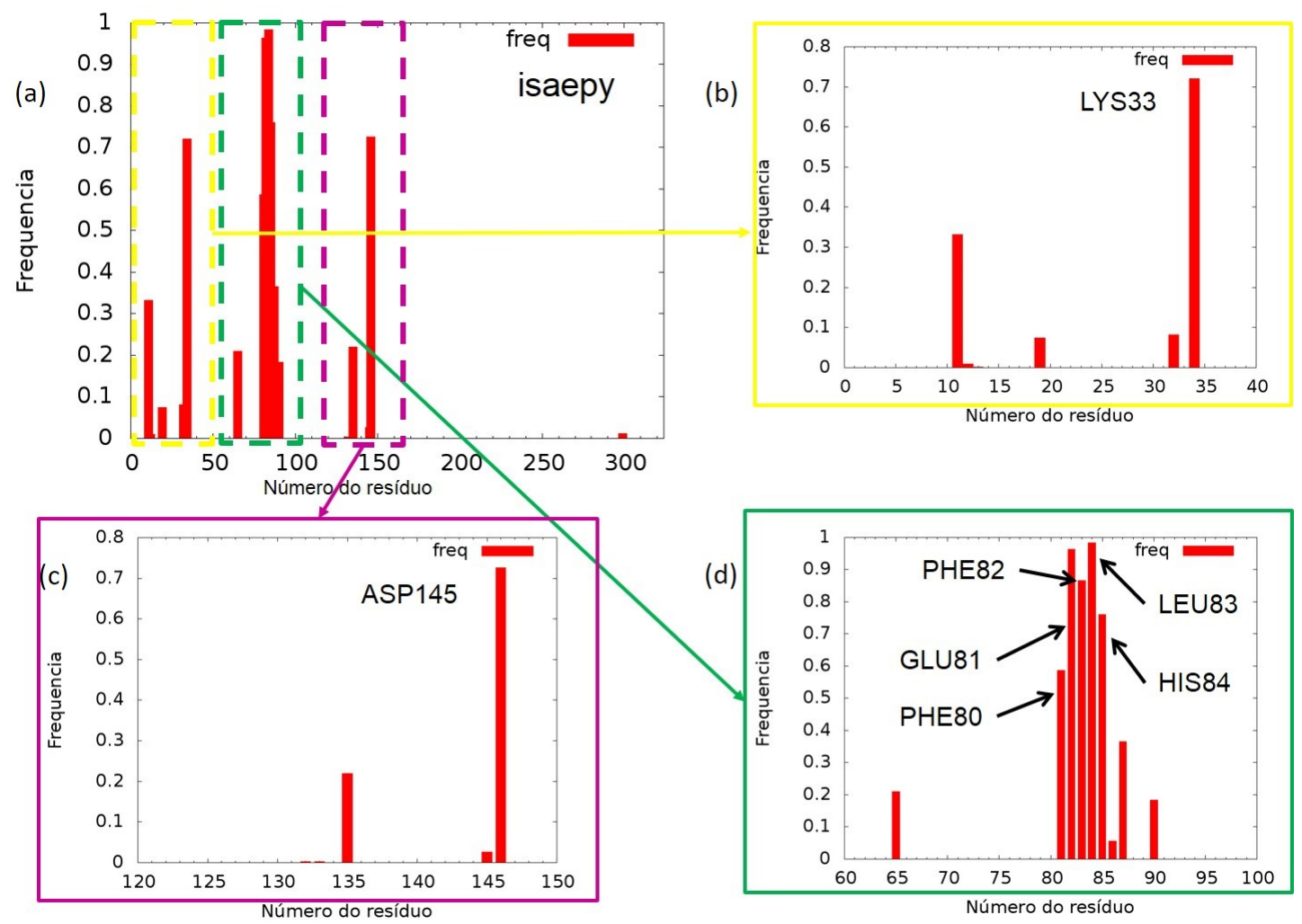

Figura 3.21: a) Histograma da frequência de interação entre os aminoácidos (número de resíduo) e o isaepy. Detalhamento das regiões: b) 0 - 40, indicado pelos retângulos pontilhado e contínuo em amarelo, repectivamente; c) 120 - 150 indicado pelos retângulos pontilhado e contínuo em violeta, repectivamente; d) 60 - 100 indicado pelos retângulos pontilhado e contínuo em verde, repectivamente.

Verificamos que os aminoácidos que mais interagem com o isaepy durante a DM são: LYS33, PHE80, GLU81, PHE82, LEU83, HIS84 e ASP145. Observamos que a LYS33 interage com o isaepy em $70 \%$ da DM e, da mesma forma como no caso do SU9516, os aminoácidos PHE80, GLU81, PHE82 e LEU83 foram os que mais estiveram em contato com o isaepy (60\%, 95\%, 88\% e $98 \%$ respectivamente). A LEU83 interagiu, através de uma ligação de hidrogênio com o isaepy durante toda a simulação, e a HIS84 interagiu em aproximadamente $80 \%$ da simulação. Estes aminoácidos estivem em contato com a parte oxindol do isaepy e foram os responsáveis por mantê-la no sítio da CDK2. Além disto, pudemos verificar a 
interação da ASP145 com o isaepy em aproximadamente $75 \%$ da DM.

Na Figura 3.22 mostramos os histogramas que nos dão as informações sobre as frequências em que os aminoácidos interagem com o isaenim.

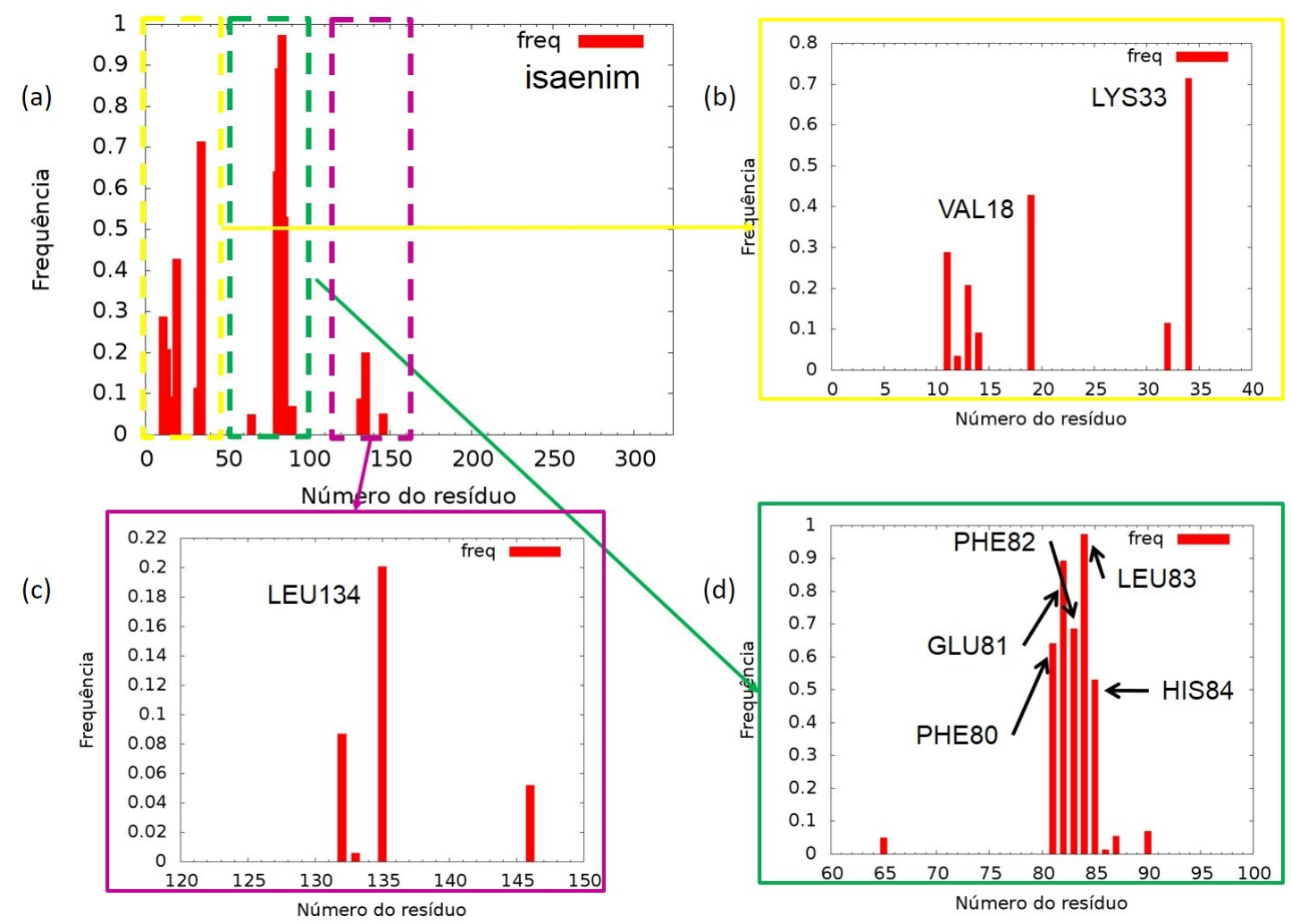

Figura 3.22: a) Histograma da frequência de interação entre os aminoácidos (número de resíduo) e o isaenim. Detalhamento das regiões: b) 0 - 40, indicado pelos retângulos pontilhado e contínuo em amarelo, repectivamente; c) 120 - 150 indicado pelos retângulos pontilhado e contínuo em violeta, repectivamente; d) 60 - 100 indicado pelos retângulos pontilhado e contínuo em verde, repectivamente.

Os aminoácidos que mais interagem com o isaenim durante a DM são: VAL18, LYS33, PHE80, GLU81, PHE82, LEU83, HIS84 e, em menor porcentagem, a LEU134. A VAL18 e a LYS33 interagem com o isaenim em $40 \%$ e $70 \%$ da DM respectivamente. Similar ao caso do isaepy, os aminoácidos PHE80, GLU81, PHE82 e LEU83 também foram os que mais estiveram em contato com o isaenim (60\%, $90 \%, 70 \%$ e $98 \%$ respectivamente). Analisando a trajetória obtida da DM, verifi- 
camos que a LEU83 interagiu com o isaenim através de uma ligação de hidrogênio, durante toda a simulação e a HIS84 interagiu em aproximadamente $50 \%$ da simulação. Da mesma forma como nos casos do SU9516 e isaepy, estes aminoácidos estiveram em contato com a parte oxindol do isaenim e, novamente, foram os responsáveis por manter a molécula no sítio da CDK2. Tivemos uma interação da LEU134 com o isaenim em aproximadamente $20 \%$ das configurações obtidas na DM. Para entender o motivo de algumas mudanças de conformações das moléculas, fizemos uma análise dos diedros do isaepy e isaenim responsáveis pelas torções das mesmas. Os diedros analisados do isaenim foram N4-C5-C6-N7, C3-N4-C5-C6 e O1-C2-C3-N4 e os resultados são mostrados na Figura 3.23. 

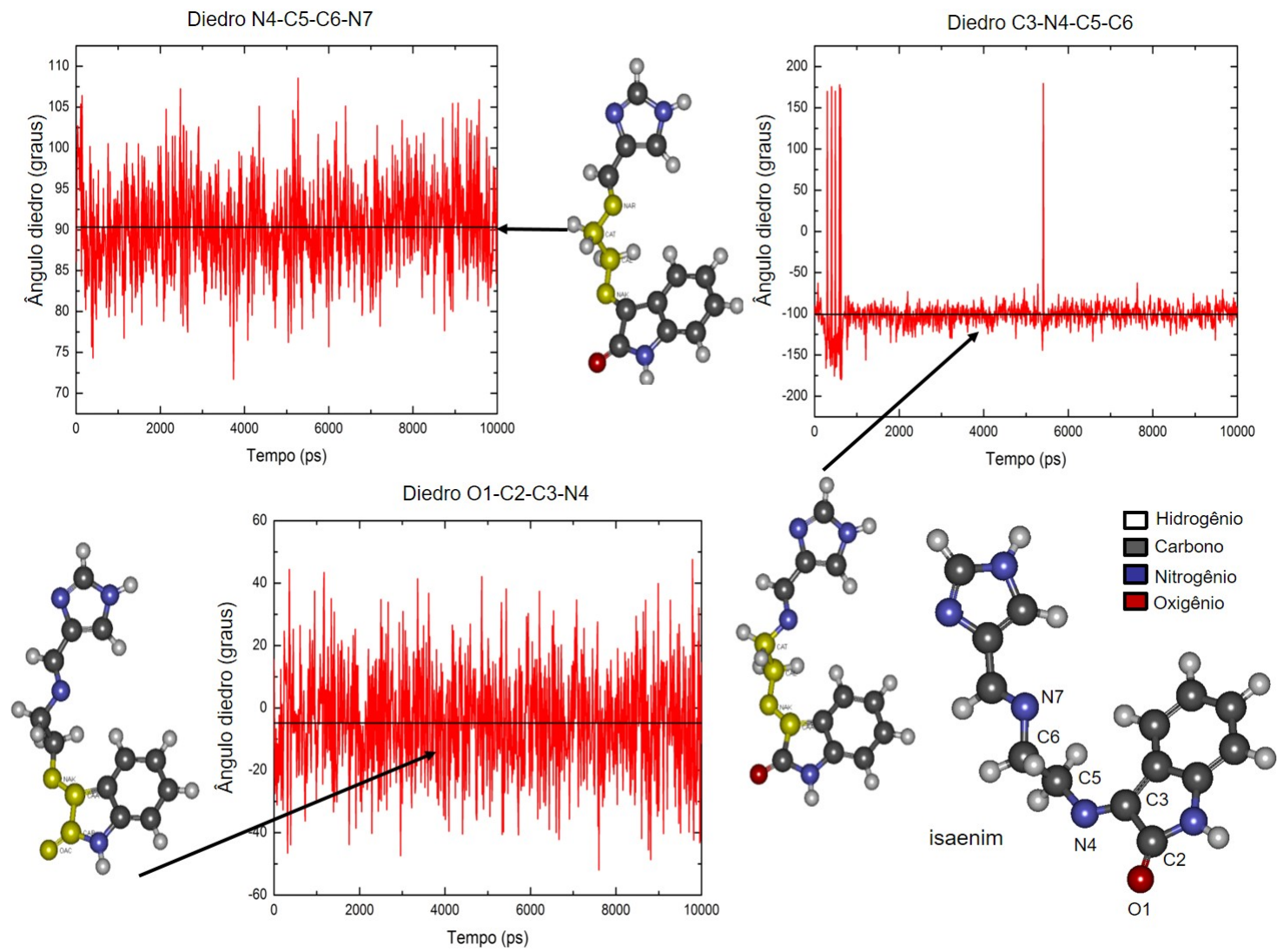

Figura 3.23: Variação dos ângulos dos diedros do isaenim analisados durante a DM: a) N4-C5-C6-N7; b) C3-N4-C5-C6; c) O1-C2-C3-N4. A linha preta representa o valor médio do ângulo do diedro e as representações da molécula ao lado dos gráficos indicam os diedros analisados (marcado em amarelo na molécula).

O valor médio do ângulo do diedro N4-C5-C6-N7 é de aproximadamente $90^{\circ}$ enquanto que, o valor médio do diedro C3-N4-C5-C6 é de aproximadamente $100^{\circ}$ (Figura 3.23b). O do diedro O1-C2-C3-N4 oscila entre -20 graus e 20 graus, mas seu valor médio ficou muito próximo de zero, indicando que este diedro esteve no plano da molécula durante praticamente toda a simulação.

Os diedros analisados do isaepy foram C1-N12-C13-C20, C10-C1-N12- C13 e C17-C16-C20-C13 e na Figura 3.24 são mostrados os resultados obtidos para estes diedros. O ângulo do diedro $\mathrm{C} 1-\mathrm{N} 12-\mathrm{C} 13-\mathrm{C} 20$ oscila entre $-50^{\circ}$ e $50^{\circ}$; no entanto, o seu valor médio está bem próximo de zero. O diedro C10-C1-N12-C13 
oscila entre $-20^{\circ}$ e $20^{\circ}$ e o seu valor médio é em torno de 10 graus, enquanto que o ângulo do diedro C17-C16-C20-C13 oscila entre $-125^{\circ}$ e $125^{\circ}$ e o seu valor médio é em aproximadamente $-25^{\circ}$.
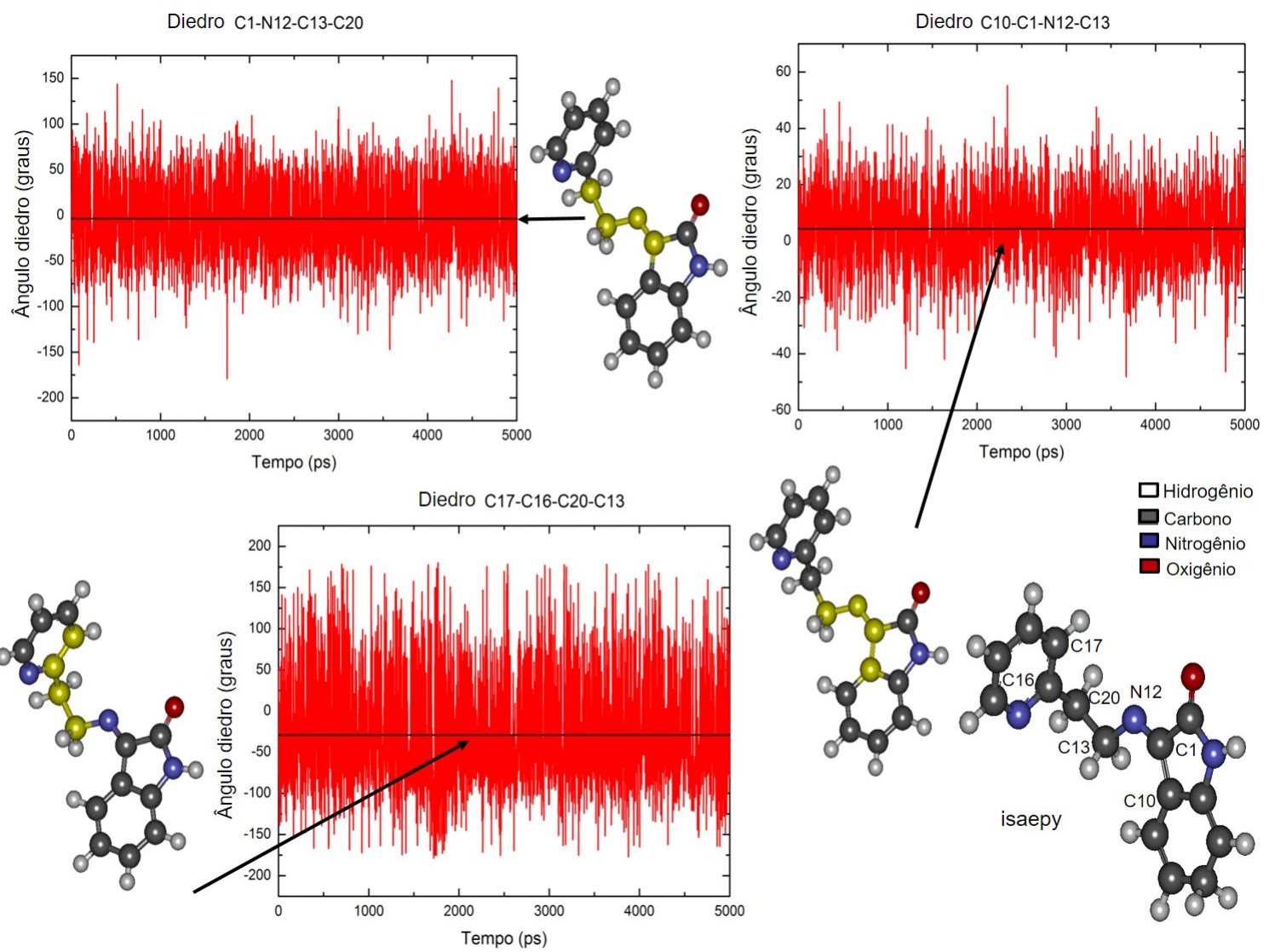

Figura 3.24: Variação dos ângulos dos diedros do isaepy durante a DM: A linha preta representa o valor médio do ângulo do diedro e as representações da molécula ao lado dos gráficos mostram os diedros analisados (marcado em amarelo na molécula).

Na Figura 3.25 destacamos as estruturas representativas do isaepy e isaenim com maior ocorrência (830 configurações para o isaenim e 900 para o isaepy) na DM e obtida pela análise de clusters. Mostramos também os aminoácidos (em até $3 \AA$ de distância dos átomos do isaepy) que mais interagiram com a molécula durante a DM. 


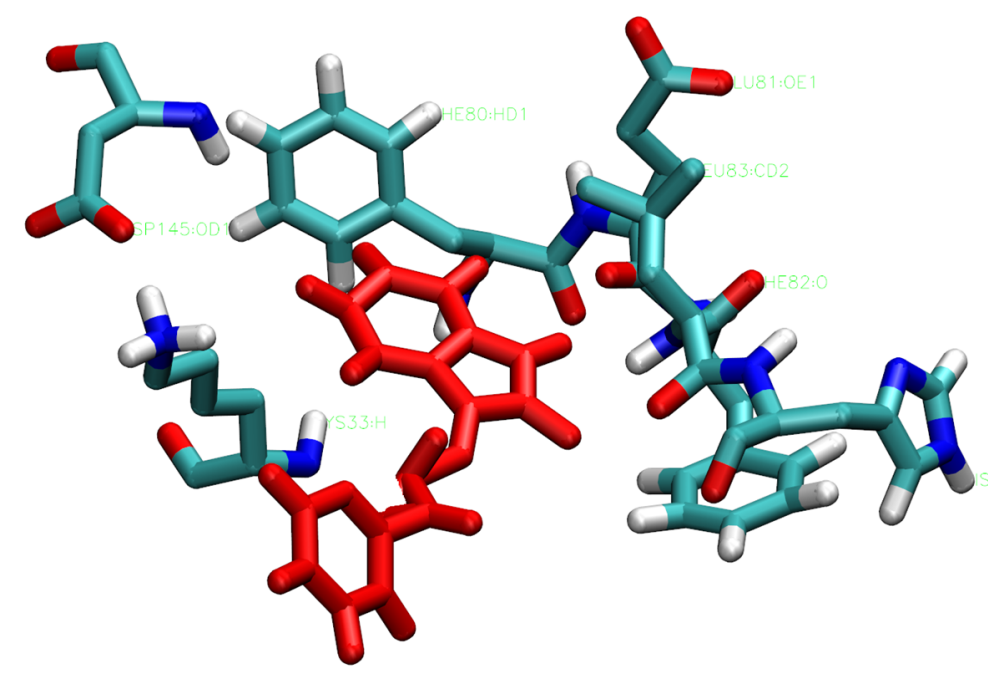

(a)

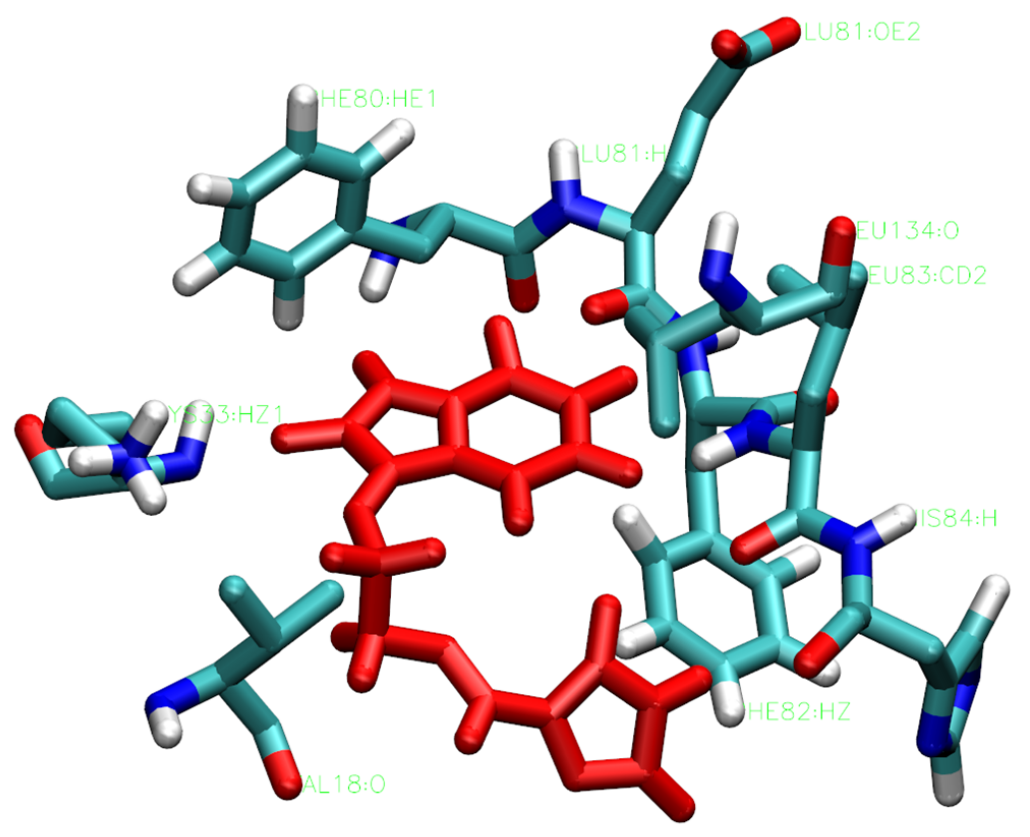

(b)

Figura 3.25: Estruturas obtidas após análise de clusters nas DMs para: (a) isaepy (em vermelho); (b) isaenim (em vermelho). Aminoácidos (átomos com legenda em verde) que mais interagiram com o isaepy e isaenim são mostrados. 
No total tivemos 12 clusters de configuração do isaenim, sendo $1.5 \AA$, o valor médio do RMSD, com relação à estrutura apresentada na Figura 3.25a. Tivemos

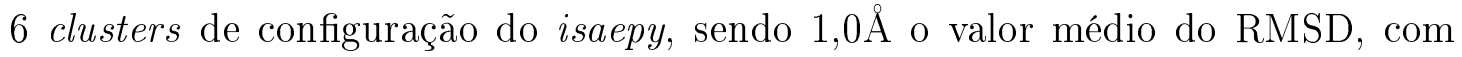
relação à estrutura apresentada na Figura 3.25b.

Na Figura 3.26 são mostrados os histogramas das interações de hidrogênio que ocorreram entre o isaepy e isaenim com os aminoácidos do sítio ativo da CDK2 durante a DM. Analisando o gráfico de ocorrências de ligação de hidrogênio entre o isaepy e os aminoácidos (Figura 3.26a) do sítio considerado verificamos a predominância de configurações com duas ligações de hidrogênio com aproximadamente $77 \%$ de ocorrências. Em seguida temos a ocorrência para uma ligação de hidrogênio (aproximadamente 15,6\% das ocorrências). Temos em torno de 3,5\% das ocorrências para duas ligações de hidrogênio, 3,7 \% de ocorrências para zero ligações de hidrogênio e 0,2 \% para configurações com quatro ligações de hidrogênio, o que pode ser considerado desprezível. Analisando o gráfico de ocorrências de ligação de hidrogênio entre o isaenim e o sítio da CDK2 (Figura 3.26b) verificamos a predominância de uma ligação de hidrogênio $(43,7 \%)$, em seguida temos a ocorrência de zero ligações de hidrogênio (41,5\%),duas ligações de hidrogênio (14\%) e três ligações de hidrogênio com aproximadamente $0,9 \%$, o que pode ser desprezado. Em uma comparação direta entre o isaepy e isaenim, o número de configurações do isaepy apresenta um maior número de ligações de hidrogênio. A ocorrência de configurações com duas ligações de hidrogênio foi predominante no CDK2/isaepy, enquanto que o caso do CDK/isaenim, houve a predominância de configurações com uma ligação de hidrogênio. Isto indica que o isaepy tem uma tendência maior de ficar estabilizado no sítio considerado e, consequentemente, seria mais difícil removê-lo. Esta análise é muito importante pois indica que o isaepy, quando inserido no sítio, teria uma tendência maior de ali permanecer e desta forma, maior eficácia em inibir a síntese de ATP, comparado ao isaenim e 
ao SU9516.

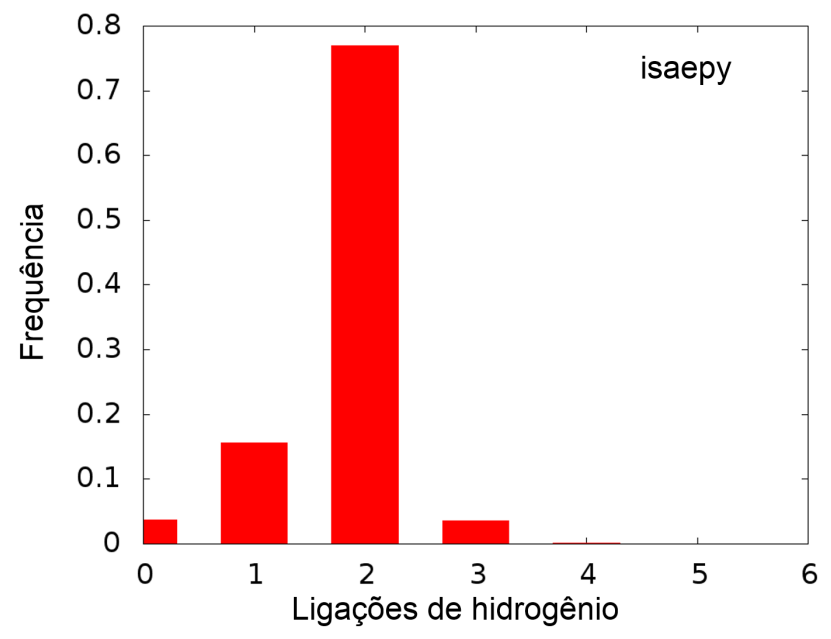

(a)

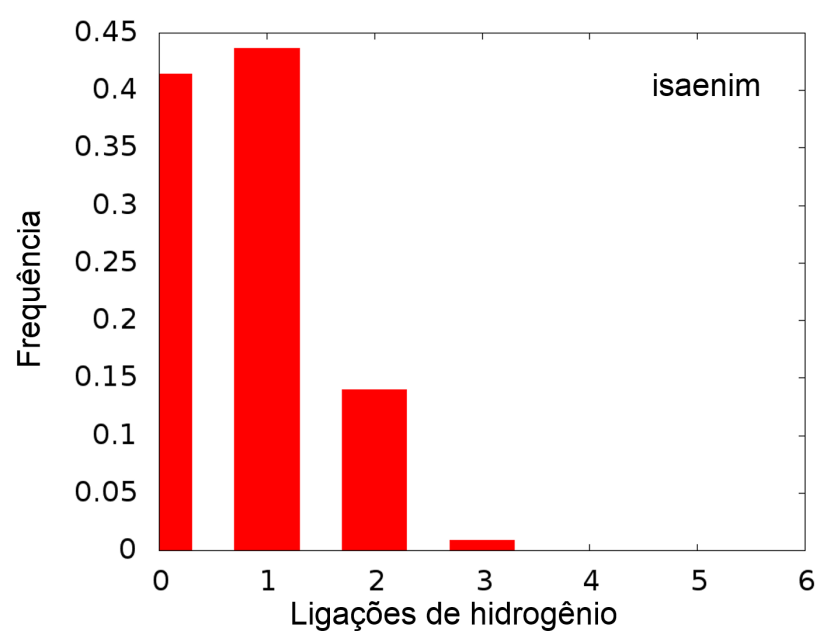

(b)

Figura 3.26: Histograma da ocorrência de ligações de hidrogênio entre os aminoacidos do sítio da CDK2 considerado e: a) isaepy; b) isaenim.

Nas Figuras 3.27 e 3.28 mostramos a comparação direta entre o SU9516, isaepy e isaenim referentes a aminoácidos ligados e ocorrências de ligação de hidrogênio. 

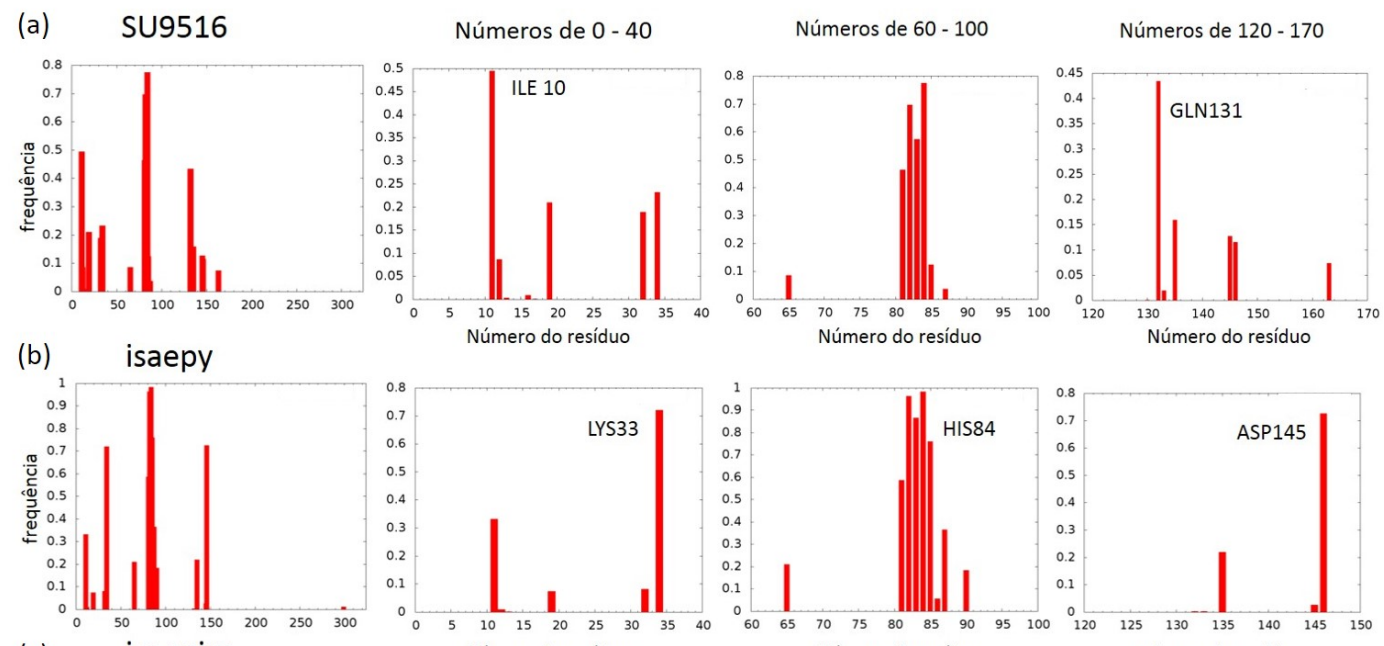

(c)
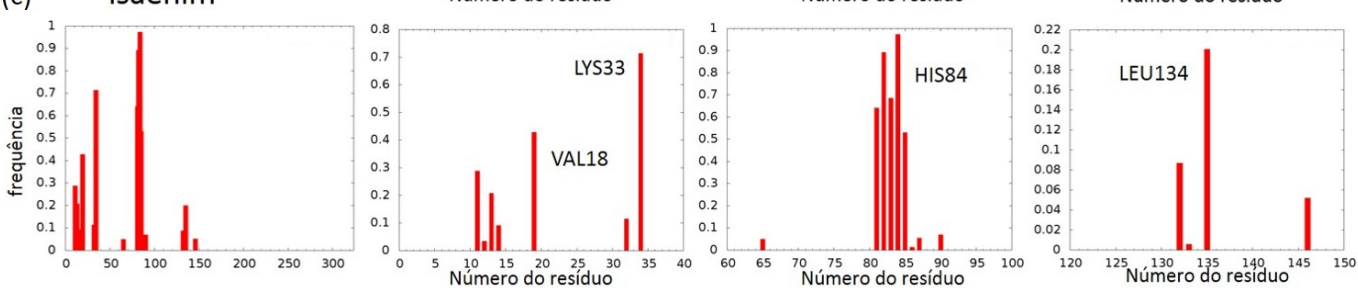

Figura 3.27: Comparação entre os histogramas de frequência de interação entre os aminoácidos do sítio (número do resíduo) e: a) SU9516; b) isaepy; c) isaenim. O detalhamento das regiões entre 0-40, 60-100 e 120-170 também são mostrados.

Analisando a Figura 3.27 verificamos que os aminoácidos que interagem com os ligantes no sítio considerado são bem semelhantes. Algumas pequenas diferenças podem sem observadas e o SU9516 interage com o ILE10, mas não se observa uma interação significativa com a LYS33 e VAL18. Estes aminoácidos interagem no caso do isaepy e somente a LYS33 para o caso do isaenim. No entanto, não observamos a interação do SU9516 com a HIS84 e esta interação é observada para o isaepy e o isaenim. Verificamos que o SU9516 está interagindo com o GLN131 (apesar de ser abaixo de 50\%), mas não observamos esta interação para o isaepy e isaenim. Em contrapartida, verificamos a interação do ASP145 no caso do isaepy e a interação com a LEU134 (apesar de ser abaixo de 20\%) no caso do isaenim. Apesar destas pequenas diferenças, o perfil dos aminoácidos que interagiram com 
as três moléculas estão bem semelhantes.
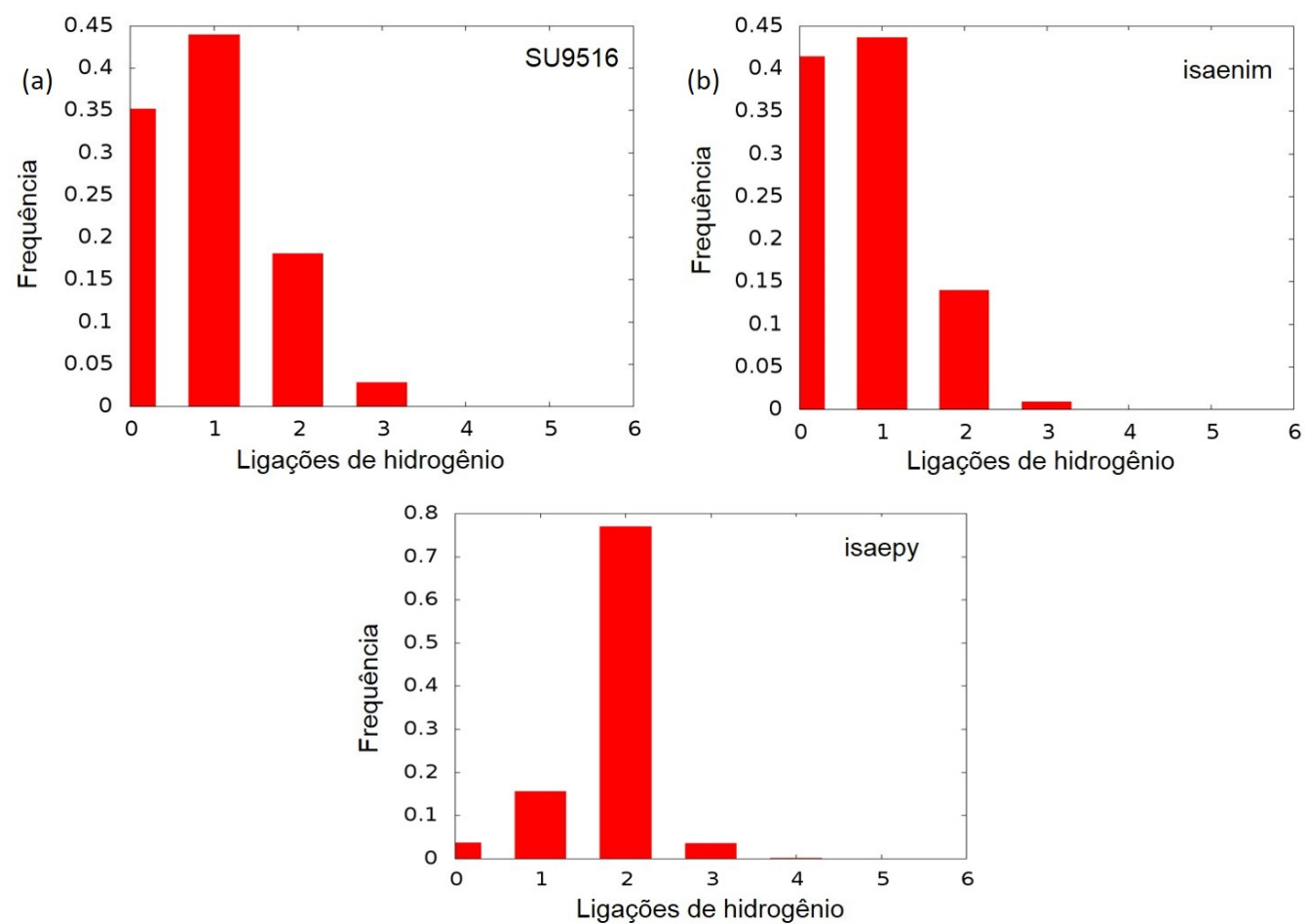

(c)

Figura 3.28: Compilação dos resultados obtidos para as ocorrências de ligações de hidrogênio entre os aminoácidos do sítio da CDK2 considerado e: a) SU9516; b) isaenim; c) isaepy.

Na Figura 3.28 verificamos que o isaepy teve um maior número de configurações com ligações de hidrogênio durante a DM e teve a predominância de duas ligações de hidrogênio com 88\% das configurações obtidas. No caso do SU9516 e isaenim, a predominância foi de uma ligação de hidrogênio e com porcentagens muito parecidas com $43 \%$ e $44 \%$ respectivamente. Estes resultados são muito interessantes e indicam que o isaepy, tendo um maior número de ligações de hidrogênio, possui uma maior estabilidade quando inserido na CDK2. 


\subsubsection{Dinâmicas da CDK1-ciclinaB/isapn e CDK1-ciclinaB /[Cu(isapn $)]^{2+}$}

Na Figura 3.29 mostramos os RMSDs dos centros de massas do isapn e $[C u(\text { isapn })]^{2+}$ e apresentamos também as conformações obtidas da análise de clusters (1500 configurações para o isapn e 2000 para o $\left.[C u(\text { isapn })]^{2+}\right)$. O deslocamento médio (representado pela linha preta no gráfico) do centro de massa em relação à sua posição inicial (estrutura obtida por docking) foi de $0.13 \mathrm{~nm}$ (Figura $3.29 \mathrm{a})$ para o isapn e $0,07 \mathrm{~nm}$ para o $[C u(\text { isapn })]^{2+}$ (Figura 3.29b). Uma variação no RMSD do isapn na região entre 8000 ps e 10000 ps ocorreu devido à torção do ângulo diedro N4-C18-C19-C17 (Figura 3.29a). Nenhuma variação similar para o $[C u(\text { isapn })]^{2+}$ foi observada e isto ocorreu devido ao íon $\mathrm{Cu}$ dificultar a torção do diedro durante a simulação da DM. Desta forma, o $[C u(\text { isapn })]^{2+}$ ficou estabilizado e manteve a sua conformação estrutural planar. No total tivemos 6 clusters de configuração para o isapn e apenas 3 para o $[C u(\text { isapn })]^{2+}$ e o RMSD dos 6 clusters em relação à estrutura apresentada na Figura 3.29a tiveram um valor médio de 1,0 $\AA$. No caso do $[C u(\text { isapn })]^{2+}$, observamos que o RMSD dos 3 clusters em relação à estrutura apresentada na Figura 3.29b, apresenta um valor muito baixo, uma vez que tivemos poucas conformações com outras configurações.

Analisando o histograma da Figura 3.30a verificamos que, no caso do isapn, uma e duas ligações de hidrogênio entre o isapn e um aminoácido do sítio estão igualmente distribuídos, com aproximadamente $40 \%$ da DM tendo estas conformações; $8 \%$ das conformações não tiveram nenhuma ligação de hidrogênio e $12 \%$ apresentaram três ligações. No caso do $[\mathrm{Cu}(\text { isapn })]^{2+}$ (Figura 3.30b), duas ligações de hidrogênio entre o $[C u(\text { isapn })]^{2+}$ e aminoácidos do sítio considerado são predominantes, com aproximadamente $60 \%$ da DM tendo estas conformações; $39 \%$ das conformações tiveram uma ligação de hidrogênio e 1\% nenhuma ligação. Estes resultados indicam que temos um número maior de conformações com duas ligações 


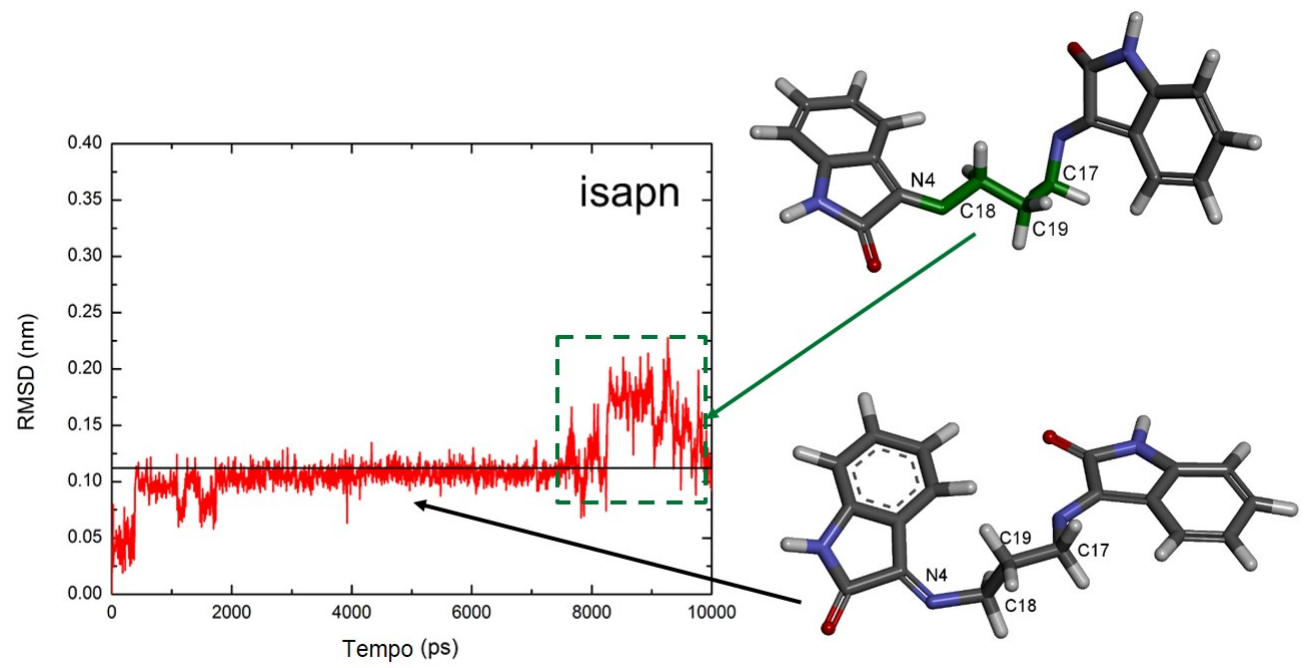

(a)

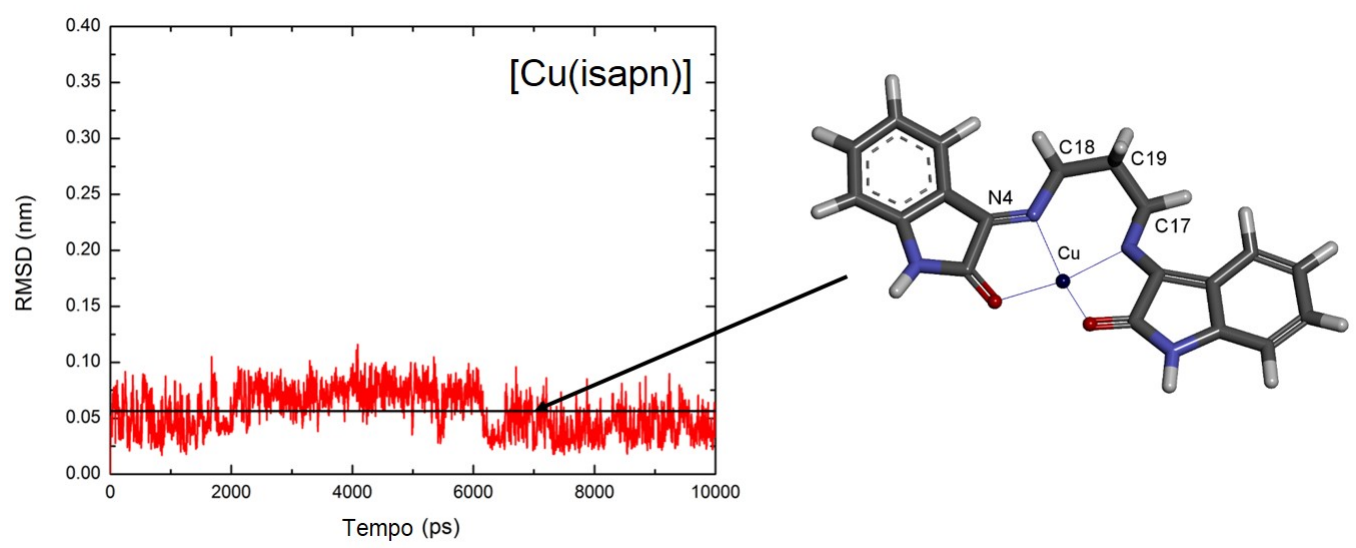

(b)

Figura 3.29: a) RMSD para o centro de massa do isapn para o sistema CDK1ciclinaB/isapn e as estruturas obtidas por análise de clusters. O quadrado pontilhado em verde indica a mudança conformacional do isapn devido a torção do diedro N4-C18C19-C17; b) RMSD para o centro de massa do $[\mathrm{Cu}(\text { isapn })]^{2+}$ para o sistema CDK1ciclinaB $/[C u(\text { isapn })]^{2+}$ e a estrutura obtida por análise de clusters.

de hidrogênio para o $[C u(\text { isapn })]^{2+}$ do que para o isapn. No entanto, verificamos que o isapn possui algumas conformações com até três ligações de hidrogênio (em $15 \%$ dos casos). 


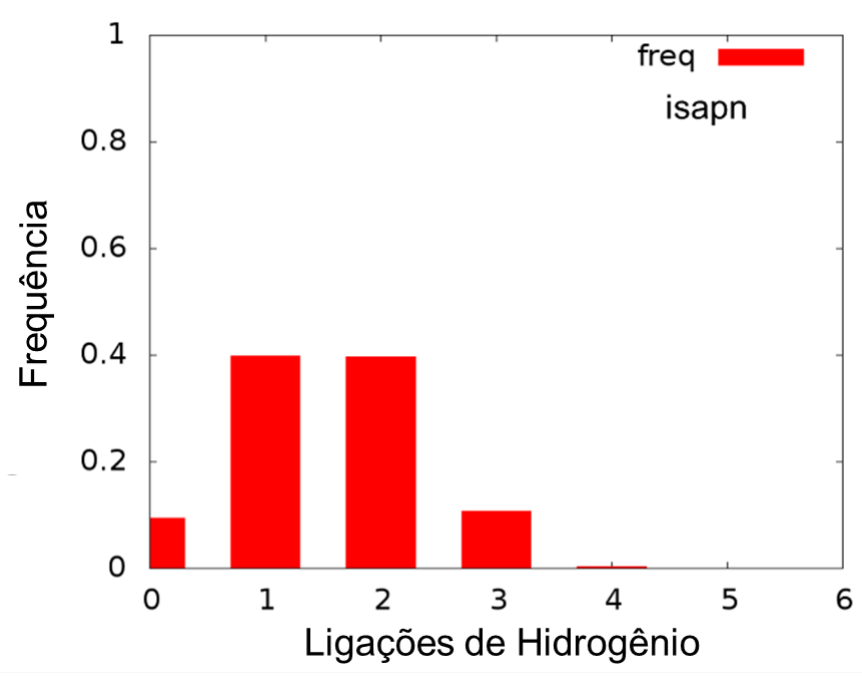

(a)

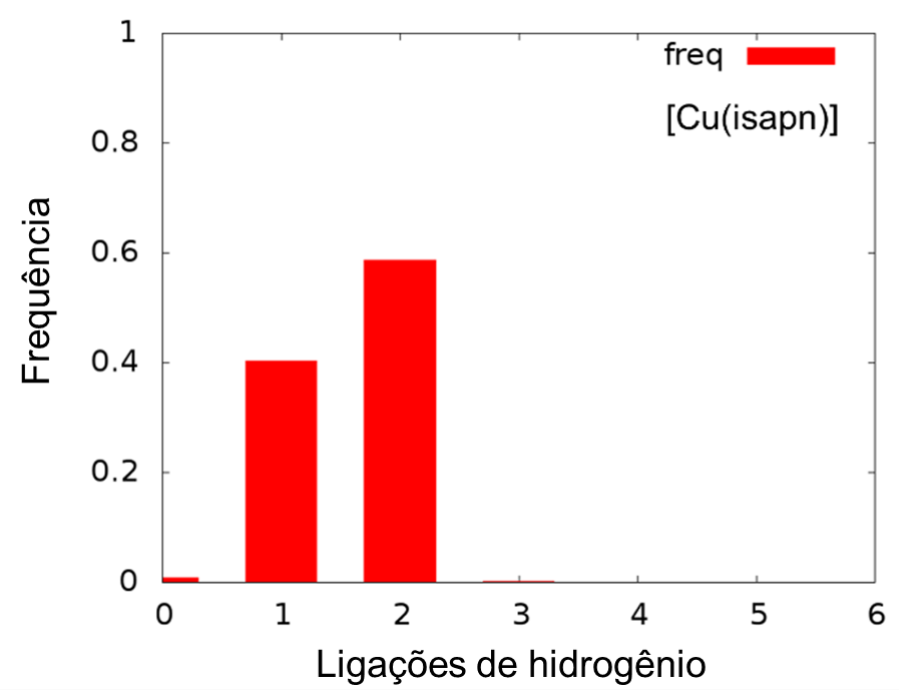

(b)

Figura 3.30: Histograma da ocorrência de ligações de hidrogênio entre os aminoácidos do sítio da CDK1 considerado e: a) isapn; b) $[\mathrm{Cu}(\text { isapn })]^{2+}$.

Na Figura 3.31 são mostradas as estruturas representativas do isapn e do $[C u(\text { isapn })]^{2+}$ com maior ocorrência e obtidas das análises de clusters. Mostramos também os histogramas que nos dão as informações sobre as frequências em 
que os aminoácidos interagem com o isapn e $[C u(\text { isapn })]^{2+}$, onde os aminoácidos são representados pelo número de resíduo utilizado nas DMs. Verificamos que os aminoácidos que mais interagem com o isapn durante a DM são: ILE10, PHE82, LEU83, GLU81, LYS33 e ASP145. Duas aminas do grupo indol interagiram, através de uma ligação de hidrogênio com a ASP145, em aproximadamente $60 \%$ da simulação, uma interação do tipo $\pi$ com o grupo fenil do PHE82, em aproximadamente $80 \%$, e verificamos também duas ligações de hidrogênio com a LYS33 e LEU83, em aproximadamente $64 \%$ e $90 \%$, respectivamente. Observamos uma competição entre o isapn e a LYS33 pelo grupo carbonil da ASP145, o que foi determinante para a igualdade dos valores das frequências de 1 e 2 ligações de hidrogênio conforme mostrado na Figura 3.30a. No caso do $[\mathrm{Cu}(\text { isapn })]^{2+}$ (Figura 3.31b) os aminoácidos que mais interagem são: ILE10, LEU83, THR84 (treonina), GLU81 e ASP145. Duas ligações de hidrogênio entre ASP145 e a amina do grupo indol do $[C u(\text { isapn })]^{2+}$ são observadas (os dois oxigênios do grupo carbonil da ASP145) e uma coordenação quadrado piramidal em torno do íon $\mathrm{Cu}$ foi observada. Isto ocorreu devido a uma interação adicional com o oxigênio da ILE10, conforme mostrado na estrutura representativa (Figura 3.31b). Os aminoácidos de número de resíduo entre 80 e 85 interagiram com o grupo benzeno do oxindol tanto no isapn quanto no $[C u(\text { isapn })]^{2+}$. Observamos que o nitrogênio N1 do $[C u(\text { isapn })]^{2+}$ formou uma ligação de hidrogênio com molécula de água do solvente, durante a simulação. Isto ocorreu devido à posição do N1 ser direcionada para "fora" da cavidade do sítio da CDK1 e, desta forma, ficando mais acessível para uma interação com as moléculas de água do solvente. Verificamos que o íon $\mathrm{Cu}$ causou uma maior estabilidade e rigidez do $[\mathrm{Cu}(\text { isapn })]^{2+}$ o que pode ser um fator determinante na melhora da eficiência do isapn, com a inserção do íon Cu,em inibir a síntese de ATP na CDK1. 

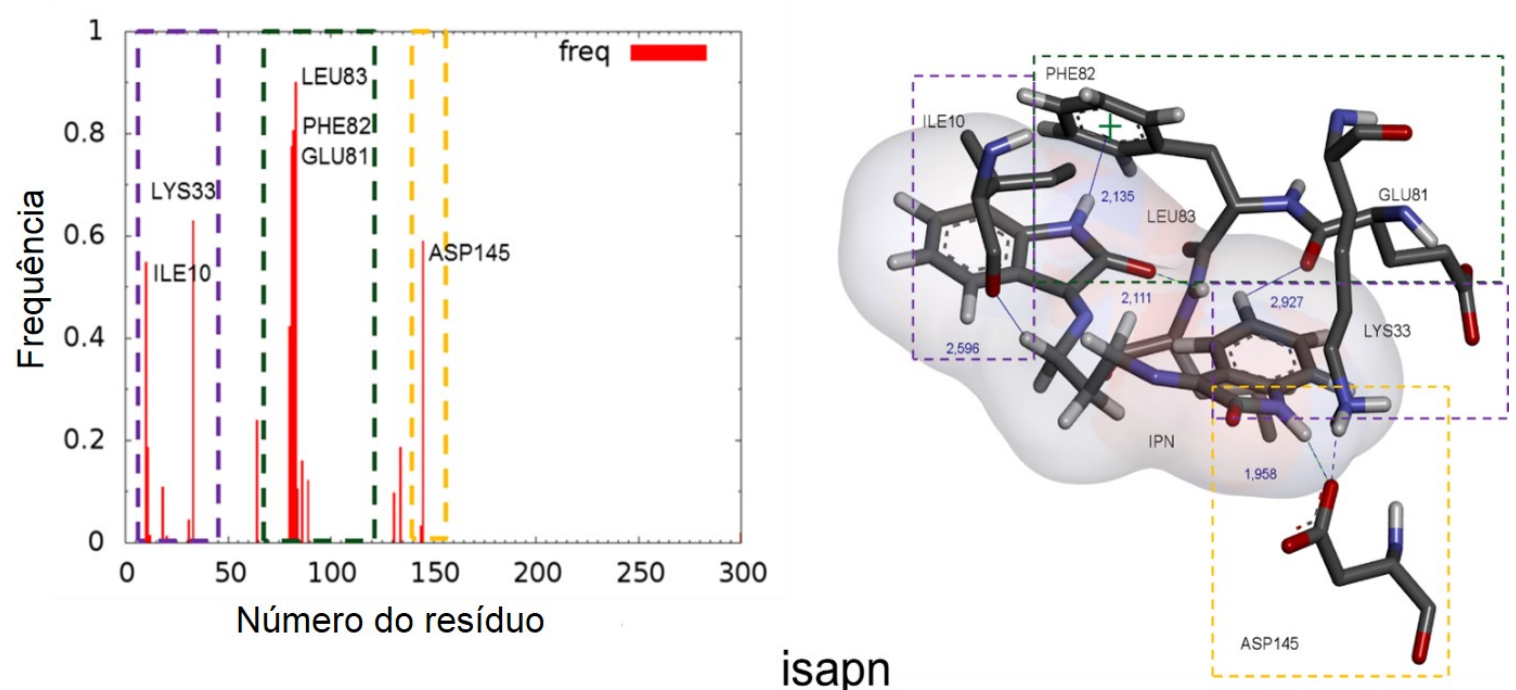

(a)
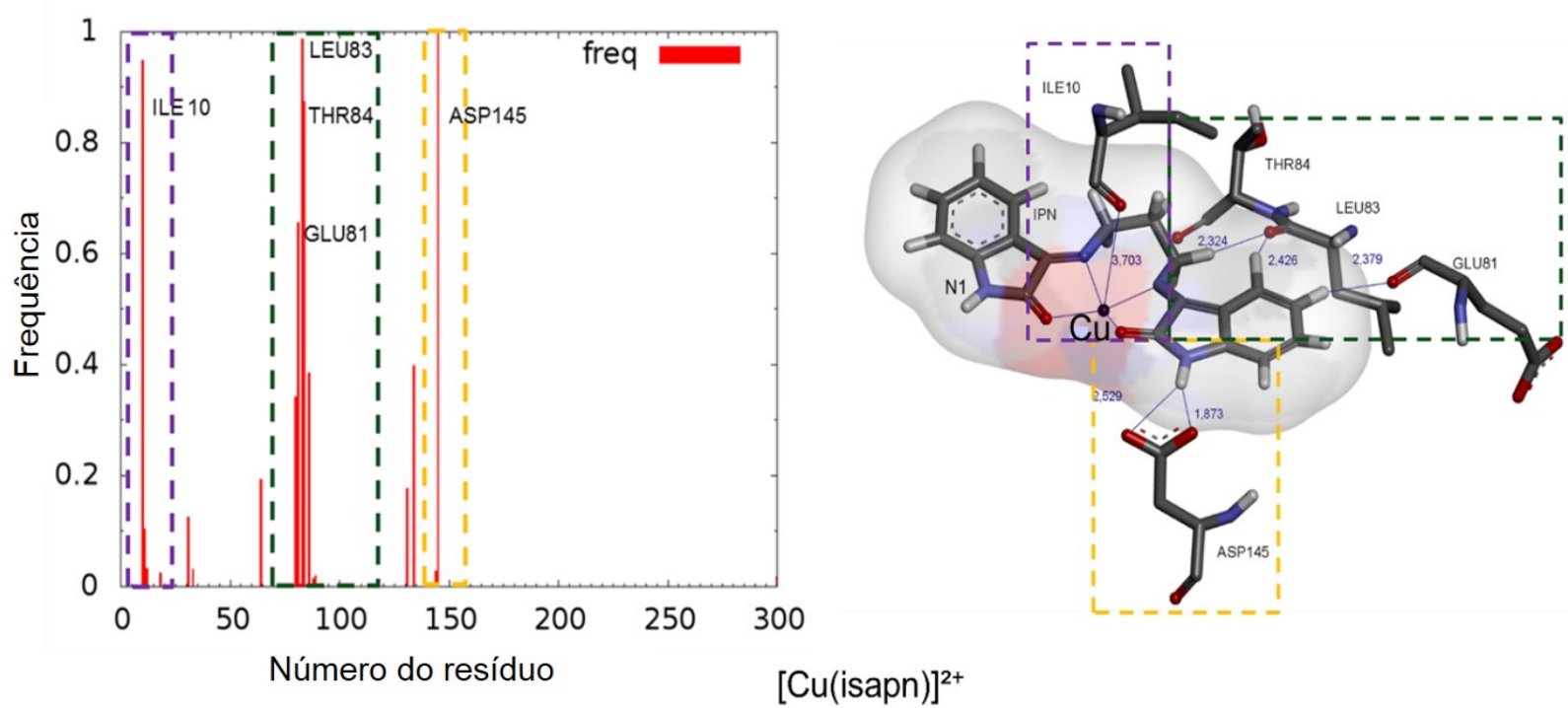

$[\mathrm{Cu}(\text { isapn })]^{2+}$

(b)

Figura 3.31: Histograma da frequência de interação entre os aminoácidos (número de resíduo) e as estruturas representativas obtidas das análises de clusters para: a) isapn; b) $[\mathrm{Cu}(\text { isapn })]^{2+}$. As distâncias de ligação são indicadas pelas linhas em azul e os aminoácidos que mais interagem com o isapn e $[\mathrm{Cu}(\text { isapn })]^{2+}$, pelos retângulos tracejados. O centroíde do anel aromático da PHE82 é representado pela cruz em cor verde. 
Medidas de eletroforese SDS-PAGE, realizadas pelo grupo da prof. Ana Maria da Costa Ferreira [77], que, analisam a atividade de desfosforilação da enzima fosfatase sobre histonas $\mathrm{H} 1$, foram utilizadas para verificar e validar os nossos estudos do isapn e $[\mathrm{Cu}(\text { isapn })]^{2+}$. Desta forma, a histona $\mathrm{H} 1$ foi primeiro fosforilada por incubação na amostra de CDK1-ciclina B e $\gamma-{ }^{32} P-A T P$ e após com a presença do ligante isapn e do complexo $[C u(\text { isapn })]^{2+}$, ambos com concentração molar de $50 \mu M$. A imagem obtida por eletroforese é mostrada na Figura 3.32: quanto menor a concentração de histona fosforilada (menos escura forem as linhas da Figura 3.32) melhor é a inibição da síntese de ATP em ADP no sítio da CDK1.

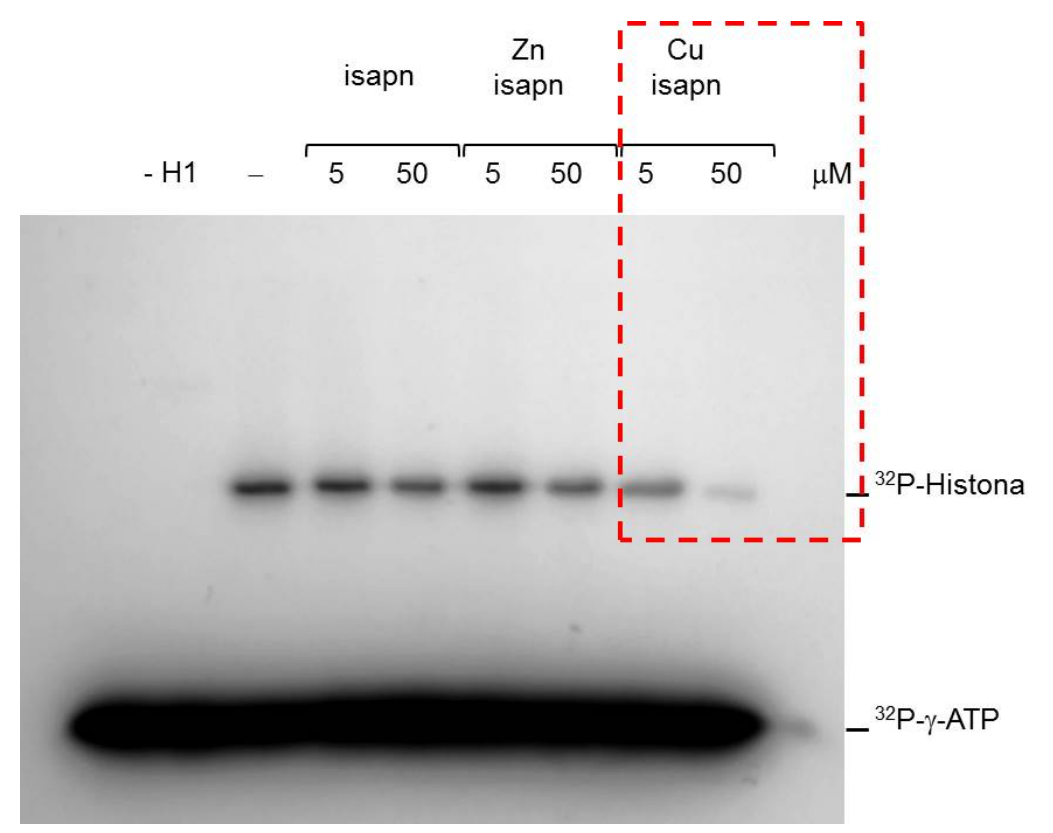

Figura 3.32: Medidas de SDS-PAGE [77] da histona H1 após a fosforilação pela CDK1ciclinaB e após a desfosforilação pela fosfatase na presença do isapn, $[\mathrm{Cu}(\text { isapn })]^{2+} \mathrm{e}$ $[Z n(\text { isapn })]^{2+}$. Os valores medidos do complexo $[C u(\text { isapn })]^{2+}$ são destacados pelo retângulo tracejado em vermelho.

Verificamos que a concentração que contêm o $[C u(\text { isapn })]^{2+}$ possui menos histona fosforilada, indicando ser melhor inibidor que o isapn e $[Z n(i s a p n)]^{2+}$ e, desta forma, a inserção do íon $\mathrm{Cu}$ no isapn melhorou muito a eficácia na inibição 
da síntese de ATP. Este resultado corrobora com as análises que fizemos de que o $[C u(\text { isapn })]^{2+}$ fica mais estabilizado no sítio e inibe de forma mais eficiente a síntese de ATP em ADP, no sítio da CDK1.

\subsection{Estudos dos parâmetros hiperfinos para o com- plexo $[C u(\text { isapn })]^{2+}$}

As medidas de acoplamento hiperfino obtidas por EPR que são apresentadas neste trabalho foram realizadas em soluções contendo água e metanol a temperatura de $77 \mathrm{~K}$ [20]. As DMs foram realizadas com o solvente explícito para o complexo $[C u(\text { isapn })]^{2+}$ e também com o PCM, de modo a analisar as distâncias de ligação entre o íon $\mathrm{Cu}$ e os átomos do isapn e distância entre $\mathrm{Cu}-\mathrm{O}^{\text {agua }}$, sendo $O^{a g u a}$ a nomenclatura utilizada aqui para os oxigênios das moléculas de água que estão nas posições axiais do íon $\mathrm{Cu}$.

A DM do $[\mathrm{Cu}(\text { isapn })]^{2+}$ em solvente explícito utilizou a geometria inicial das posições atômicas obtidas nos cálculos dentro da DFT após a relaxação estrutural. As cargas parciais nos átomos do $[C u(\text { isapn })]^{2+}$ foram obtidas pelo método CHELPG e PCM da água. O valor para o raio de Van der Waals do íon Cu foi de $1,4 \AA$. Dois contra íons de cloro $\left(\mathrm{Cl}^{-}\right)$foram adicionados para que a carga líquida total do sistema fosse nula. O $[\mathrm{Cu}(\text { isapn })]^{2+}$ foi centrado em uma caixa de dimensões $50 \AA ̊ x 50 \AA ̊ x 50 \AA$ e foi preenchida com 4120 moléculas de água. Adotamos as condições periódicas de contorno e o tamanho da célula foi escolhido de modo a garantir que o $[C u(\text { isapn })]^{2+}$ não interagisse com a sua imagem nas células vizinhas. As DMs para o $[C u(\text { isapn })]^{2+}$ em solvente explicito foram realizadas para as temperaturas de $77 \mathrm{~K}$ e $300 \mathrm{~K}$.

Na Figura 3.33 apresentamos os valores de RMSD para o centro de massa do complexo $[C u(\text { isapn })]^{2+}$, a partir da posição inicial, durante as trajetórias das 
dinâmicas moleculares às temperaturas de $77 \mathrm{~K}$ e $300 \mathrm{~K}$ respectivamente.

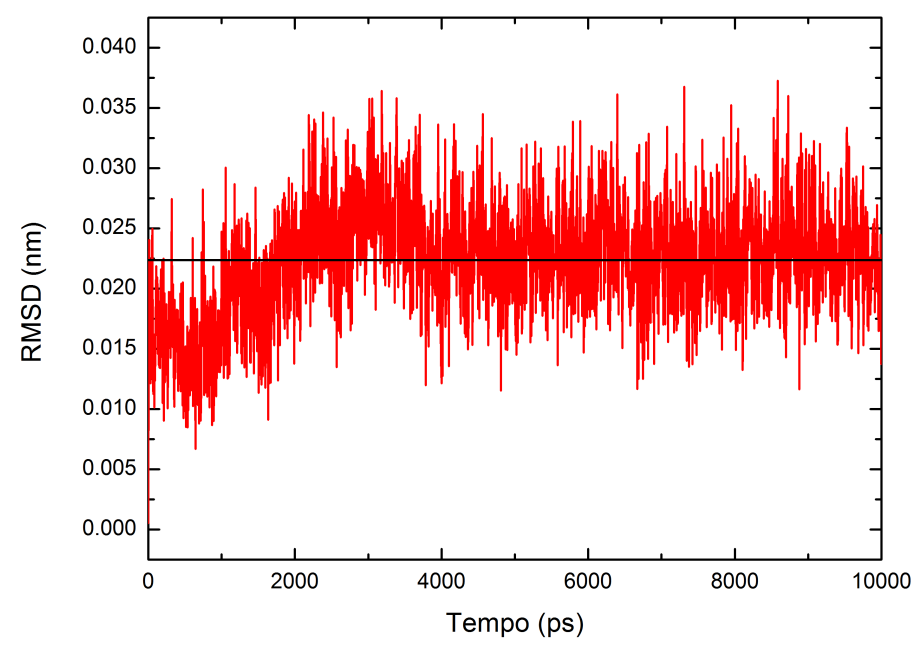

(a)

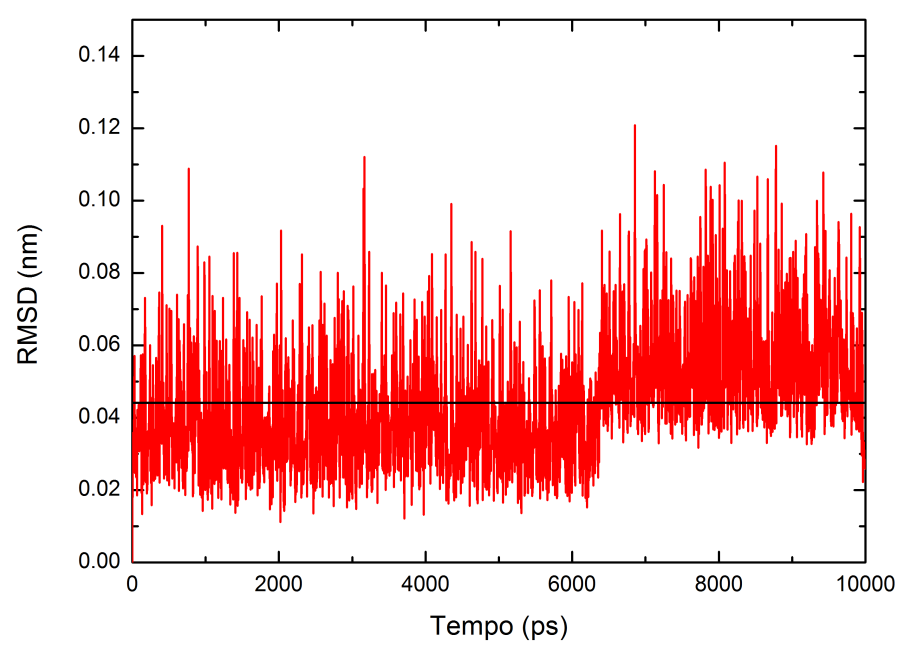

(b)

Figura 3.33: RMSD para o centro de massa do $[C u(\text { isapn })]^{2+}$ para as DMs, em solvente explícito de: (a) $77 \mathrm{~K}$ e (b) $300 \mathrm{~K}$.

O valor médio do RMSD para a DM a $77 \mathrm{~K}$ (representado pela linha preta na 
Figura 3.33) é 0, $0224 \pm 0,0001 \mathrm{~nm}$ (Figura 3.33a). Esta quantidade indica pouco deslocamento do $[C u(\text { isapn })]^{2+}$ em torno da posição de equilíbrio inicial. No caso da dinâmica à 300K, observamos que o valor médio do RMSD é 0,0442 $\pm 0,0004$ nm (Figura 3.33b), aproximadamente duas vezes maior que o valor obtido para a dinâmica à $77 \mathrm{~K}$. Isto ocorreu devido ao aumento da temperatura acarretar um aumento na vibração dos átomos do sistema e, consequentemente, do $[C u(\text { isapn })]^{2+}$. As moléculas de água durante as trajetórias das dinâmicas moleculares clássicas se organizaram em camadas de solvatação ao redor do $[C u(\text { isapn })]^{2+}$, como podemos verificar através da função de distribuição radial $\mathrm{g}(\mathrm{r})$ do par $C u-O^{\text {agua }}$ (Figura 3.34). Em particular, observamos que os oxigênios das moléculas de água permaneceram mais tempo, durante a DM a 300K, a uma distância de 2,55 $\pm 0,04$ $\AA$ do cobre e 2,45 $\pm 0,04 \AA$ para a DM a $77 \mathrm{~K}$. Verificamos uma redução de 0,1 A da distância do $C u-O^{\text {agua }}$ quando comparamos as DMs a $77 \mathrm{~K}$ e 300K. Esta redução pode ser considerada pequena, face ao fato de que a diferença entre as temperaturas é de $223 \mathrm{~K}$. 


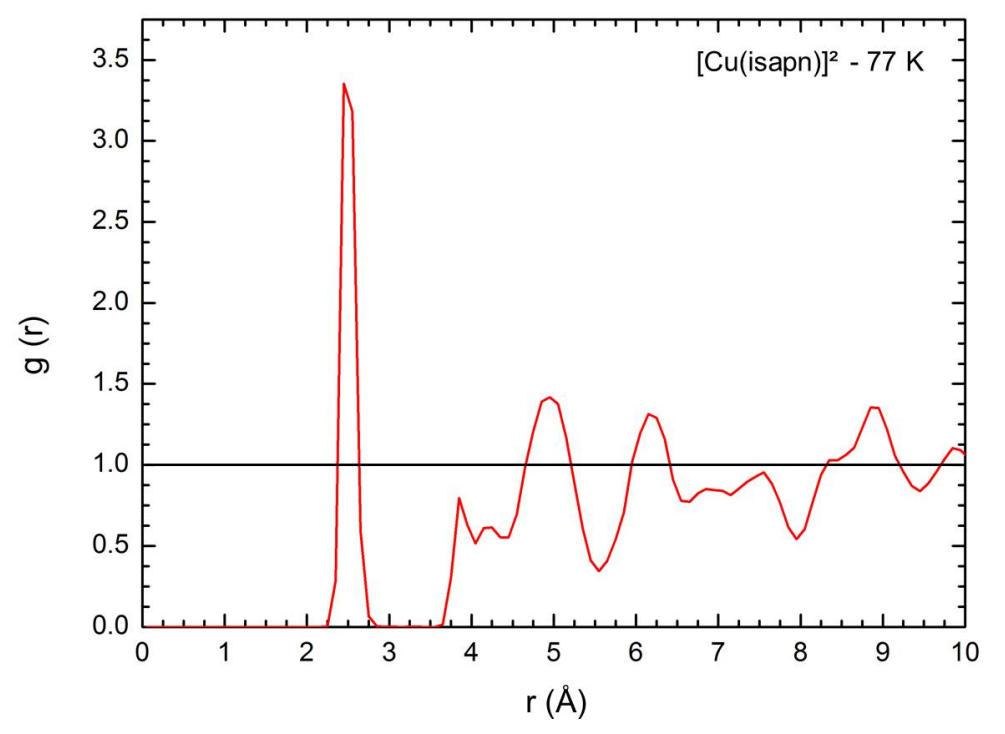

(a)

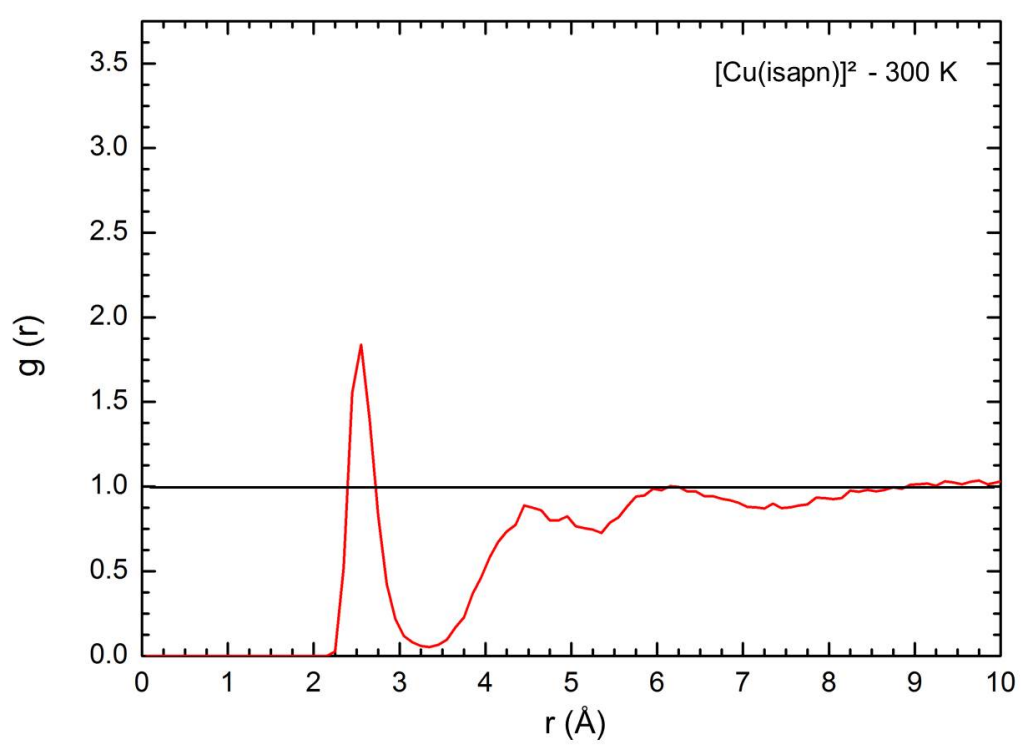

(b)

Figura 3.34: Função de distribuição radial $g(\mathrm{r})$ do par $C u-O^{\text {agua }}$ durante as DMs do complexo $[\mathrm{Cu}(\text { isapn })]^{2+}$ a: (a) $77 \mathrm{~K}$ e (b) $300 \mathrm{~K}$.

Na Figura 3.34 verificamos que o primeiro pico da $\mathrm{g}(\mathrm{r})$, relacionado à primeira camada de solvatação, é muito mais intenso na DM a $77 \mathrm{~K}$ do que a $300 \mathrm{~K}$ e os 
valores de r foram $3,35 \AA$ e $1,84 \AA$ respectivamente. Isto é esperado, uma vez que, com a redução da temperatura temos um menor grau de agitação das moléculas do sistema e, desta forma, um aumento na densidade de moléculas de água em torno do íon $\mathrm{Cu}$. Ao verficarmos as $\mathrm{g}(\mathrm{r})$, e as configurações obtidas para os sistemas durante as DMs do $[C u(\text { isapn })]^{2+}$, observamos que duas moléculas de água ligadas à região axial do cobre foram predominantes e a DM à $77 \mathrm{~K}$ apresentou um maior número de configurações com estas características. Na Figura 3.35 mostramos a sobreposição das conformações obtidas para o complexo $[C u(\text { isapn })]^{2+}$ e moléculas de água que se encontram a uma distância de até 2,5 A. Observamos que as conformações do $[C u(\text { isapn })]^{2+}$, assim como as moléculas de água que fazem parte da primeira esfera de coordenação do íon $\mathrm{Cu}$, obtidas na DM a 77K não se modificaram significativamente em relação às suas posições iniciais (Figura 3.35a). No caso da DM a 300K, as conformações (últimas 500 conformaçoes são apresentadas na Figura 3.35b) do $[\mathrm{Cu}(\text { isapn })]^{2+}$ e das moléculas de água tiveram um comportamento oposto ao observado para a dinâmica a 77K (Figura 3.35b). As posições dos átomos das moléculas variaram bastante em relação às posições iniciais e verificamos uma grande agitação e vibração molecular das águas próximas ao sítio do íon $\mathrm{Cu}$. 


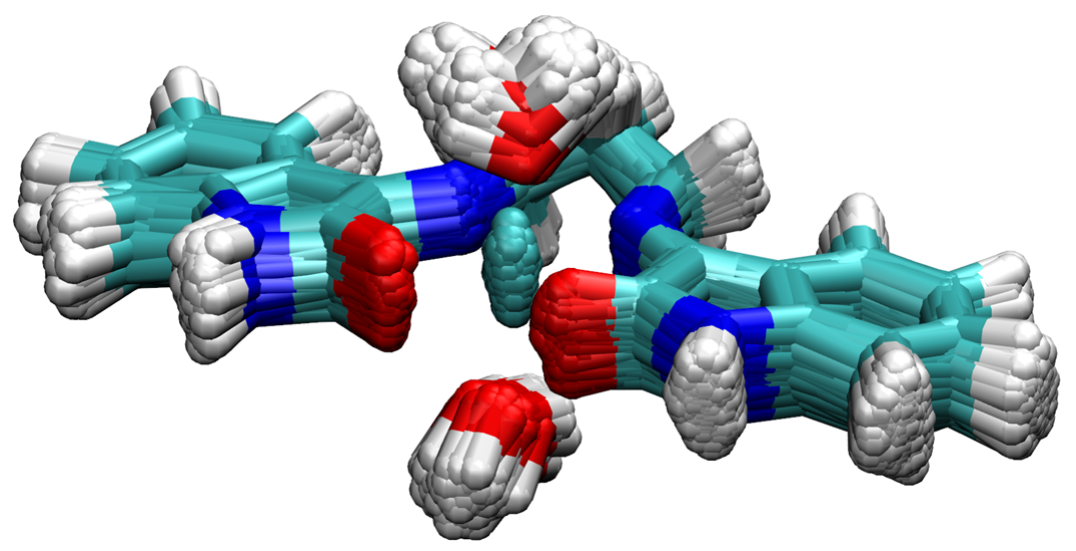

(a)

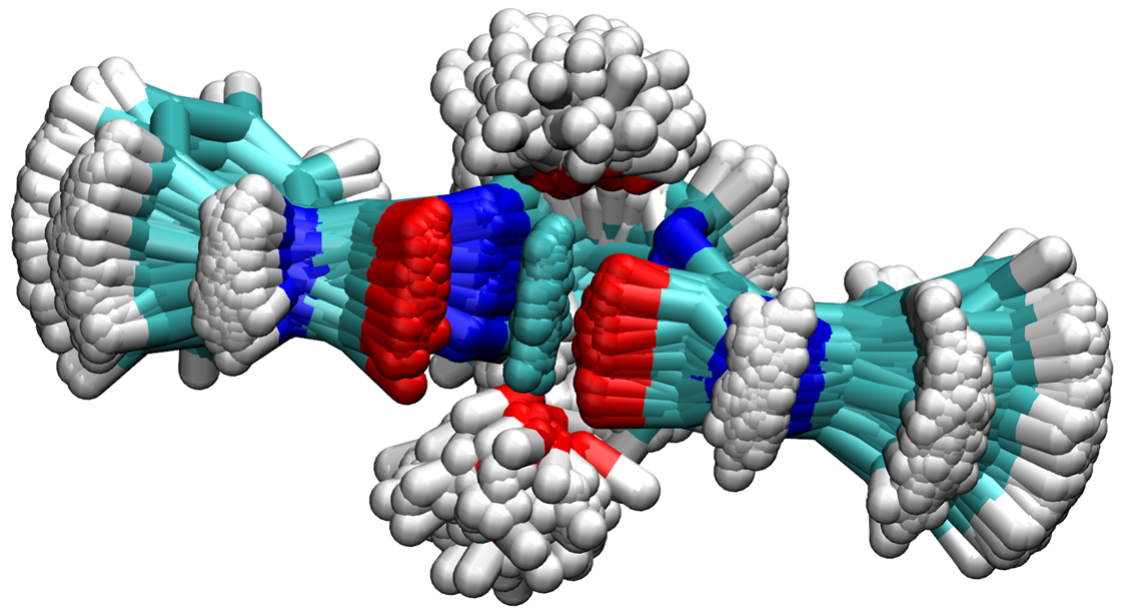

(b)

Figura 3.35: Sobreposição das conformações do complexo $[C u(\text { isapn })]^{2+}$ obtidas nas DMs a: (a) $77 \mathrm{~K}$ e (b) 300K. Os átomos de $\mathrm{C}$ e Cu estão representados pela cor verde, $\mathrm{H}$ na cor branca, $\mathrm{O}$ em vermelho e $\mathrm{N}$ em azul.

\subsubsection{Os parâmetros de acoplamento hiperfino para o íon $\mathrm{Cu}$}

Utilizando o código computacional ORCA [78], obtivemos os cálculos dos parâmetros hiperfinos através de um método que considera os efeitos relativísticos do acoplamento [79-81]. Este método utiliza a equação de Dirac com a aproxima- 
ção de ordem zero (Zero Order Regular Approximation - ZORA) [82] e a segunda ordem do acoplamento Spin-Órbita é obtida através de métodos perturbativos [80].

Com a diagonalização do tensor $\overleftrightarrow{A}$, o elemento da diagonal de maior valor em módulo é denominado de $A_{\|}$e a média dos outros dois elementos da diagonal é denominado de $A_{\perp}$. Se adotarmos a direção z do sistema de eixos principais como a componente com o maior acoplamento hiperfino, o valor de $A_{\|}$é dado pela interação entre o spin nuclear $\mathbf{I}_{\mathbf{z}}$ e o spin eletrônico $\mathbf{S}_{\mathbf{z}}$. No caso do $A_{\perp}$, o valor será dado pela média de $A_{x x}$ e $A_{y y}$, ou seja, $\left(A_{x x}+A_{y y}\right) / 2$. O tensor $\overleftrightarrow{\mathbf{A}}$ pode ser representado pelas componentes $A_{\|}$e $A_{\perp}$.

Calculamos os tensores $\overleftrightarrow{\mathbf{A}}$ (acoplamento hiperfino) e $\overleftrightarrow{\mathrm{g}}$ no sítio do íon $\mathrm{Cu}$ e comparamos com medidas de EPR da literatura [21, 77]. Os valores do acoplamento hiperfino medidos para o complexo $[C u(\text { isapn })]^{2+}$, em solução água + metanol e à $77 \mathrm{~K}$, são mostrados na tabela 3.4. As medidas de EPR a de $300 \mathrm{~K}$ são difíceis de serem obtidas devido à falta de resolução ótima para a medida nesta temperatura.

Tabela 3.4: Parâmetros hiperfinos medidos por EPR para o complexo $[$ Cu(isapn $)]^{2+}$ em solução água + metanol e à temperatura de $77 \mathrm{~K}$ [21].

\begin{tabular}{ccccc}
\hline \hline $\begin{array}{c}\text { Complexo } \\
{[C u(\text { isapn })]^{2+}}\end{array}$ & $g_{\perp}$ & $g_{\|}$ & $\begin{array}{c}A_{\|} \\
\left(10^{-4} \mathrm{~cm}^{-1}\right)\end{array}$ & $\begin{array}{c}g_{\|} / A_{\|} \\
(\mathrm{cm})\end{array}$ \\
\hline $\mathrm{pH}=4$ & $2,101 \pm 0,005$ & $2,445 \pm 0,005$ & $131 \pm 13$ & $187 \pm 18$ \\
$\mathrm{pH}=5$ & $2,102 \pm 0,005$ & $2,444 \pm 0,005$ & $131 \pm 13$ & $187 \pm 18$ \\
$\mathrm{pH}=6$ & $2,102 \pm 0,005$ & $2,255 \pm 0,005$ & $194 \pm 19$ & $116 \pm 16$ \\
$\mathrm{pH}=7$ & $2,112 \pm 0,005$ & $2,256 \pm 0,005$ & $196 \pm 19$ & $115 \pm 11$ \\
$\mathrm{pH}=9$ & $2,103 \pm 0,005$ & $2,258 \pm 0,005$ & $194 \pm 19$ & $116 \pm 11$ \\
$\mathrm{pH}=10$ & $2,092 \pm 0,005$ & $2,262 \pm 0,005$ & $194 \pm 19$ & $116 \pm 11$ \\
$\mathrm{pH}=11$ & $2,088 \pm 0,005$ & $2,266 \pm 0,005$ & $195 \pm 19$ & $116 \pm 11$ \\
\hline \hline
\end{tabular}


Na tabela 3.4 temos que $A_{\|}\left(10^{-4} \mathrm{~cm}^{-1}\right)=g_{\|} \beta A_{\|}(G)=0,46686 X 10^{-4} g_{\|} A_{\|}(G)$; onde $\beta=1,39969 \mathrm{MHz} / \mathrm{G}$. Realizamos os cálculos dos parâmetros hiperfinos para os seguintes sistemas: 1) complexo $[C u(\text { isapn })]^{2+}$ no meio PCM (simulando a água) e sem moléculas de água na região axial do íon $\mathrm{Cu}$ e com estruturas obtidas através de cálculos ab initio; 2) complexo $[C u(\text { isapn })]^{2+}$ no meio PCM e com duas moléculas de água na região axial do íon $\mathrm{Cu}$ com estrutura obtida através de cálculos ab initio; 3) complexo $[\mathrm{Cu}(\text { isapn })]^{2+}$ inserido no sítio da CDK1 utilizando a estrutura obtida da análise de clusters; 4) complexo $[C u(\text { isapn })]^{2+}$ inserido no solvente explicito (água) a 77K. 5) complexo $[\mathrm{Cu}(\text { isapn })]^{2+}$ inserido no solvente explicito e a 300K. As conformações dos sistemas 3, 4 e 5 foram obtidas através de cálculos de DM. Na Figura 3.36 mostramos as estruturas obtidas para a realização dos cálculos dos parâmetros de acoplamento hiperfino.

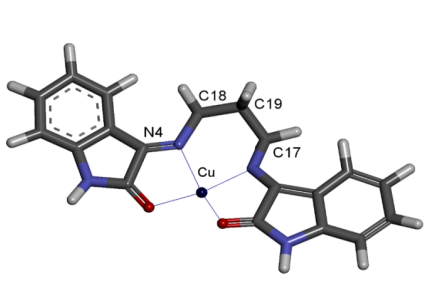

(a)

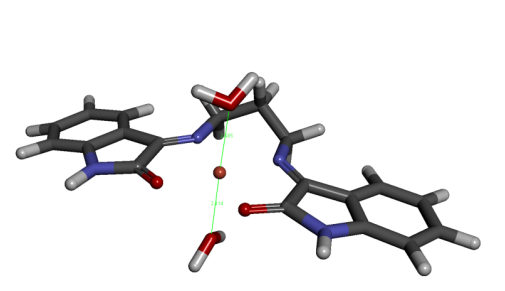

(b)

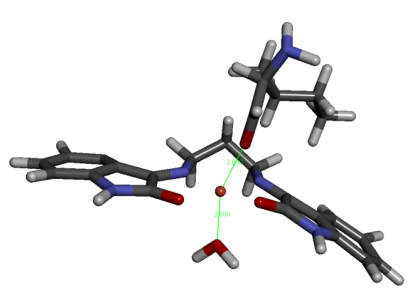

(c)

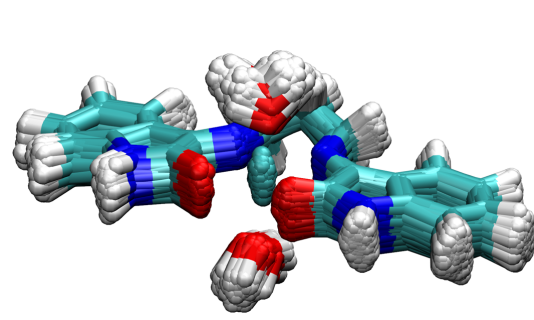

(d)

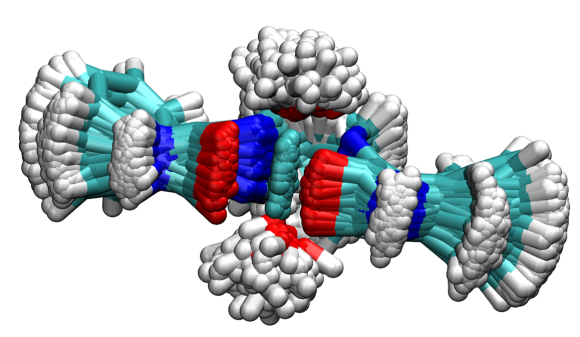

(e)

Figura 3.36: Conformações do complexo $[\mathrm{Cu}(\text { isapn })]^{2+}$ para os cálculos dos parâmetros hiperfinos: (a) $[\mathrm{Cu}(\text { isapn })]^{2+}$; (b) $[\mathrm{Cu}(\text { isapn })]^{2+}$ com duas moléculas de água; (c) $[C u(\text { isapn })]^{2+}$ inserido na CDK1; (d) conformações do $[C u(\text { isapn })]^{2+}$ obtidos na DM a $77 \mathrm{~K}$; (e) conformações do $[$ Cu(isapn $)]^{2+}$ obtidas na DM a $300 \mathrm{~K}$. 


\section{Parâmetros hiperfinos no sítio do íon $\mathrm{Cu}$ no meio contínuo polarizado (PCM) e inserido na CDK1}

Na tabela 3.5 são apresentados os valores obtidos para o $g_{\perp}, g_{\|}, A_{\|}$e $g_{\|} / A_{\|}$ no sítio do íon $\mathrm{Cu}$ no $[\mathrm{Cu}(\text { isapn })]^{2+}$ com e sem duas moléculas de água na região axial do íon $\mathrm{Cu}$, e no sítio do íon $\mathrm{Cu}$ no $[\mathrm{Cu}(\text { isapn })]^{2+}$ na CDK1. Os cálculos de otimização de geometria foram realizados em meio PCM (simulando a água). A estrutura utilizada para o cálculo do $[C u(\text { isapn })]^{2+}$ com duas moléculas de água na região axial do íon $\mathrm{Cu}$, foi obtida através da análise das conformações obtidas na DM a temperatura de $77 \mathrm{~K}$. Esta análise foi feita baseada na distância média da ligação das moléculas de água com o íon $\mathrm{Cu}(2,47 \AA)$. A partir da estrutura escolhida, fizemos o cálculo de otimização da geometria e de estrutura eletrônica, no meio PCM.

Tabela 3.5: Valores calculados para o $g_{\perp}, g_{\|}, A_{\|}$e $g_{\|} / A_{\|}$no sítio do íon $\mathrm{Cu}$ no $[C u(\text { isapn })]^{2+},[C u(\text { isapn })]^{2+}$ com duas moléculas de água (em meio PCM) e o $[\mathrm{Cu}(\text { isapn })]^{2+}$ inserido na CDK1.

\begin{tabular}{ccccc}
\hline \hline $\begin{array}{c}\text { Sistemas } \\
\text { estudados }\end{array}$ & $g_{\perp}$ & $g_{\|}$ & $\begin{array}{c}A_{\|} \\
\left(10^{-4} \mathrm{~cm}^{-1}\right)\end{array}$ & $\begin{array}{c}g_{\|} / A_{\|} \\
(\mathrm{cm})\end{array}$ \\
\hline$[\mathrm{Cu}(\text { isapn })]^{2+}$ & 2,089 & 2,298 & 232 & 110,30 \\
\hline$[\mathrm{Cu}(\text { isapn })]^{2+}$ & 2,081 & 2,358 & 194 & 121,5 \\
com duas $\mathrm{H}_{2} \mathrm{O}$ & & & & \\
\hline$[\mathrm{Cu}(\text { isapn })]^{2+}$ & 2,136 & 2,362 & 177 & 133,35 \\
inserido na CDK1 & & & & \\
\hline \hline
\end{tabular}

Observamos que o menor valor do $A_{\|}$foi obtido para o $[C u(\text { isapn })]^{2+}$ inserido na CDK1 e o maior para o $[C u(\text { isapn })]^{2+}$ em meio PCM e verificamos que os valores obtidos para o $[C u(\text { isapn })]^{2+}$ com duas moléculas de água e inserido na 
CDK1 estão dentro da região dos valores do $A_{\|}$medidos. O valor cálculado para o $[C u(\text { isapn })]^{2+}$ com duas moléculas de água $\left(194 X 10^{-4} \mathrm{~cm}^{-1}\right)$ coincidiu com os medidos em pH 9 e 10.

Notamos que os maiores valores de $g_{\|}$e $g_{\perp}$ são observados para o caso do $[C u(\text { isapn })]^{2+}$ inserido na CDK1, porém com valores próximos aos do $[C u(\text { isapn })]^{2+}$ com $2 \mathrm{H}_{2} \mathrm{O}$ e em PCM. Fazendo a comparação entre o os valores calculados com os medidos por EPR, verificamos que os valores obtidos estão dentro da faixa dos valores medidos em diferentes pHs. Na tabela 3.5 apresentamos as razões $g_{\|} / A_{\|}$ nos casos aqui estudados e a maior razão $(133,35 \mathrm{~cm})$ foi para o $[C u(\text { isapn })]^{2+}$ inserido na CDK1. Na comparação das razões $g_{\|} / A_{\|}$cálculadas com os medidos, verificamos que somente o valor obtido para o $[$ Cu(isapn $)]^{2+}(110,30 \mathrm{~cm})$ não está dentro da região dos valores medidos. Estas diferenças indicam diferentes características em torno do íon $\mathrm{Cu}$ e conforme o aumento da razão $g_{\|} / A_{\|}$, nos casos estudados, podemos observar um aumento na distorção tetragonal da coordenação do íon $\mathrm{Cu}$.

\section{Parâmetros hiperfinos do $[C u(\text { isapn })]^{2+}$ em solvente explicito à tempe- ratura de $77 \mathrm{~K}$ e $300 \mathrm{~K}$}

As conformações utilizadas foram obtidas através de uma varredura das configurações geradas nas trajetórias das DMs. Com o objetivo de completar a geometria tetragonal (coordenação 6) do íon $\mathrm{Cu}$, foram selecionadas as configurações que continham duas moléculas de água que estavam na região axial do íon $\mathrm{Cu}$ e, a partir deste critério, obtivemos 32 configurações para a dinâmica à $77 \mathrm{~K}$ e 20 configurações para a dinâmica à $300 \mathrm{~K}$. Estas configurações foram selecionadas após um mapeamento de todas as configurações obtidas das trajetórias das DMs onde adotamos um intervalo de 50 configurações entre as selecionadas. Desta forma, do total de 2002 configurações obtidas de toda a trajetória das DMs, foram escolhidas 
as configurações do $[C u(\text { isapn })]^{2+}$ com duas moléculas de água em um intervalo de 50 configurações. Após a seleção das configurações, fizemos os cálculos dos parâmetros hiperfinos para cada configuração escolhida (20 para a dinâmica à 300 K e 32 para a dinâmica à $77 \mathrm{~K}$ ) e um tratamento estatístico para obter um valor médio para os parâmetros $A_{\|}, g_{\|}$e $g_{\perp}$. Na tabela 3.6 mostramos os valores médios obtidos para o $A_{\|}, g_{\|}, g_{\perp}$ e $g_{\|} / A_{\|}$para o $[C u(\text { isapn })]^{2+}$ com duas moléculas de água na região axial do íon $\mathrm{Cu}$ obtidos das DMs a $77 \mathrm{~K}$ e a $300 \mathrm{k}$. O desvio considerado foi o desvio da média dos valores médios obtidos.

Tabela 3.6: Valores calculados para o $A_{\|}, g_{\|}, g_{\perp}$ e $g_{\|} / A_{\|}$no sítio do íon $\mathrm{Cu}$ no $[C u(\text { isapn })]^{2+}$ com duas moléculas de água, com configurações espaciais obtidas nas DMs a $77 \mathrm{~K}$ e a $300 \mathrm{~K}$.

\begin{tabular}{ccccc}
\hline \hline $\begin{array}{c}\text { Sistemas } \\
\text { estudados }\end{array}$ & $\begin{array}{c}A_{\|} \\
\left(10^{-4} \mathrm{~cm}^{-1}\right)\end{array}$ & $g_{\|}$ & $g_{\perp}$ & $\begin{array}{c}g_{\|} / A_{\|} \\
(\mathrm{cm})\end{array}$ \\
\hline$[\mathrm{Cu}(\text { isapn })]^{2+}$ & & & & \\
duas $\mathrm{H}_{2} \mathrm{O}$ & $211 \pm 2$ & $2,323 \pm 0,002$ & $2,108 \pm 0,001$ & 110,20 \\
axiais ao $\mathrm{Cu}(77 \mathrm{~K})$ & & & & \\
\hline$[\mathrm{Cu}(\text { isapn })]^{2+}$ & & & & \\
duas $\mathrm{H}_{2} \mathrm{O}$ & $209 \pm 3$ & $2,324 \pm 0,003$ & $2,108 \pm 0,002$ & 110,95 \\
axiais ao $\mathrm{Cu}(300 \mathrm{~K})$ & & & & \\
\hline \hline
\end{tabular}

Os valores dos parâmetros hiperfinos obtidos das DMs (tabela 3.6) foram muito próximos, independente da diferença de temperatura. No entanto, os valores obtidos de $A_{\|}$na dinâmica a $77 \mathrm{~K}$ e na dinâmica a $300 \mathrm{~K}$ estão um pouco fora da faixa dos valores medidos para o $A_{\|}$em diferentes pHs (tabela 3.4). No caso do $g_{\perp}$ e do $g_{\|}$, observamos que os valores obtidos nas dinâmicas a $77 \mathrm{~K}$ e a $300 \mathrm{~K}$ estão dentro da faixa dos valores medidos para estes parâmetros. As razões $g_{\|} / A_{\|}$ obtidas das duas dinâmicas $(110 \mathrm{~cm})$ foram praticamente idênticos e estão abaixo 
das razões medidas por EPR em diferentes pHs. Um fator importante pode ter contribuído para esta semelhança entre os valores calculados em diferentes temperaturas e é ilustrado pelo fato de que as medidas de Dicroísmo Circular (DC) para a estabilidade relativa do $[\mathrm{Cu}(\text { isapn })]^{2+}[23]$ indicarem um valor da constante de estabilidade do complexo da ordem de $10^{12}$ o que pode ser considerado alto. Desta forma, devido a alta estabilidade do $[\mathrm{Cu}(\text { isapn })]^{2+}$, os nossos resultados dos parâmetros hiperfinos obtidos das DMs a $77 \mathrm{~K}$ e 300K não variaram e, portanto, estão de acordo com os resultados de DC. Isto significa que o $[\mathrm{Cu}(\text { isapn })]^{2+}$ continou com as suas propriedades químicas mesmo com o aumento da temperatura. 


\section{Capítulo 4}

\section{Conclusões}

Neste trabalho propusemos um estudo através de cálculos ab initio de estrutura eletrônica, docking molecular e dinâmica molecular clássica para os ligantes isaepy, isapn, $[\mathrm{Cu}(\text { isapn })]^{2+}$, isaenim e SU9516 inseridos no sítio de ligação do ATP nas CDK2 e CDK1. Estes ligantes, exceto o SU9516, foram sintetizados pelo grupo da professora Ana Maria da Costa Ferreira do Instituto de Química (IQUSP) e o SU9516 tem atividade antitumoral já verificada e está bem consolidada na literatura. O objetivo foi tentar determinar qual destes ligantes, baseado em oxindóis, potencializa a inibição da síntese de ATP em ADP das CDKs e, desta forma, induz a apoptose de células cancerígenas. Baseado neste objetivo, tentamos dar uma resposta, através das nossas simulações computacionais, dentre os ligantes sintetizados, o que possuí uma melhor eficácia em inibir a síntese de ATP e também compreender o mecanismo de funcionamento desta inibição. Investigamos também a influência do $\mathrm{Cu}$ quando complexado com o $[\mathrm{Cu}(\text { isapn })]^{2+}$ e se ocorre um aumento da eficácia do isapn na inibição. Verificamos e validamos o estudo do isapn e $[\mathrm{Cu}(\text { isapn })]^{2+}$, quando inseridos no sítio de ligação do ATP da CDK1, através de medidas de eletroforese em gel (SDS-PAGE) da literatura. Também apresentamos os cálculos dos acoplamentos hiperfinos das conformações do 
$[C u(\text { isapn })]^{2+}$ obtidos em meio polarizado contínuo e em solvente explicito. Estes cálculos foram comparados com medidas de EPR do $[C u(\text { isapn })]^{2+}$ em solução de água + metanol.

Para conseguir modelar os sistemas apresentados aqui foi preciso encontrar as estruturas ótimas para as CDK1 e CDK2 e os ligantes. No caso dos ligantes tivemos que utilizar uma abordagem de cálculos de estrutura eletrônica para ter uma completa descrição da mínima energia da molécula e informações sobre as distribuições de carga. Nos baseamos na estrutura do SU9516 que tem informação de raio-X e na referência [23], para montar as estruturas dos ligantes. Observamos que a abordagem do cálculo dentro da DFT tem um fator determinante para o êxito na obtenção da distribuição de carga nos átomos das moléculas. As conclusões que obtivemos sobre os cálculos de estrutura eletrônica foram: 1) o mínimo de energia para os ligantes complexados com o $\mathrm{Cu}$ tiveram uma conformação planar e obedeceram a um padrão de simetria; 2) o meio químico ao qual os ligantes foram submetidos (vácuo e em PCM) são determinantes e modificam, nos casos dos ligantes não complexados com o $\mathrm{Cu}$, a estrutura otimizada. No entanto, para o caso do $[C u(\text { isapn })]^{2+}$, a estrutura permaneceu a mesma da conformação inicial, independentemente do meio químico simulado; 3) o meio químico simulado não influenciou na distribuição de carga obtida no caso do isapn. No entanto, como esperado, a inserção do $\mathrm{Cu}$ no isapn influenciou os resultados de distribuição de cargas nos átomos.

O utilização da técnica de docking molecular foi importante para os estudos de DM. Validamos a técnica utilizada fazendo a comparação entre a estrutura do SU9516 "âncorada" no sítio da CDK2 com informações obtidas de raio-X para a estrutura "âncorada" da literatura. Notamos que em todos os dockings realizados neste trabalho, os aminoácidos dos sítios da CDK1 e CDK2 que interagiram com os ligantes testados foram praticamente os mesmos, com algumas pequenas vari- 
ações de aminoácidos. Tivemos muitas interações semelhantes (com os mesmos aminoácidos PHE80, LYS33 e ASP145) no sítio da CDK2 com a parte oxindol do isaenim, isaepy e SU9516, devido à semelhança na geometria e composição química das moléculas. Verificamos valores próximos de afinidade energética também para os três casos, tendo o SU9516 a menor afinidade energética. Concluímos que o menor valor de energia obtido para SU9516 é devido a sua estrutura ser menor em relação ao isaenim e isaepy e também ao menor grau de liberdade de movimentação do SU9516, uma vez que não possui um diedro que liga dois oxindóis como no caso do isaenim e isaepy. No caso das interações entre os aminoácidos do sítio da CDK1 e o isapn e $[C u(\text { isapn })]^{2+}$, as afinidades de ligação tiveram valores muito próximos e a estrutura do $[C u(\text { isapn })]^{2+}$ ficou planar mesmo após o docking, indicando que o $\mathrm{Cu}$ deixou a estrutura bem rígida e restringiu os graus de liberdade da molécula. No entanto, maiores estudos e também a utilização de outros softwares como GOLD, DOCK e Hex ainda são necessários para um aperfeiçoamento da técnica.

Após os cálculos das DMs, tanto para os sistemas que envolvem a CDK2 quanto para CDK1, observamos que todas as dinâmicas estiveram bem equilibradas e estabilizadas e, desta forma, conseguimos realizar com êxito as equilibrações dos sistemas com a metodologia e o protocolo aplicados neste estudo. Da comparação entre as dinâmicas realizadas para sistemas CDK2/ligante, concluímos que o isaepy foi o que se manteve mais estabilizado no sítio da CDK2. Isto foi concluído com base nos resultados de RMSD da molécula, maior número de ligações de hidrogênio e da análise de clusters. O isaepy teve um menor número de clusters de configuração (seis no total) o que indica que o isaepy não apresentou muita modificação na sua conformação durante a simulação e que ficou mais estabilizado em relação às simulações com o SU9516 e o isaenim. Para o caso das dinâmicas dos sistemas CDK2/ligante, os aminoácidos que mais interagiram com os ligantes foram 
PHE80, GLU81, PHE82 e LEU83. No caso dos sistemas CDK1-ciclinaB/ligante, uma variação similar no RMSD, para o isapn e o $[C u(\text { isapn })]^{2+}$ foi observada e verificamos que o íon metálico restringiu os graus de liberdade do isapn durante toda a simulação. Portanto, o complexo $[\mathrm{Cu}(\text { isapn })]^{2+}$ está mais estabilizado dentro do sítio e manteve a sua configuração planar durante a dinâmica. Após as análises de números de ligação de hidrogênio e de clusters, concluímos que o isapn tem um aumento na sua inibição com a adição do Cu. Esta conclusão, baseada nos resultados obtidos pelas DMs, e corroborada com as medidas de eletroforese e, desta forma, validaram os nossos modelos construídos para as simulações. Notamos que os resultados das dinâmicas apresentadas neste trabalho assim como as discussões dos mesmos já foram publicados [21, 77].

Os estudos do acoplamento hiperfino do sítio do Cu para o complexo $[\mathrm{Cu}(\text { isapn })]^{2+}$ foram realizados e discutidos. Fizemos também a investigação da influência da temperatura, no caso do $[C u(\text { isapn })]^{2+}$ em solvente explícito (água), na obtenção dos parâmetros hiperfinos. Verificamos que as moléculas de água inseridas na região axial do $\mathrm{Cu}$ influenciaram os resultados dos parâmetros de acoplamento hiperfino $A_{\|}, g_{\|}$e $g_{\perp}$ e na razão $g_{\|} / A_{\|}$. Os nossos valores dos parâmetros hiperfinos no sítio do Cu para os sistemas $[C u(\text { isapn })]^{2+}$ em meio polarizado contínuo (PCM), $[C u(\text { isapn })]^{2+}$ com duas moléculas de água e $[C u(\text { isapn })]^{2+}$ inserido na CDK1 foram considerados satisfatórios, uma vez que estavam todos dentro da faixa dos valores para o $A_{\|}, g_{\|}$e $g_{\perp}$ e da razão $g_{\|} / A_{\|}$medidos por EPR. Outra conclusão importante que obtivemos foi na comparação entre os parâmetros medidos por EPR em solvente (água + metanol) a $77 \mathrm{~K}$ com as nossas simulações do $[C u(\text { isapn })]^{2+}$ em solvente explícito a $77 \mathrm{~K}$ e $300 \mathrm{~K}$ onde os valores aqui obtidos das dinâmicas, para os parâmetros hiperfinos, ficaram dentro da faixa dos valores medidos por EPR com variação do pH. Outra conclusão importante foi que o fator temperatura não influenciou os valores dos parâmetros hiperfinos nas nossas 
simulações. Isto indica que a estabilidade do complexo $[C u(\text { isapn })]^{2+}$ é muito alta mesmo com altas energias de vibração da molécula e do solvente. Este resultado foi corroborado com o valor medido, através da técnica de Dicroísmo Circular, da constante de estabilidade para o $[C u(\text { isapn })]^{2+}$, que é da ordem de $10^{12}$, o que pode ser considerado muito alto. Ao analisarmos a distribuição radial do par $\mathrm{Cu}-\mathrm{O}^{\text {agua }}$ verificamos que a primeira esfera de coordenação do $\mathrm{Cu}-\mathrm{H}_{2} \mathrm{O}$ nas duas dinâmicas estão à mesma distância para as dinâmicas a $77 \mathrm{~K}$ e $300 \mathrm{~K}$, o que indica que as distâncias médias entre $C u-O^{a g u a}$ foram muito próximas nas duas dinâmicas e que a estabilidade do complexo foi verificada. Alguns fatores das DMs que ainda permitem futuras investigações são: o raio de Van der Waals utilizado para o $\mathrm{Cu}$, cujo o valor utilizado, $1.4 \AA$, é válido para átomos de $\mathrm{Cu}$ inseridos em ligas metálicas e óxidos metálicos; utilizar outros solventes para simular outros ambientes químicos com diferentes pHs, uma vez que as nossas simulações envolvem somente moléculas de água como solvente; testar outros funcionais e funções de base dos nossos cálculos dentro da DFT e testar outros métodos de obtenção das distribuições de carga dos átomos do complexo $[\mathrm{Cu}(\text { isapn })]^{2+}$.

Neste trabalho, conseguimos obter uma modelagem que permite uma análise tanto qualitativa quanto quantitativa do comportamento dos ligantes estudados quando inseridos no sítio de ligação da ATP da CDK1 e da CDK2. O nosso estudo pretendeu contribuir para elucidar os mecanismos de funcionamento da inibição da síntese de ATP em ADP na CDK1 e CDK2, assim como auxiliar no desenvolvimento de novos ligantes baseados em oxindóis que podem possuir a mesma funcionalidade dos ligantes apresentados neste estudo, porém com uma maior eficácia. 


\section{Lista de Tabelas}

2.1 Valores ponderados, termos e significados utilizados na função scoring do Autodock Vina 4 [49]. . . . . . . . . . . . . . . . 22

3.1 Distribuição de cargas obtidas pelo método CHELPG para o isapn e $[\mathrm{Cu}(\text { isapn })]^{2+}$. A nomenclatura dos átomos se refere à Figura $3.3 \quad 37$

3.2 Distâncias de equilíbrio $r_{e q}$ e constantes de força $k_{r}$ para o íon $\mathrm{Cu}$ no complexo $[C u(\text { isapn })]^{2+} \ldots \ldots \ldots \ldots \ldots$. . . . . . . . 52

3.3 Ângulos de equilíbrio $\theta_{e q}$ e constantes de força $k_{\theta}$ para o íon $\mathrm{Cu}$ no complexo $[C u(\text { isapn })]^{2+} \ldots \ldots \ldots \ldots \ldots \ldots$. . . . . . . . . 52

3.4 Parâmetros hiperfinos medidos por EPR para o complexo $[\mathrm{Cu}(\text { isapn })]^{2+}$ em solução água + metanol e à temperatura de $77 \mathrm{~K}$ [21]. . . . . . 84

3.5 Valores calculados para o $g_{\perp}, g_{\|}, A_{\|}$e $g_{\|} / A_{\|}$no sítio do íon $\mathrm{Cu}$ no $[C u(\text { isapn })]^{2+},[C u(\text { isapn })]^{2+}$ com duas moléculas de água (em meio PCM) e o $[C u(\text { isapn })]^{2+}$ inserido na CDK1. . . . . . . . . 86

3.6 Valores calculados para o $A_{\|}, g_{\|}, g_{\perp}$ e $g_{\|} / A_{\|}$no sítio do íon $\mathrm{Cu}$ no $[C u(\text { isapn })]^{2+}$ com duas moléculas de água, com configurações espaciais obtidas nas DMs a $77 \mathrm{~K}$ e a $300 \mathrm{~K} \ldots$. . . . . . . . 88 


\section{Lista de Figuras}

1.1 As fases do ciclo de divisão celular mitótico e as CDKs que participam e auxiliam as fases do ciclo [2]. . . . . . . . . . 3

1.2 Tipos de inibidores que atuam nas CDKs: a) tipo I que competem no sítio de ligação da ATP; b) tipo II que reconhecem e desativam a conformação das CDKs e c) tipo III que interagem com o sítio alostérico das CDKs [13]. . . . . . . . . . . . . . 4

1.3 Esquema da estrutura em 2D do oxindol. . . . . . . . . 5

1.4 Esquema de alguns complexos metálicos derivados de oxindolaminas que estão em estudo $[20,22,23] . \ldots \ldots \ldots$

1.5 Estruturas, obtidas de cálculos no âmbito da DFT, dos inibidores que são estudados neste trabalho: (a) SU9516, (b) isapn, (c) $[C u(\text { isapn })]^{2+},(\mathrm{d})$ isaepy e (e) isaenim. . . . . . . . . . 8

3.1 Estruturas obtidas por cálculos de estrutura eletrônica: (a) isaenim, (b) $[\mathrm{Cu}(\text { isaenim })]^{2+}$, (c) isaepy e (d) $\left[\mathrm{Cu}(\text { isaepy }) \mathrm{H}_{2} \mathrm{O}\right]^{1+}$. As distâncias de ligação do íon $\mathrm{Cu}$ no isaenim e isaepy são mostradas na cor verde.

3.2 Estruturas obtidas: (a) SU9516, (b) isapn e (c) $[C u(\text { isapn })]^{2+}$. As distâncias de ligação O-H no SU9516 e do íon $\mathrm{Cu}$ no $[\mathrm{Cu}(\text { isapn })]^{2+}$ são mostradas na cor verde. 
3.3 Sobreposição das estruturas obtidas em vácuo e em PCM (em amarelo) para (a) isapn e (b) $[C u(i s a p n)]^{2+} \ldots \ldots \ldots . \ldots . \ldots 36$

3.4 Estruturas da CDK1/ciclinaB (esquerda, identificador PDB: 1T30) e CDK2/ciclinaA (direita, identificador PDB: 1FIN). O círculo vermelho indica a posição onde o inibidor interage com o sítio nas CDKs onde ocorre a ligação das moléculas de ATP. . . . . . . . . 40

3.5 Estrutura do SU9516 obtida por raio-X (em vermelho) e através do método de docking utilizado neste trabalho. . . . . . . . . . . . 41

3.6 Ilustração do docking do (a) SU9516 e do (b) isaepy no sítio da

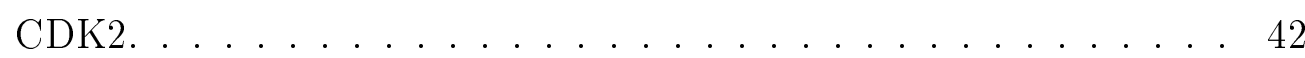

3.7 Ilustração do docking do isaenim no sítio da CDK2. . . . . . . . . 43

3.8 Aminoácidos, com seus nomes de resíduos, a uma distância de até $3 \AA$ do (a) SU9516 e (b) isaepy. As superfícies de potencial eletrostático do SU916 e do isaepy são mostradas em cinza claro e a ligação de hidrogênio é ilustrada pela linha pontilhada em verde. . 45

3.9 Aminoácidos, com seus nomes de resíduos, a uma distância de até $3 \AA$ do isaenim. A superfície de potencial eletrostático do isaenim é mostrada em cinza claro e a ligação de hidrogênio é ilustrada pela linha pontilhada em verde. . . . . . . . . . . . . 46

3.10 Ilustração da configuração obtida por docking para o (a) isapn e para o (b) $[C u(\text { isapn })]^{2+}$ no sítio ativo da CDK1. . . . . . . . . 47

3.11 Aminoácidos com seus nomes de resíduos a uma distância de até 3 $\AA$ do (a) isapn e (b) $[C u(\text { isapn })]^{2+}$. As linhas em azul ilustram as distâncias de ligação e o ângulo torcional do diedro N4-C18-C19-C17 e as linhas em amarelo ilustram as interações $\pi$. . . . . . . . . 49 
3.12 Átomos similares em torno do íon $\mathrm{Cu}$ (em marrom) nos complexos metálicos: a) $[C u(\text { isaenim })]^{2+}$ e b) $[C u(\text { isapn })]^{2+}$. NX e NP são os nitrogênios (em azul), C1, C2 e C3 são os carbonos (em ciano) e O são os oxigênios (vermelho). Distâncias de ligação em A. . . . . . . 51

3.13 Raio de giro R(g) para a CDK2 nos sistemas (a) CDK2/SU9516, (b) CDK2/isaepy e (c) CDK2/isaenim. . . . . . . . . . . . 54

$3.14 \mathrm{R}(\mathrm{g})$ obtidos durante a DM para os sistemas CDK1-ciclina B/isapn e CDK1-ciclina $\mathrm{B} /[\mathrm{Cu}(\text { isapn })]^{2+}$. As linhas vermelhas representam a média do $\mathrm{R}(\mathrm{g})$ para as proteínas durante a simulação. . . . . . . . 55

3.15 RMSD para o centro de massa do SU9516 para o sistema CDK2/SU9516. 56

3.16 a) Histograma da frequência de interação entre os aminoácidos (número de resíduo) e o SU9516. Detalhamento das regiões: b) 0 - 40, indicado pelos retângulos pontilhado e contínuo em amarelo, repectivamente; c) 60 - 100 indicado pelos retângulos pontilhado e contínuo em verde, repectivamente; d) 120 - 170 indicado pelos retângulos pontilhado e contínuo em violeta, repectivamente. . . . . 57

3.17 Estrutura do SU9516 (em vermelho) obtida após análise de clusters na DM. Aminoácidos (átomos com legenda em verde) que mais interagiram com o SU9516 são mostrados. . . . . . . . . . . 58

3.18 Histograma da ocorrência de ligação de hidrogênio entre os aminoácidos e o SU9516 inserido na CDK2. . . . . . . . . . . . 59

3.19 a) RMSD para a CDK2 (curva em preto) e do seu backbone (curva em verde); b) RMSD para o centro de massa do isaepy para o sistema CDK2/isaepy. . . . . . . . . . . . . 60

3.20 a) RMSD da CDK2 (curva em preto) e do seu backbone (curva em verde); b) RMSD para o centro de massa do isaenim para o sistema CDK2/isaenim. . . . . . . . . . . . . . 6 60 
3.21 a) Histograma da frequência de interação entre os aminoácidos (número de resíduo) e o isaepy. Detalhamento das regiões: b) 0 - 40, indicado pelos retângulos pontilhado e contínuo em amarelo, repectivamente; c) 120 - 150 indicado pelos retângulos pontilhado e contínuo em violeta, repectivamente; d) 60 - 100 indicado pelos retângulos pontilhado e contínuo em verde, repectivamente. . . . . . 62

3.22 a) Histograma da frequência de interação entre os aminoácidos (número de resíduo) e o isaenim. Detalhamento das regiões: b) 0 - 40, indicado pelos retângulos pontilhado e contínuo em amarelo, repectivamente; c) 120 - 150 indicado pelos retângulos pontilhado e contínuo em violeta, repectivamente; d) 60 - 100 indicado pelos retângulos pontilhado e contínuo em verde, repectivamente. . . . . .

3.23 Variação dos ângulos dos diedros do isaenim analisados durante a DM: a) N4-C5-C6-N7; b) C3-N4-C5-C6; c) O1-C2-C3-N4. A linha preta representa o valor médio do ângulo do diedro e as representações da molécula ao lado dos gráficos indicam os diedros analisados (marcado em amarelo na molécula). . . . . . . . . . 65

3.24 Variação dos ângulos dos diedros do isaepy durante a DM: A linha preta representa o valor médio do ângulo do diedro e as representações da molécula ao lado dos gráficos mostram os diedros analisados (marcado em amarelo na molécula) . . . . . . . . . . 66

3.25 Estruturas obtidas após análise de clusters nas DMs para: (a) isaepy (em vermelho); (b) isaenim (em vermelho). Aminoácidos (átomos com legenda em verde) que mais interagiram com o isaepy e isaenim são mostrados. . . . . . . . . . . . . . . . 67

3.26 Histograma da ocorrência de ligações de hidrogênio entre os aminoacidos do sítio da CDK2 considerado e: a) isaepy; b) isaenim. . . 
3.27 Comparação entre os histogramas de frequência de interação entre os aminoácidos do sítio (número do resíduo) e: a) SU9516; b) isaepy; c) isaenim. O detalhamento das regiões entre 0-40, 60-100 e 120-170 também são mostrados. . . . . . . . . . . . . . . 70

3.28 Compilação dos resultados obtidos para as ocorrências de ligações de hidrogênio entre os aminoácidos do sítio da CDK2 considerado e: a) SU9516; b) isaenim; c)isaepy. . . . . . . . . . . . . . . 71

3.29 a) RMSD para o centro de massa do isapn para o sistema CDK1ciclinaB/isapn e as estruturas obtidas por análise de clusters. O quadrado pontilhado em verde indica a mudança conformacional do isapn devido a torção do diedro N4-C18-C19-C17; b) RMSD para o centro de massa do $[C u(\text { isapn })]^{2+}$ para o sistema CDK1ciclinaB $/[C u(\text { isapn })]^{2+}$ e a estrutura obtida por análise de clusters. 73

3.30 Histograma da ocorrência de ligações de hidrogênio entre os aminoácidos do sítio da CDK1 considerado e: a) isapn; b) $[C u(\text { isapn })]^{2+} .74$

3.31 Histograma da frequência de interação entre os aminoácidos (número de resíduo) e as estruturas representativas obtidas das análises de clusters para: a) isapn; b) $[C u(\text { isapn })]^{2+}$. As distâncias de ligação são indicadas pelas linhas em azul e os aminoácidos que mais interagem com o isapn e $[C u(\text { isapn })]^{2+}$, pelos retângulos tracejados. O centroíde do anel aromático da PHE82 é representado pela cruz em cor verde. . . . . . . . . . . . . . . 76

3.32 Medidas de SDS-PAGE [77] da histona H1 após a fosforilação pela CDK1-ciclinaB e após a desfosforilação pela fosfatase na presença do isapn, $[C u(\text { isapn })]^{2+}$ e $[Z n(i \text { sapn })]^{2+}$. Os valores medidos do complexo $[\mathrm{Cu}(\text { isapn })]^{2+}$ são destacados pelo retângulo tracejado em vermelho. . . . . . . . . . . . . . . . 77 
3.33 RMSD para o centro de massa do $[C u(\text { isapn })]^{2+}$ para as DMs, em solvente explícito de: (a) 77K e (b) 300K. . . . . . . . . . 79

3.34 Função de distribuição radial $\mathrm{g}(\mathrm{r})$ do par $C u-O^{\text {agua }}$ durante as DMs do complexo $[C u(\text { isapn })]^{2+}$ a: (a) $77 \mathrm{~K}$ e (b) 300K. . . . . . . 81

3.35 Sobreposição das conformações do complexo $[\mathrm{Cu}(\text { isapn })]^{2+}$ obtidas nas DMs a: (a) 77K e (b) 300K. Os átomos de C e Cu estão representados pela cor verde, $\mathrm{H}$ na cor branca, $\mathrm{O}$ em vermelho e $\mathrm{N}$ em

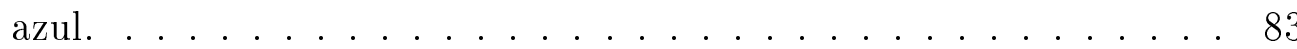

3.36 Conformações do complexo $[\mathrm{Cu}(\text { isapn })]^{2+}$ para os cálculos dos parâmetros hiperfinos: (a) $[\mathrm{Cu}(\text { isapn })]^{2+}$; (b) $[\mathrm{Cu}(\text { isapn })]^{2+}$ com duas moléculas de água; (c) $[C u(\text { isapn })]^{2+}$ inserido na CDK1; (d) conformações do $[C u(\text { isapn })]^{2+}$ obtidos na DM a $77 \mathrm{~K}$; (e) conformações do $[C u(\text { isapn })]^{2+}$ obtidas na DM a 300 K. . . . . . . . . 85 


\section{Bibliografia}

[1] L. Ronconi e P. J. Sadler. Coor. Chem. Rev. 251, 1633 (2007).

[2] J. W. Harper e P. D. Adams. Chem. Rev. 101, 2511 (2001).

[3] T. Hunter. Cell 80, 225 (1995).

[4] M. E. M. Noble, J. A. Endicott e L. N. Johnson. Science 303, 1800 (2004).

[5] D. O. Morgan. Annu. Rev. Cell Dev. Biol. 13, 261 (1997).

[6] P. Cohen. Nature reviews. Drug discovery, 309 (2002).

[7] P. Cohen e D. R. Alessi. ACS Chem. Biol. 8, 96 (2013).

[8] D. R. Hodgson e M. Schröder. Chem. Soc. Rev. 40, 1211 (2011).

[9] G. Krauss. Biochemistry of Signal Transduction and Regulation. Editora Wiley-VCH, (1999).

[10] J. Zhang, P. L. Yang e N. S. Gray. Nature Rev. Cancer 9, 28 (2009).

[11] C. García-Echeverría, P. Traxler e D.B. Evans. Med. Res. Rev. 20, 28 (2000).

[12] Z. Fang, C. Grutter e D. Rauh. Chem. Biol. 8, 58 (2013).

[13] Z. H. Foda e M. A. Seeliger. Nature Chemical Biology 10, 796 (2014). 
[14] S. Lapenna e A. Giordano. Nature reviews. Drug discovery 8, 547 (2009).

[15] M. C. Linder. Mut. Res. 475, 141 (2001).

[16] J.T. Wolfe, D. Ross e G.M. Cohen. FEBS Lett. 352, 58 (1994).

[17] F. Liang, C. Wu, H. Lin, T. Li, D. Gao, Z. Li, J. Wei, C. Zheng e M. Sun. Bioorg. Med. Chem. Lett. 13, 2469 (2003).

[18] Y. Xiao, D. Chen, X. Zhang, Q. Cui, Y. Fan, C. Bi e Q. P. Dou. Int. J. Oncol. 37, 81 (2010).

[19] M. C. Rodriguez-Argüelles, M. Belicchi, F. Bisceglie, C. Pelizzi, G. Pelosi, S. Pinelli e M. Sassi. J. Inorg. Biochem. 98, 313 (2004).

[20] G. Cerchiaro, K. Aquilano, G. Filomeni, G. Rotilio, M. R. Ciriolo e A. M. C. Ferreira. J. Inorg. Biochem. 99, 1433 (2005).

[21] A. M. C. Ferreira, P. A. D. Petersen, H. M. Petrilli e M. R. Ciriolo. Molecular basis for anticancer and antiparasite activities of copper-based drugs. In: Redox-Active Therapeutics. Spinger. In Press, (2015).

[22] G. Filomeni, S. Pccirillo, L. Graziani, S. Cardaci, A. M. C. Ferreira, G. Rotilio e M. R. Ciriolo. Carcinogenesis. 30, 1115 (2009).

[23] V. C. da Silveira, G. F. Caramori, M. P. Abbott, M. B. Gonçalves, H. M. Petrilli e A. M. C. Ferreira. J. Inorg. Biochem. 103, 1331 (2009).

[24] M. E. Lane, B. Yu, A. Rice, K. E. Lipson, C. Liang, L. Sun, C. Tang e Wadler S. Cancer Res. 61, 6170 (2001).

[25] R.A. Blake, M. A. Broome e S. A. Courtneidge. Mol. Cell Biol. 20, 9018 (2000). 
[26] A. D. Laird et al. Cancer Res. 60, 4152 (2000).

[27] P. Hohenberg e W. Kohn. Phys. Rev. B 136 (1964).

[28] W. Kohn e L.J. Sham. Phys. Rev. A 140 (1965).

[29] J. Tomasi e R. Cammi. Chem. Rev. 105, 2999 (2005).

[30] J. Kohanoff. Electronic Structure Calculations for Solids and Molecules Theory and Computational Methods. Cambridge Universtiy Press, (2006).

[31] M. Born e J. R. Oppenheimer. Adv. Phys. 84, 457 (1927).

[32] J. C. Slater. Phys. Rev. 38, 1109 (1931).

[33] M. A. Castro e S. Canuto. O Método Hartree-Fock. In: Métodos de Química Teórica e Modelagem Molecular. Editora Livraria da Física, (2007).

[34] J. D. M. Vianna, A. Fazzio e S. A. Canuto. Teoria Quântica de Moléculas e Sólidos. Editora Livraria da Física, (2004).

[35] J. P. Perdew, K. Burke e M. Ernzerhorf. Phys. Rev. Lett. 77, 3865 (1996).

[36] K. Coutinho e N. H. Morgon. Métodos de Química Teórica e Modelagem Molecular. Eds. Livraria da Física, (2007).

[37] A. D. Becke. J. Chem. Phys. 98, 1372 (1993).

[38] A. D. Becke. Phys. Rev. A 38, 3098 (1988).

[39] J. P. Perdew e Y. Wang. Phys. Rev. B 45, 13244 (1992).

[40] C. Lee, W. Yang e R. G. Parr. Phys. Rev. B 37, 785 (1988).

[41] S.H Vosko, L. Wilk e M. Nusair. Can. J. Phys. 58, 1200 (1980). 
[42] A. D. Becke. J. Chem. Phys. 104, 1040 (1996).

[43] A. Szabo e N. S. Ostlund. Modern Quantum Chemistry. Dover Publications, (1996).

[44] E. R. Davidson e D. Feller. Chem. Rev. 86, 681 (1986).

[45] D. B. Cook. Handbook of Computational Quantum Chemistry. Oxford University Press, (1998).

[46] A. Leach. Molecular Modelling: Principles and Applications. Pearson Prentice Hall, (2001).

[47] J. A. Pople e R. Krishnan. J. Chem. Phys. 72, 650 (1980).

[48] C. S. Magalhães e H. J. C. Barbosa. Métodos de Docking Receptor-Ligante Para O Desenho Racional de Compostos Bioativos. In Métodos de Química Teórica e Modelagem Molecular. Livraria da Física, (2007).

[49] O. Trott e A. J. Olson. J. Phys. Chem. 31, 455 (2010).

[50] L. Martinez e M. S. Skaf. Fundamentos de Simulação por Dinâmica Molecular. In Métodos de Química Teórica e Modelagem Molecular. Livraria da Física, (2007).

[51] C. M. Breneman e K. B. Wiberg. J. Comp. Chem. 11, 361 (1990).

[52] P. A. Kollman e P. K. Weiner. J. Comp. Chem. 2, 287 (1981).

[53] P. A. Kollman e W. D. Cornell. J. Am. Chem. Soc. 117, 5179 (1995).

[54] M. Karplus e et. all. J. Comp. Chem. 30, 1545 (2009).

[55] H. J. C. Berendsen e R. van Drunen. Comput. Phys. Commun. 91, 43 (1995). 
[56] C. Oostenbrink e W. F. van Gunsteren. J. Comp. Chem. 25, 1656 (2004).

[57] C. Oostenbrink e W. F. van Gunsteren. J. Eur. Biophys 34, 273 (2005).

[58] K. Spiegel e P. Carloni. J. Comp. Chem. 29, 38 (2007).

[59] M. P. Allen e D. J. Tildesley. Computer Simulations of Liquids. Oxford University Press, (1989).

[60] T. Darden e L. Pedersen. J. Chem. Phys. 98, 10089 (1993).

[61] H. J. C. Berendsen e et. al. Gromacs User Manual version 4.5.6. (2010).

[62] H. J. C. Berendsen e W. F. van Gunsteren. J. Chem. Phys. 81, 3684 (1984).

[63] M. Parrinello e A. Rahman. J. Appl. Phys. 52, 7182 (1981).

[64] S. Nosé e M. L. Klein. Mol. Phys. 50, 1055 (1983).

[65] M. J. Frisch e et. al. (2009).

[66] S. Betzi e E. Schonbrunn. ACS Chem. Biol. 6, 492 (2011).

[67] P. D. Jeffrey e N. P. Pavletich. Nature 376, 313 (1995).

[68] U. Schulze-Gahmen e S. H. Kim. J. Med. Chem 39, 4540 (1996).

[69] C. F. McGrath e et. al. J. Biomol. Struct. Dyn. 22, 493 (2005).

[70] Moshinsky e et. al. Biochem. Biophys. Res. Commun. 310, 1026 (2003).

[71] L. Heady e et. al. J. Med. Chem 49, 5141 (2006).

[72] A. K. Malde e A. E. Mark. J. Chem. Theory and Comp. 7, 4026 (2011).

[73] M. M. Reif e C. Oostenbrink. J. Chem. Theory and Comp. 9, 1247 (2013). 
[74] Wanda Andreoni e Alessandro Curioni. Parallel Computing 26, 819 (2000).

[75] Dominik Marx e Juerg Hutter. Ab Initio Molecular Dynamics. Cambridge University Press, (2009).

[76] J. Wang e P. A. Kollman. J. Comp. Chem. 25, 1157 (2004).

[77] P. A. D. Petersen, R. B. Miguel, F. A. Gonzales-Zubiate, C. C. Oliveira, N. Kumar, R. R. do Nascimento, H. M. Petrilli e A. M. C. Ferreira. J. Biol. Inorg. Chem. 20, 1205 (2015).

[78] F. Neese. Wiley Interdiscip. Rev. Comp. Mol. Sci. 2, 73 (2012).

[79] F. Neese. J. Chem. Phys. 115, 11080 (2001).

[80] F. Neese. J. Chem. Phys. 118, 3939 (2003).

[81] M. Kaupp e V. G. Malkin. Calculation of NMR and EPR Parameters. Wiley - VCH, (2004).

[82] E. van Lenthe e P. E. S. Wormer. J. Chem. Phys. 108, 4783 (1998). 